Review

\title{
Preparation and Application of 2D MXene-Based Gas Sensors: A Review
}

\author{
Qingting $\mathrm{Li}^{1}$, Yanqiong $\mathrm{Li}^{2}$ and Wen Zeng ${ }^{1, *}$ \\ 1 College of Materials Science and Engineering, Chongqing University, Chongqing 400030, China; \\ 202009021056@cqu.edu.cn \\ 2 School of Electronic Information \& Electrical Engineering, Chongqing University of Arts and Sciences, \\ Chongqing 400030, China; 20170031@cqwu.edu.cn \\ * Correspondence: wenzeng@cqu.edu.cn; Tel.: +86-023-65102466
}

check for

updates

Citation: Li, Q.; Li, Y.; Zeng, W. Preparation and Application of 2D MXene-Based Gas Sensors: A Review. Chemosensors 2021, 9, 225. https:// doi.org/10.3390/chemosensors 9080225

Academic Editor: Elisabetta Comini

Received: 7 July 2021

Accepted: 3 August 2021

Published: 14 August 2021

Publisher's Note: MDPI stays neutral with regard to jurisdictional claims in published maps and institutional affiliations.

Copyright: (c) 2021 by the authors. Licensee MDPI, Basel, Switzerland. This article is an open access article distributed under the terms and conditions of the Creative Commons Attribution (CC BY) license (https:// creativecommons.org/licenses/by/ $4.0 /)$.

\begin{abstract}
Since MXene (a two-dimensional material) was discovered in 2011, it has been favored in all aspects due to its rich surface functional groups, large specific surface area, high conductivity, large porosity, rich organic bonds, and high hydrophilicity. In this paper, the preparation of MXene is introduced first. HF etching was the first etching method for MXene; however, HF is corrosive, resulting in the development of the in situ $\mathrm{HF}$ method (fluoride $+\mathrm{HCl}$ ). Due to the harmful effects of fluorine terminal on the performance of MXene, a fluorine-free preparation method was developed. The increase in interlayer spacing brought about by adding an intercalator can affect MXene's performance. The usual preparation methods render MXene inevitably agglomerate and the resulting yields are insufficient. Many new preparation methods were researched in order to solve the problems of agglomeration and yield. Secondly, the application of MXene-based materials in gas sensors was discussed. MXene is often regarded as a flexible gas sensor, and the detection of ppb-level acetone at room temperature was observed for the first time. After the formation of composite materials, the increasing interlayer spacing and the specific surface area increased the number of active sites of gas adsorption and the gas sensitivity performance improved. Moreover, this paper discusses the gas-sensing mechanism of MXene. The gas-sensing mechanism of metallic MXene is affected by the expansion of the lamellae and will be doped with $\mathrm{H}_{2} \mathrm{O}$ and oxygen during the etching process in order to become a p-type semiconductor. A p-n heterojunction and a Schottky barrier forms due to combinations with other semiconductors; thus, the gas sensitivities of composite materials are regulated and controlled by them. Although there are only several reports on the application of MXene materials to gas sensors, MXene and its composite materials are expected to become materials that can effectively detect gases at room temperature, especially for the detection of $\mathrm{NH}_{3}$ and VOC gas. Finally, the challenges and opportunities of MXene as a gas sensor are discussed.
\end{abstract}

Keywords: MXene; gas sensors; gas sensitivity mechanism; HF etching

\section{Introduction}

In recent years, due to the development of industrial production and the emission of automobile exhaust, environmental pollution has become particularly serious. Fortunately, people have gradually paid attention to the impact of the emitted gas on the environment and human health [1]. Nitrogen-containing gases, such as $\mathrm{NO}_{2}$ from fossil fuels and automobile exhausts, can cause acid rain that is harmful to the environment and can cause damage to human eyes and the respiratory tract [2-4]. $\mathrm{NH}_{3}$ is widely used in petroleum, explosives, and other industries, but it will cause damage to the respiratory system, eyes, and skin. According to the U.S. Occupational Safety and Health Administration (OSHA) regulations, the safe value of $\mathrm{NH}_{3}$ gas is only $35 \mathrm{ppm}$ for $15 \mathrm{~min}$ and $25 \mathrm{ppm}$ for $8 \mathrm{~h}$. If it exceeds this value, $\mathrm{NH}_{3}$ will cause serious harm to the individual [5-7]. $\mathrm{H}_{2} \mathrm{~S}$ is a flammable, highly toxic, and dangerous gaseous compound. The inhalation of $\mathrm{H}_{2} \mathrm{~S}$ with concentrations $>500$ ppm will cause people to lose their breath in a short period of time. Long-term 
exposure to low concentrations of $\mathrm{H}_{2} \mathrm{~S}$ can cause serious harm to the eyes, respiratory tract and central nervous system. Aiming at ensuring human health, the Association Advancing Occupational and Environmental Health stipulates that the amount of $\mathrm{H}_{2} \mathrm{~S}$ gas in the occupational environment shall not exceed $10 \mathrm{ppm}[8,9] \cdot \mathrm{H}_{2}$ is an essential gas in chemical experiments and the chemical industry, and it has a wide range of applications in all aspects. However, $\mathrm{H}_{2}$ is a colorless and odorless flammable gas, rendering it difficult to be detected. The concentration of $\mathrm{H}_{2}$ in the air over $4 \%$ can easily cause an explosion, which poses a considerable safety hazard [10-12]. The "greenhouse effect" has always been a hot topic in society, and the emission of $\mathrm{CO}_{2}$ and $\mathrm{CO}$ is the main reason for the greenhouse effect. $\mathrm{CO}$ is colorless and tasteless, and humans can develop arrhythmia and respiratory disorders after inhaling a large amount of CO $[13,14]$. The aforementioned gases are all necessary in industrial production, but their potential threats are detrimental to humans and the ecological environment. Therefore, the development of a gas sensor is of great significance. Moreover, the goal of the development of gas sensors is to produce sensors that possess high sensitivity, fast response and recovery speed, selectivity, and low working temperature in order to realize real-time monitoring of gas concentration and to avoid irreversible consequences.

Currently, many materials have been researched and developed for gas sensors, such as metal oxides [15-24], carbon-based materials [2,25-28], conductive polymers [29-32], metal organic frameworks (MOF) [33-35], and rare-earth oxides [36-38], etc. Metal oxides are classified into n-type (such as $\mathrm{TiO}_{2}$ and $\mathrm{SnO}_{2}$ ) and p-type (such as $\mathrm{CuO}, \mathrm{ZrO}_{2}$, and $\mathrm{WO}_{3}$ ). Researchers favor metal oxide as a gas sensor due to its excellent sensitivity, small size, and low cost [39]. For instance, Wang et al. [40] used KIT-6 as the hard template to synthesize $\mathrm{WO}_{3}$ modified with $\mathrm{Au}$ particles. The $\mathrm{Au}-\mathrm{WO}_{3}$ sensor showed excellent gas sensitivity for detecting trimethylamine (The response was $42.56 \%$ and the sensor only took $1 \mathrm{~s}$ to respond under $100 \mathrm{ppm}$ trimethylamine at $268^{\circ} \mathrm{C}$ ). Chaloeipote et al. [41] used $3 \mathrm{D}$ printing technology to synthesize $\mathrm{CuO}$. The $\mathrm{CuO}$ sensor showed a nice gas response to the detection of $\mathrm{NO}_{2}$ (The response of detecting $200 \mathrm{ppm} \mathrm{NO}$ at room temperature was $14.17 \%$ ). However, sensors were made from metal oxides as gas-sensitive materials usually achieve higher response in the range of $200^{\circ} \mathrm{C}$ to $500{ }^{\circ} \mathrm{C}$, which increases the cost of gas detection and the potential safety hazards caused by high temperatures [34]. Carbonbased materials (such as graphene (GO) and carbon nanotube (CNT)) are considered room temperature gas sensors because of their excellent conductivity, large surface area, and good mechanical properties [42]. CNT and GO are often used to fabricate gas sensors due to their high carrier mobility, high specific surface area, and special structure [25]. For example, Yan et al. [43] used electrophoretic deposition to deposit multi-walled carbon nanotubes (MWCNT) on porous silicon. The gas sensor showed excellent gas sensitivity (When the sensor was exposed to $1 \mathrm{ppm} \mathrm{NO}$ at room temperature, the response was $8.5 \%$, and the response time/recovery time was 37/34 s). Gupta et al. [44] synthesized a reduced graphene oxide (rGO) film by chemical synthesis that was modified by high edge-functionalization. The prepared gas sensor showed an excellent response to $\mathrm{CO}_{2}$ (The response of $500 \mathrm{ppm} \mathrm{CO}_{2}$ at room temperature was $50 \% \mathrm{~Hz} / \mu \mathrm{g}$ and response time and recovery time was $26 / 10 \mathrm{~s}$ ). Conductive polymers are favored because of their low working temperature and high sensing performance, including polyaniline (PANI), polypyrrole (PPy), and polythiophene (PTh) [29,30]. For example, polyaniline (PANI), which is easy to synthesize, has adjustable conductivity, and possesses high stability under environmental conditions. Thus, PANI is one of the most studied conductive polymers in gas sensors [31]. Polypyrrole (PPy) is widely used in gas sensors due to its controllable conductivity, ease of manufacturing and low-budget [32]. Adhikari et al. [45] used sodium cholate micelles as a soft template in order to synthesize ribbon-like nanostructured polypyrrole (PPy). When the gas sensor detected $100 \mathrm{ppm}$ ethanol at room temperature, the response of the sensor was $87.64 \%$, and the response and recovery time was $2 / 31 \mathrm{~s}$. Metal-organic framework (MOF) bridges organic connectors and metal centers, possessing a porous structure [46]. MOF has received extensive attention from researchers owing to its porosity, 
ultra-high surface area $\left(\sim 2000 \mathrm{~m}^{2} \mathrm{~g}^{-1}\right)$, structural diversity and excellent adsorption affinity, and it can be used as precursors to further derive various materials. Zeolite imidazole ester frameworks (ZIF-8 and ZIF-67) have been studied in the direction of gas sensitivity [34,35]. Zhan et al. [47] successfully synthesized a series of polyhedral ZIF-8 nanostructures with molar ratios by the solvothermal method. Due to the porosity of the ZIF- 8 nanostructure and the high free charge carrier density, when the ZIF-8 sensor was exposed to $100 \mathrm{ppm}$ $\mathrm{NO}_{2}$ at $350{ }^{\circ} \mathrm{C}$, the sensor showed a high gas response (118.5\%) and a rapid response and recovery time was observed (113.5 s and $111.5 \mathrm{~s}$, respectively). Among many sensors, two-dimensional (2D) nanomaterials (including black phosphorus (BP), transition metal dichalcogenides (TMD), 2D MXene, etc.) are prominent in the gas sensor due to large specific surface area and many adsorption sites [48,49]. Among them, MXene was a new 2D nanomaterial discovered in 2011.

In 2011, Naguib et al. mixed the $\mathrm{Ti}_{3} \mathrm{AlC}_{2}$ powder and $\mathrm{TiC}$ powder for heating and then they used $\mathrm{HF}$ to remove the $\mathrm{Al}$ layer in order to obtain a 2D multilayer nanostructure $\mathrm{Ti}_{3} \mathrm{C}_{2} \mathrm{~T}_{x}$, which was called MXene [50]. The formula of MXene is $\mathrm{M}_{n+1} \mathrm{X}_{n} \mathrm{~T}_{x}(n=1,2$, or 3), where $\mathrm{M}$ represents early transition metals, such as Ti, V, Sc, Cr, etc.; $\mathrm{X}$ is carbon or nitrogen; and $\mathrm{T}$ is surface functional groups such as $-\mathrm{OH},-\mathrm{O}$ and $-\mathrm{F}$. MXene is mainly synthesized by getting rid of the A layer of the MAX phase of the bulk, where A comes from the elements of IIIA or IVA [51-53]. The MAX phase is a form of layered hexagonal ternary transition metal (TM) carbides and nitrides with $\mathrm{P}_{63} / \mathrm{mmc}$ symmetry [54,55]. Since the bond of the A layer in the MAX is solid, it cannot be damaged easily by shearing force or mechanical cutting; that is, it is hard to peel the MX layer from the MAX by these methods. Since, the connection strength of the $\mathrm{M}-\mathrm{X}$ bond is more robust than that of the M-A bond in MXene, etching is the best method to remove the A from the MAX phase [56]. Nowadays, there are more than 200 MAX phases based on various combinations, and a variety of MXene materials have been synthesized, such as $\mathrm{Mo}_{2} \mathrm{C}, \mathrm{Ta}_{4} \mathrm{C}_{3}, \mathrm{Nb}_{2} \mathrm{C}, \mathrm{TiCN}$, and $\mathrm{V}_{2} \mathrm{C}[57,58]$. For example, Ghasali et al. [59] used microwaves to heat the $\mathrm{Al}-\mathrm{V}_{2} \mathrm{O}_{5}-\mathrm{C}$ and it etched with $\mathrm{HF}$ to obtain $\mathrm{V}_{2} \mathrm{C}$ with very low defect density. Mei et al. [60] used UV-induced selective etching to etch $\mathrm{Mo}_{2} \mathrm{Ga}_{2} \mathrm{C}$ in order to obtain $\mathrm{Mo}_{2} \mathrm{C}$. The flexible battery assembled with this $\mathrm{Mo}_{2} \mathrm{C}$ achieved excellent rate performance and cycle stability and exhibited excellent capacity retention in the bent state. Since the advent of MXene and due to its rich surface functional groups, large specific surface area, high conductivity, large porosity, rich organic bonds, and high hydrophilicity, it can be used as a glucose sensor, electrode material, electromagnetic shielding material, super capacitors, energy storage, and nanofluids, etc. [60-63].

MXene has played a significant role in supercapacitors and battery materials. However, the studies conducted on gas sensors are far from sufficient. At the same time, there are only a few reviews focusing on gas sensors made of MXene [64-67]. In this work, we reviewed the synthesis method of MXene, the application of MXene in gas sensors, and the mechanism of gas sensors. We aim to introduce MXene and gas sensors in detail and to contribute to the body of research relative to MXene in gas sensors.

\section{Synthesis of MXene}

The synthesis of MXene include many aspects. This paper only reviews the synthesis methods that may be beneficial to gas sensors. Firstly, the synthesis of MXene materials, etching method, is discussed. Secondly, some subsequent preparation procedures will optimize its performance after etching. For example, an intercalator is added in order to increase the interlayer spacing. Finally, the preservation, use and yield of MXene are of great significance to the practical application, so the synthesis methods which can improve the dispersion of MXene and carry out large-scale production are discussed.

\subsection{Etching}

The synthesis method of MXene significantly affects the morphology and performance of MXene. At present, scholars in various fields have conducted a lot of research on MXene's synthesis method. There are two methods for synthesizing 2D materials: one is 
the bottom-up method, including physical vapor deposition and chemical vapor deposition; the other is the top-down method, including peeling (micromechanical, solution processing or ultrasonic processing) and selective etching [68]. The bottom-up method must use a vacuum chamber and a substrate for growth. This method limits the final size of the deposited material, while the top-down method does not have these limitations [68]. In this section, the etching of the top-down method will be discussed and other methods will not be dwelt on.

According to previous reports, most $\mathrm{Ti}_{3} \mathrm{C}_{2} \mathrm{~T}_{x}$ was prepared by etching $\mathrm{Ti}_{3} \mathrm{AlC}_{2}$ using high temperature and HF solution, which was the method used for the first discovery of $\mathrm{Ti}_{3} \mathrm{C}_{2} \mathrm{~T}_{x}$ [69,70]. The method to discover $\mathrm{Ti}_{3} \mathrm{C}_{2} \mathrm{~T}_{x}$ for the first time was: $(1) \mathrm{Ti}_{3} \mathrm{AlC}_{2}$ powder was prepared by ball milling $\mathrm{Ti}_{2} \mathrm{AlC}$ and $\mathrm{TiC} ;(2) \mathrm{Ti}_{3} \mathrm{AlC}_{2}$ powder was heated at $1350{ }^{\circ} \mathrm{C}$ for $2 \mathrm{~h}$ under argon; (3) The calcined powder was immersed in a 50\% HF solution for $2 \mathrm{~h}$; (4) The deionized water was used to wash the obtained solution, and products were collected after centrifuged and dried [50]. The procedure is shown in Figure 1a. The reaction mechanism of the etching is as follows [50]:

$$
\begin{gathered}
\mathrm{Ti}_{3} \mathrm{AlC}_{2}+3 \mathrm{HF}=\mathrm{AlF}_{3}+3 / 2 \mathrm{H}_{2}+\mathrm{Ti}_{3} \mathrm{C}_{2} \\
\mathrm{Ti}_{3} \mathrm{C}_{2}+2 \mathrm{H}_{2} \mathrm{O}=\mathrm{Ti}_{3} \mathrm{C}_{2}(\mathrm{OH})_{2}+\mathrm{H}_{2} \\
\mathrm{Ti}_{3} \mathrm{C}_{2}+2 \mathrm{HF}=\mathrm{TI}_{3} \mathrm{C}_{2} \mathrm{~F}_{2}+\mathrm{H}_{2}
\end{gathered}
$$

Reaction (1) is the reaction of $\mathrm{Ti}_{3} \mathrm{AlC}_{2}$ in order to generate $\mathrm{Ti}_{3} \mathrm{C}_{2}$ layer; Reaction (2) and reaction (3) are the reactions of the generated $\mathrm{Ti}_{3} \mathrm{C}_{2}$ layer with $\mathrm{H}_{2} \mathrm{O}$ and $\mathrm{HF}$, indicating the formation of $-\mathrm{OH}$ and $-\mathrm{F}$ terminations on $\mathrm{Ti}_{3} \mathrm{C}_{2}$, also namely $\mathrm{T}_{x}$. In the HF etching process, MXene is affected by temperature, HF solution concentration, reaction time, and ball milling time [71-73]. For example, Li et al. [71] discussed the effects of time, temperature, $\mathrm{Ti}_{3} \mathrm{AlC}_{2}$ source, and $\mathrm{HF}$ solution concentration on the synthesis of $\mathrm{Ti}_{3} \mathrm{C}_{2}$. The research found that the low reaction temperature and the low HF solution concentration would cause the MAX phase to remain after a long etching period. With the increase in HF concentration and etching temperature, peeling off MAX was easier and the more MXene was obtained. In addition, the longer the etching time, the better the MXene stripping. Using $49 \% \mathrm{HF}$ to peel off $\mathrm{A}$ at $60^{\circ} \mathrm{C}$, it took at least $8 \mathrm{~h}$ to peel off successfully. It was different from the effective peeling in $2 \mathrm{~h}$ that described in the previous literature. This might be that the used $\mathrm{Ti}_{3} \mathrm{AlC}_{2}$ was different. The higher the activity of $\mathrm{Ti}_{3} \mathrm{AlC}_{2}$, the less reaction time was required. When the etching time was extended to $24 \mathrm{~h}$, a MXene sheet with completed stripping and a thickness of $\sim 30 \pm 5 \mathrm{~nm}$ can be obtained. Su et al. [72] studied the effect of reaction temperature and ball milling time on the synthesis of $\mathrm{Ti}_{3} \mathrm{C}_{2}$, and found that high etching temperature and longer ball milling duration resulted in faster conversion of $\mathrm{Ti}_{3} \mathrm{C}_{2}$ MXene. Using HF to etch MXene is the most common and effective method. However, HF is highly toxic and corrosive, threatening to individuals and unfriendly to the environment. So it is indispensable to exploit an effective and harmless method to synthesize MXene [74]. 
(a)

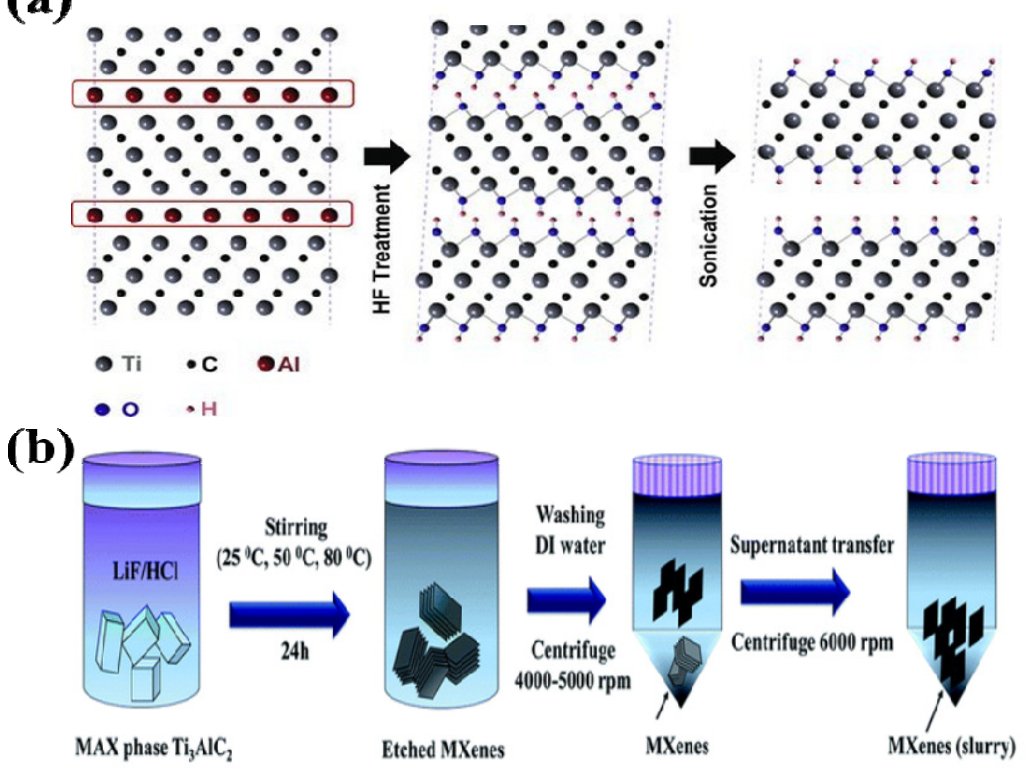

Figure 1. (a) $\mathrm{Ti}_{3} \mathrm{C}_{2} \mathrm{~T}_{x}$ synthesized by HF etching (Reproduced with permission from [50]. Copyright 2011, John Wiley and Sons); (b) $\mathrm{Ti}_{3} \mathrm{C}_{2} \mathrm{~T}_{x}$ synthesized by $\mathrm{HCl}+\mathrm{LiF}$ etching (Reproduced with permission from [75]. Copyright 2020, the Royal Society of Chemistry).

Using $\mathrm{HCl}$ and $\mathrm{LiF}$ to generate $\mathrm{HF}$ instead of directly using $\mathrm{HF}$, avoiding the threat of direct use of HF, this method is called the "in-situ HF method" [76]. The first "in-situ HF method" was reported in 2014 [77,78]. The specific method reported in the literature was: (1) Dissolving $\mathrm{LiF}$ in $\mathrm{HCl}$; (2) Adding $\mathrm{Ti}_{3} \mathrm{AlC}_{2}$ powder and heating the mixture at $40{ }^{\circ} \mathrm{C}$ for $45 \mathrm{~h}$; (3) Rinsing it in order to get the clean MXene. The preparation of MXene by $\mathrm{HCl}+\mathrm{LiF}$ is shown in Figure $1 \mathrm{~b}$ [75]. Compared with MXene synthesized by HF, MXene synthesized using $\mathrm{LiF}+\mathrm{HCl}$ had larger lateral dimensions and no nano-scale defects. $\mathrm{Li}^{+}$and $\mathrm{H}_{2} \mathrm{O}$ molecules were embedded, leading to the expansion of the interlayer spacing and the weakness of the interaction between MXene layers. The obtained MXene showed larger and more dispersed flakes and had higher yield, so $\mathrm{LiF}+\mathrm{HCl}$ was widely used to synthesize MXene [77,79,80]. For example, Kim et al. [81] used $\mathrm{LiF}+\mathrm{HCl}$ to synthesize MXene with low noise, high metal conductivity, and functionalized surface. Its signal-to-noise ratio was much higher than that of other two-dimensional materials, including black phosphorus (BP), $\mathrm{MoS}_{2}$, and reduced graphene oxide (RGO). The lower detection limit of VOC gas (acetone, ethanol, and propionaldehyde) at room temperature was 50-100 ppb. In addition to $\mathrm{LiF}$, there are other fluoride salts (such as $\mathrm{NaF}, \mathrm{CaF}_{2}, \mathrm{FeF}_{3}$, $\mathrm{KF}, \mathrm{NH}_{4} \mathrm{HF}_{2}, \mathrm{NaHF}_{2}, \mathrm{KHF}_{2}$, and $\mathrm{NH}_{4} \mathrm{HF}_{2}$ ) that can react with $\mathrm{HCl}$ to generate $\mathrm{HF}$ [82-88]. For example, Akinola et al. [82] used $\mathrm{NaF}$ and $\mathrm{HCl}$ to prepare $\mathrm{Cr}_{2} \mathrm{C}$ MXene, which achieved high yield, low by-products, fast etching time and large sheet area. The cations were well embedded between the MXene sheets, which made MXene layers more spaced apart. Wang et al. [83] used $\mathrm{FeF}_{3}$ and $\mathrm{HCl}$ to synthesize $\mathrm{Ti}_{3} \mathrm{C}_{2} \mathrm{~T}_{x}$ for the first time. MXene prepared by $\mathrm{FeF}_{3}+\mathrm{HCl}$ had a higher number of hydroxyl/oxygen terminal groups, which changed the surface of MXene and resulted in a significant change in its hydrophilicity. Although $\mathrm{HCl}$ and fluoride are fewer harmful than $\mathrm{HF}$, fluoride with etching effect is negative to the device [89]. Fluoride etching of MXene normally results in abundant fluorine terminals on MXene, which are harmful to electronic conductivity, surface tunability, and electrochemical performance [90].

In recent years, there has been a lot of research on the synthesis of MXene by F-free etching, such as alkali etching [91-94], electrochemical etching [95-97], halogen etching [98,99], hydrothermal etching $[90,100]$, and Lewis acid $[74,101]$, etc. In theory, it is feasible to use alkali as an etchant to etch $\mathrm{Ti}_{3} \mathrm{AlC}_{2}$. Because $\mathrm{Al}$ can be dissolved by alkali owing to the high reactivity of $\mathrm{Al}$. Li et al. [91] successfully synthesized $\mathrm{Ti}_{3} \mathrm{C}_{2} \mathrm{~T}_{x}$ using the $\mathrm{NaOH}$-assisted 
hydrothermal method. The experiment temperature was $270{ }^{\circ} \mathrm{C}$ and the concentration of $\mathrm{NaOH}$ solution was $27.5 \mathrm{M}$. The high temperature and $\mathrm{NaOH}$ concentration were conducive to the dissolution of $\mathrm{Al}$ (Figure 2). This was the first time that MXene has been synthesized by only alkali etching and many $-\mathrm{OH}$ and $\mathrm{O}$ terminals could be produced by this method. Based on alkali etching, scholars have developed other methods that cooperate with alkali etching. Zhang et al. [92] successfully synthesized $\mathrm{Ti}_{3} \mathrm{C}_{2}(\mathrm{OH})_{2}-\mathrm{MXene}$ nanobelts with abundant surface hydroxyl terminals using a small amount of $\mathrm{H}_{2} \mathrm{O}$-assisted $\mathrm{KOH}$. The synthesis process is shown in Figure 3. $\mathrm{KOH}$ and water contents were essential to the etching process and could affect the thickness of MXene. The morphology of MXene could be controlled by $\mathrm{KOH}$ and water contents. Xue et al. [93] used a chemical combined ball milling method to etch $\mathrm{Ti}_{3} \mathrm{C}_{2}$ MXene with tetramethylammonium hydroxide (TMAOH) and $\mathrm{LiCl}$ solution. Figure 4 is the preparation process. The specific surface area of the F-free MXene reached $38.93 \mathrm{~m}^{2} / \mathrm{g}$ due to its hierarchical porous structure and the terminals which only were oxygen-containing groups $(\mathrm{O} / \mathrm{OH})$. Rafieerad et al. [94] used $\mathrm{HCl}$-assisted $\mathrm{KOH}$ alkaline etching in order to synthesize $\mathrm{Ta}_{4} \mathrm{C}_{3} \mathrm{~T}_{x}$ MXene. The biggest problem with alkaline etching was that $\mathrm{Al}$ and alkaline medium formed insoluble $\mathrm{Al}(\mathrm{OH})_{3}$ and $\mathrm{AlO}(\mathrm{OH})$ on the surface of MXene to hinder further etching. $\mathrm{HCl}$ was used to assist the synthesis. During the synthesis process, aluminum atoms passed through $\mathrm{HCl}$ to quickly chlorinated. It would produce soluble aluminum chloride $\left(\mathrm{AlCl}_{3}\right)$, which might reduce insoluble aluminide and promote the etching. The synthesis process is shown in Figure 5.

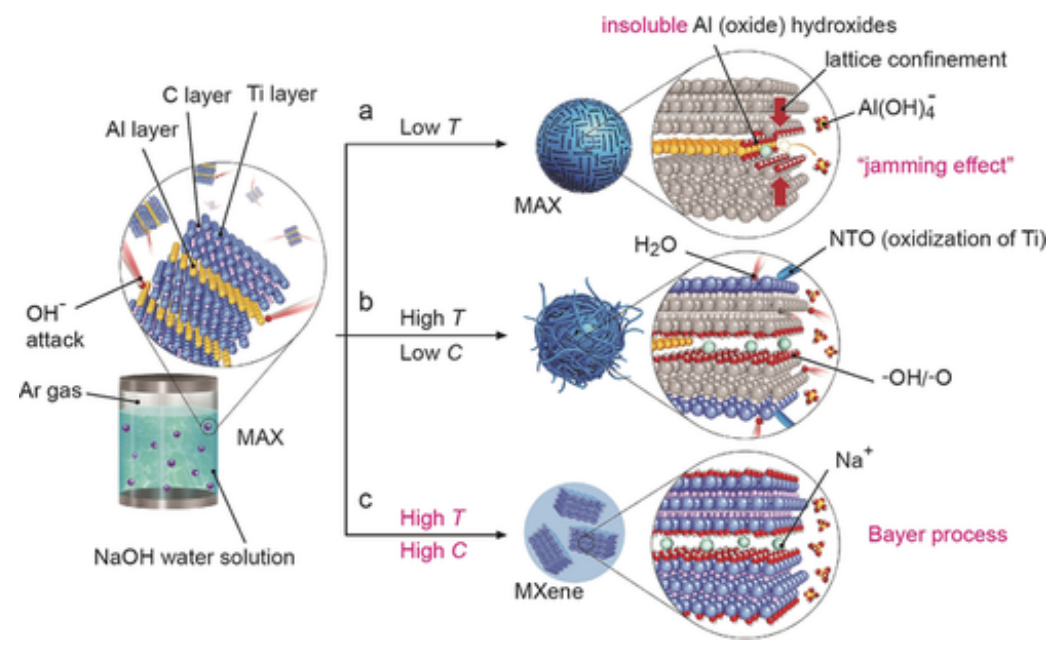

Figure 2. The reaction between $\mathrm{Ti}_{3} \mathrm{AlC}_{2}$ and $\mathrm{NaOH}$ water solution, (a) Reaction at low temperature; (b) Reaction at high temperature and low $\mathrm{NaOH}$ concentration; (c) Reaction at high temperature and high $\mathrm{NaOH}$ concentration (Reproduced with permission from [91]. Copyright 2021, John Wiley and Sons).

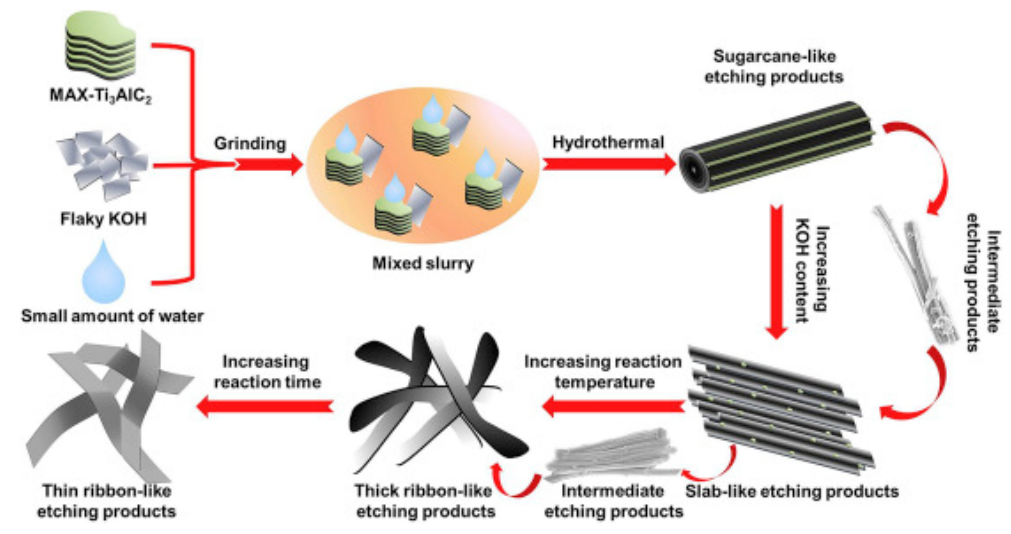

Figure 3. Schematic illustration of the synthesis of $\mathrm{Ti}_{3} \mathrm{C}_{2}(\mathrm{OH})_{2}$ by water-assisted potassium hydroxide (Reproduced with permission from [92]. Copyright 2019, Elsevier). 


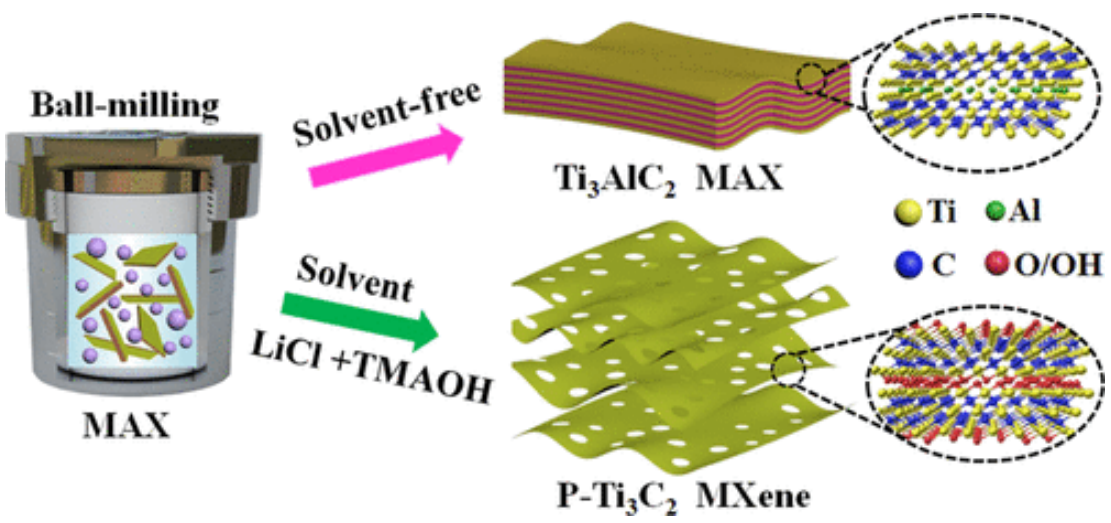

Figure 4. Schematic diagram of the preparation of $\mathrm{Ti}_{3} \mathrm{C}_{2}$ by chemical-combined ball milling (Reproduced with permission from [93]. Copyright 2020, American Chemical Society).
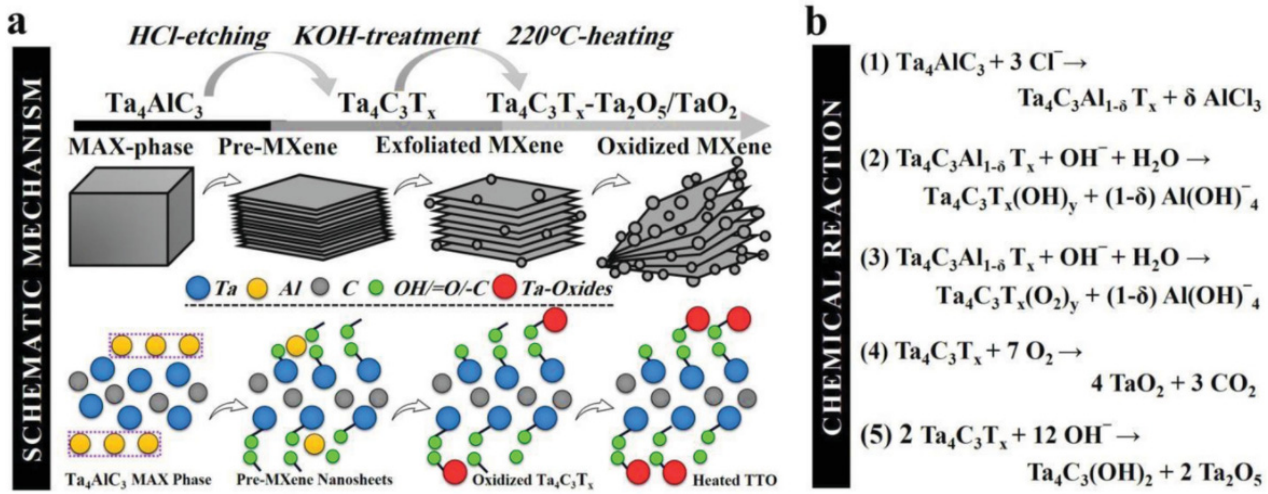

Figure 5. (a) Sketch map of the preparation of $\mathrm{Ta}_{4} \mathrm{C}_{3} \mathrm{~T}_{x}$ by $\mathrm{HCl} / \mathrm{KOH}$; (b) The reaction equation of $\mathrm{HCl} / \mathrm{KOH}$ to prepare $\mathrm{Ta}_{4} \mathrm{C}_{3} \mathrm{~T}_{x}$ (Reproduced with permission from [94]. Copyright 2021, John Wiley and Sons).

There are also related reports using only $\mathrm{HCl}$ as an etchant. Wang et al. [90] used the $\mathrm{HCl}$ hydrothermal method to obtain fluorine-free $\mathrm{Mo}_{2} \mathrm{C} \mathrm{MXene} \mathrm{with} \mathrm{a} \mathrm{production}$ efficiency of $98 \%$. Since there was F-free etching, the terminals of MXene were only chlorine and oxygen-containing terminals. The surface functional groups could be adjusted by adding $\mathrm{N}$ source or $\mathrm{S}$ source to the hydrothermal reactor during the etching process. Unlike the accordion structure of the other MXene, the structure of $\mathrm{Mo}_{2} \mathrm{CT}_{x}$ that obtained by the $\mathrm{HCl}$ hydrothermal method showed a clear layered structure (Figure 6). This method provides ideas for the development of better F-free MXene.

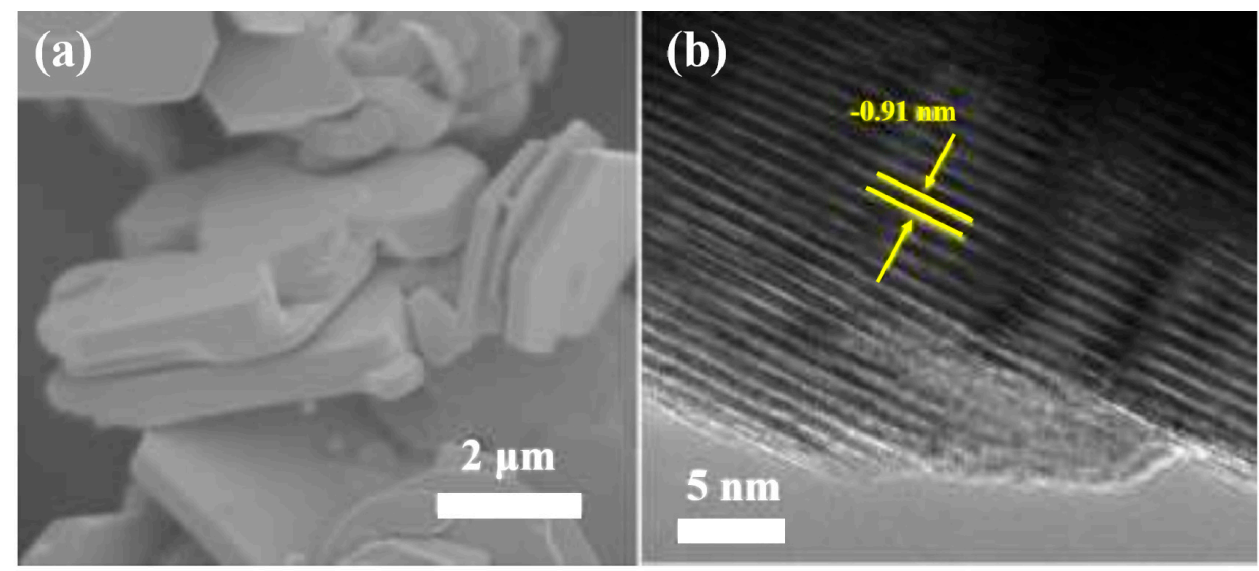

Figure 6. The SEM (a) and TEM (b) of $\mathrm{Mo}_{2} \mathrm{C}$ synthesized by $\mathrm{HCl}$-Based hydrothermal etching (Reproduced with permission from [90]. Copyright 2021, John Wiley and Sons). 
Halogen etching can also be used as an etching method for MXene. Jawaid et al. [98] used halogens $\left(\mathrm{Br}_{2}, \mathrm{I}_{2}, \mathrm{ICl}, \mathrm{IBr}\right)$ to synthesize $\mathrm{Ti}_{3} \mathrm{C}_{2} \mathrm{~T}_{x}$ MXene successfully. Choosing different halogens for etching led to different terminals on MXene. The process is shown in Figure 7. For reaction by-products, the inert gas was continuously circulated in the purification system to remove volatile by-products in order to obtain pure MXene. Tetrabutyl ammonium halide was added as a stabilizer salt in order to separate by-products. Halogen etching was used to expand the MXene layer spacing and it could also be etched in other MAX phases except for $\mathrm{Ti}_{3} \mathrm{AlC}_{2}$. Halogen etching can become a new green, F-free etching method. Shi et al. [99] used iodine etching (IE) in anhydrous acetonitrile $\left(\mathrm{CH}_{3} \mathrm{CN}\right)$ to synthesize fluorine-free $\mathrm{Ti}_{3} \mathrm{C}_{2} \mathrm{~T}_{x}$ MXene. The average size of the obtained MXene was about $1.8 \mu \mathrm{m}$, with high productivity $(71 \%)$, high oxygen content $(18.7 \mathrm{wt} \%)$ and high conductivity $\left(1250 \mathrm{~S} \mathrm{~cm}^{-1}\right)$. This method was that the MAX powder was immersed in the $\mathrm{I}_{2}-\mathrm{CH}_{3} \mathrm{CN}$ mixture. Since the Ti-Al bond was weaker than the Ti-C bond, iodine could selectively eliminate $\mathrm{Al}$ from the MAX phase. $\mathrm{HCl}$ solution was used to wash away excess $\mathrm{AlI}_{3}$ and MXene layers in the obtained products. The process is shown in Figure 8. The performance of the supercapacitor prepared by this method was far superior to the previously reported MXene material.

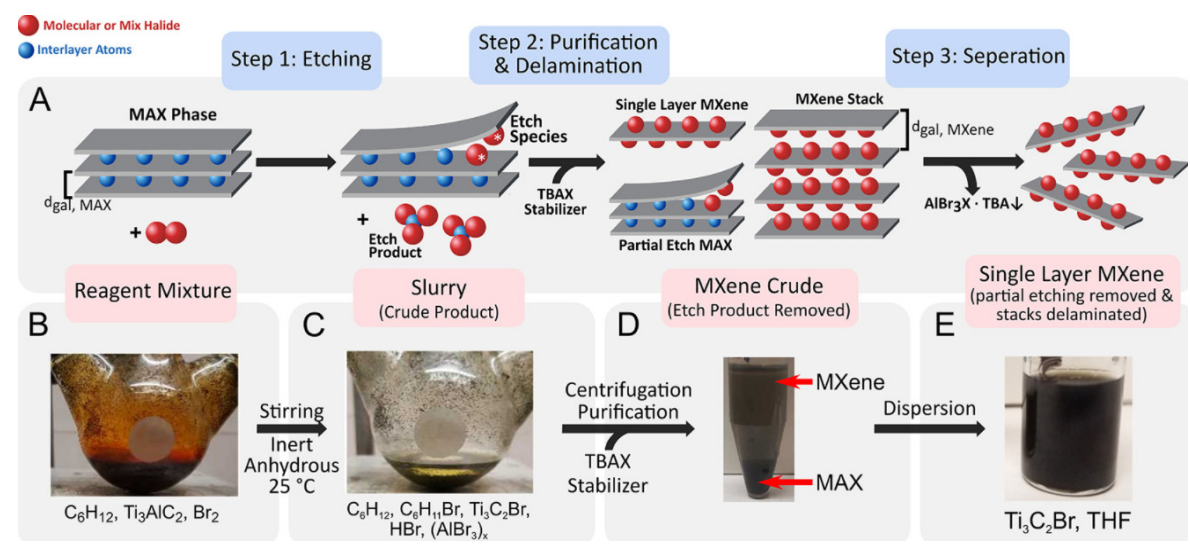

Figure 7. (A) Schematic illustration of the preparation of $\mathrm{Ti}_{2} \mathrm{C}_{2} \mathrm{~T}_{x}$ by halogen etching; (B) Experimental photos of reagent mixture; (C) Experimental photos of mixture with etchant; (D) Experimental photos of the crude MXene; (E) Experimental photos of the single layer MXene (Reproduced with permission from [98]. Copyright 2021, American Chemical Society).

a

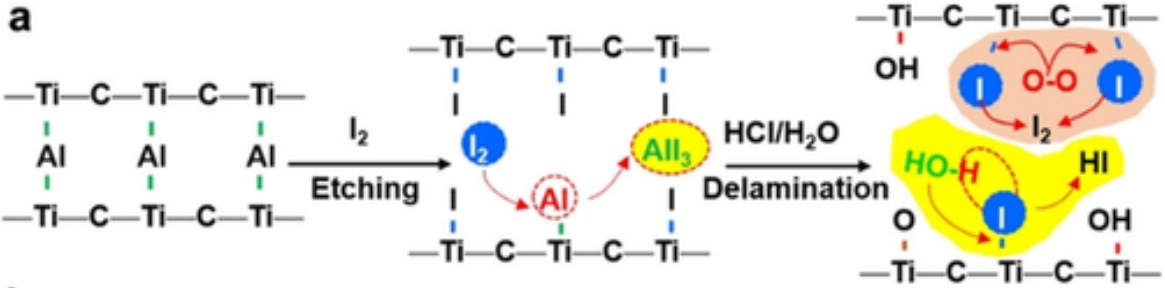

b

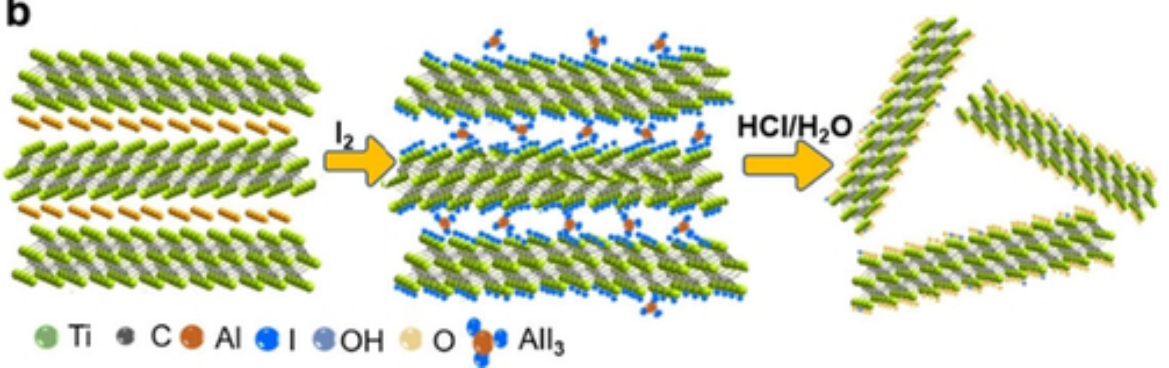

Figure 8. The bond schematic diagram (a) and the model schematic diagram (b) of the preparation of $\mathrm{Ti}_{3} \mathrm{C}_{2} \mathrm{~T}_{x}$ by iodine etching (Reproduced with permission from [99]. Copyright 2021, John Wiley and Sons). 
Lewis acid etching is a new fluorine-free etching method. Li et al. [74] immersed $\mathrm{Ti}_{3} \mathrm{SiC}_{2}$ in the $\mathrm{CuCl}_{2}$ Lewis salt. Redox reaction occurred between $\mathrm{Ti}_{3} \mathrm{SiC}_{2}$ and $\mathrm{CuCl}_{2}$ to etch the Si in order to form $\mathrm{Ti}_{3} \mathrm{C}_{2} \mathrm{~T}_{x}$ MXene. Then, the obtained MXene was washed in ammonium persulfate solution (Figure 9). $\mathrm{SiCl}_{4}$, born during the reaction, could be used as an expansion agent to be embedded in the MXene layer. MXene embedded by water did not release any $-\mathrm{OH}$, which meant that the hydrophilicity of the MXene surface was reduced. The Lewis acid etching method proposed here provides a new idea for preparing MXene without F. However, this method needs to be carried out at $750{ }^{\circ} \mathrm{C}$. Excessively high temperature is detrimental to cost and product, so it still needs to develop the other F-free methods.
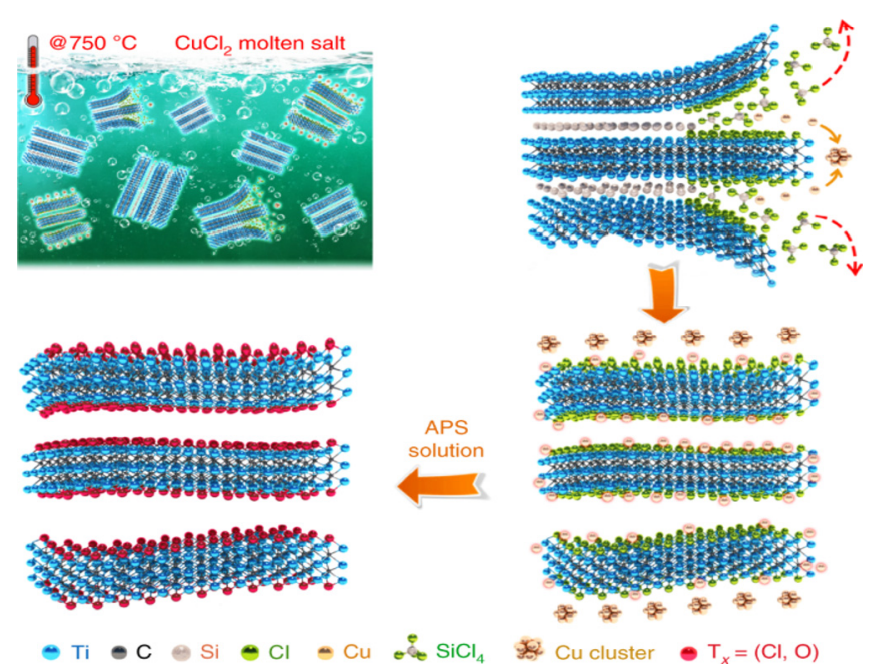

Figure 9. Schematic illustration of the preparation of $\mathrm{Ti}_{3} \mathrm{C}_{2} \mathrm{~T}_{x}$ by Lewis acidic etching (Reproduced with permission from [74]. Copyright 2020, Springer Nature).

It is reported that the volume expansion of $\mathrm{Al}$ and $\mathrm{Li}$ will exceed $100 \%$ when forming $\mathrm{Al}-\mathrm{Li}$ alloy. Using this expansion, the interlayer binding force can be reduced, making the $\mathrm{Al}$ layer to be separated from the MAX possible. Sun et al. [89] prepared singlelayer and few-layer fluorine-free $\mathrm{Ti}_{3} \mathrm{C}_{2} \mathrm{~T}_{x}$ based on the intercalation-alloying-expansionmicroexplosion mechanism. The electric field forced to promote the embedding of $\mathrm{Li}^{+}$ in electrolyte in the Al layer of MAX and an Al-Li alloy was formed. Then, there happened to be the expansion of the Al-Al layer. When placing the lithiated MAX into the water, the Al-Li layer would react with $\mathrm{H}_{2} \mathrm{O}$ and bring $\mathrm{H}_{2}$. A micro explosion occurred between layers, which caused MAX to peel off into $\mathrm{Ti}_{3} \mathrm{C}_{2} \mathrm{~T}_{x}$ nanosheets (Figure 10). The $\mathrm{Ti}_{3} \mathrm{C}_{2} \mathrm{~T}_{x}$ prepared by this method had an ultra-thin translucent structure, and had a high yield and a fast speed, which was advantageous for realizing the actual production of MXene. 


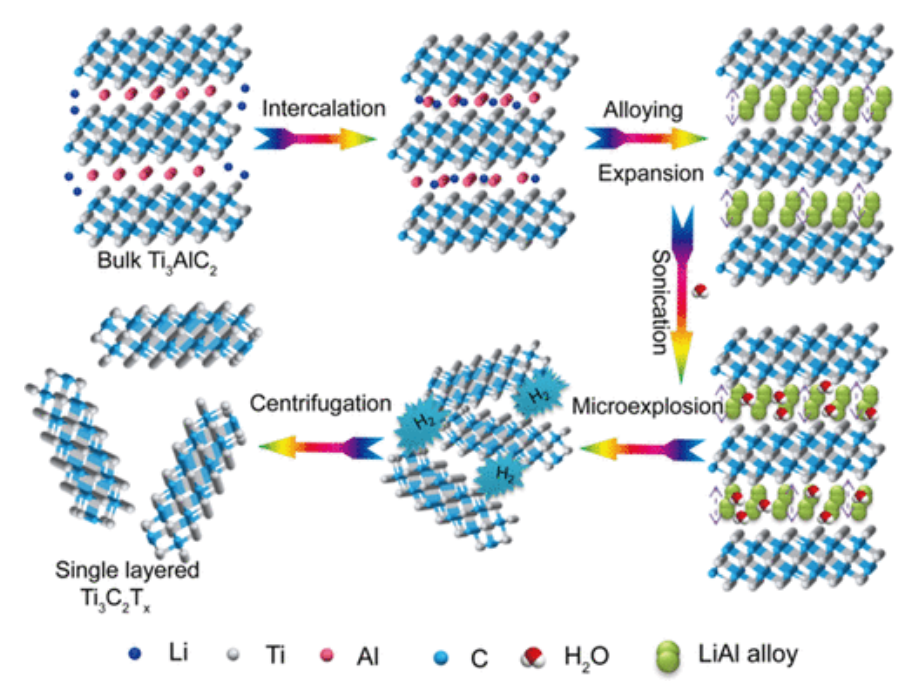

Figure 10. Schematic illustration of the preparation of $\mathrm{Ti}_{3} \mathrm{C}_{2} \mathrm{~T}_{x}$ by lithiation-expansion-microexplosion (Reproduced with permission from [89]. Copyright 2019, American Chemical Society).

In MXene, $\mathrm{Mo}_{2} \mathrm{Ga}_{2} \mathrm{C}$ is an ultraviolet absorbing material, with excellent ultraviolet response characteristics [60]. According to the UV response characteristics of $\mathrm{Mo}_{2} \mathrm{Ga}_{2} \mathrm{C}$, Mei et al. [60] successfully synthesized $\mathrm{Mo}_{2} \mathrm{C}$ MXene with high yield, high quality, and mesoporous structure using UV-induced etching within a few hours. The experimental procedure of UV-induced etching was: (1) The $\mathrm{Mo}_{2} \mathrm{Ga}_{2} \mathrm{C}$ precursor was etched by UV irradiation; (2) The MXene was peeled off with ultrasonic in order to obtain independent MXene nanosheets. The procedure is shown in Figure 11. This method was fast and did not involve HF acid. It was of great significance to MXene with UV response characteristics, but it limited its use to the general MXene, which is not sensitive to UV.

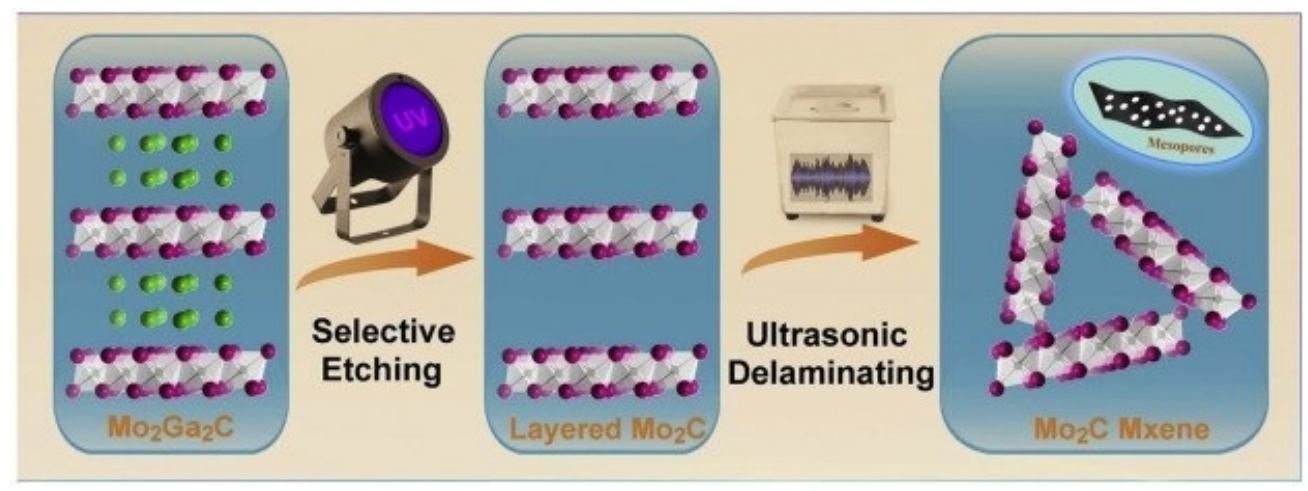

Figure 11. Schematic illustration of the synthesis of $\mathrm{Mo}_{2} \mathrm{Ga}_{2} \mathrm{C}$ by UV-induced etching (Reproduced with permission from [60]. Copyright 2020, Elsevier).

One of the methods to be mentioned in particular is electrochemical etching. Electrochemical etching would not only etch the A layer, but also over-etch the $\mathrm{M}$ layer. Sun et al. [95] successfully synthesized $\mathrm{Ti}_{2} \mathrm{CT}_{x}$ MXene by electrochemical etching in $\mathrm{HCl}$ solution for the first time. The process of this method was: (1) Al was selectively getting rid of from the MAX phase; (2) The cathode potential increased and both $\mathrm{Al}$ and Ti have etched away, leaving carbide-derived carbon (CDC). The procedure is shown in Figure 12. The etched sample had three structures: carbide-derived carbon, MXene, and unetched MAX. MXene was separated from these structures by ultrasound. Since no fluoride ions were involved in the etching process, there were only $-\mathrm{Cl},-\mathrm{O}$, and $-\mathrm{OH}$ terminals in MXene. 


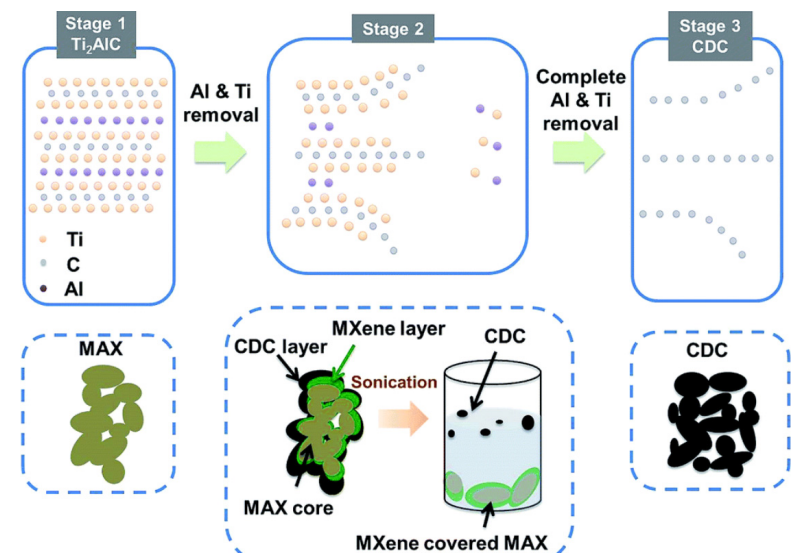

Figure 12. Schematic illustration of the preparation of $\mathrm{Ti}_{2} \mathrm{CT}_{x}$ by $\mathrm{HCl}$ solution (Reproduced with permission from [95]. Copyright 2017, the Royal Society of Chemistry).

Until now, the F-free etching method has not been studied enough and a lot of theoretical and practical work is still needed. The F-containing etching methods using HF and $\mathrm{LiF}+\mathrm{HCl}$ are still the most used.

\subsection{Intercalator}

Due to the in-plane covalent bond and the van der Waals force between the layers, the MXene has a small interlayer spacing. The increase in interlayer spacing makes the specific surface area larger, makes active sites greater, and makes ion transport channels wider. Additionally, it is crucial to the performance of MXene [102]. When the intercalators were added in MXene, the intercalation makes the layers swell, so the distance between the layer increases. The intercalator mainly includes organic molecules and metal cations. In 2013, Mashtalir et al. [103] inserted hydrazine hydrate $\left(\mathrm{HM}, \mathrm{N}_{2} \mathrm{H}_{4} \bullet \mathrm{H}_{2} \mathrm{O}\right)$ and DMFin $\mathrm{Ti}_{3} \mathrm{C}_{2} \mathrm{~T}_{x}$ in dimethyl sulfoxide (DMSO) for the first time. After ultrasonic treatment, the embedding of HM and DMF caused the layer spacing of MXene to increase (Figure 13a,b). Since then, the research on intercalators used for layering has gradually increased. Qian et al. [104] used DMSO to layer $\mathrm{Ti}_{3} \mathrm{C}_{2} \mathrm{~T}_{x}$ in order to obtain dispersed MXene flakes. As for the MXene treated by DMSO, there were the replacement of $-\mathrm{F}$ by $-\mathrm{OH}$, the increase of interlayer spacing, and the enhancement of hydrophilicity during the delamination process. The theoretical model of DMSO that was embedded in $\mathrm{Ti}_{3} \mathrm{C}_{2} \mathrm{O}_{2}$ and $\mathrm{Ti}_{3} \mathrm{C}_{2}(\mathrm{OH})_{2}$ was studied. It was found that the interlayer spacing of $\mathrm{Ti}_{3} \mathrm{C}_{2}(\mathrm{OH})_{2}$ was larger than that of $\mathrm{Ti}_{3} \mathrm{C}_{2} \mathrm{O}_{2}$ after DMSO embedding. It might be because of the hydrogen atoms of $\mathrm{Ti}_{3} \mathrm{C}_{2}(\mathrm{OH})_{2}$ and the methyl group of DMSO. Hydrogen atoms and the methyl group were mutually exclusive. In addition, $\mathrm{Ti}_{3} \mathrm{C}_{2}(\mathrm{OH})_{2}$ and DMSO interacted electrostatically to promote interlayer dispersion. Overbury et al. [105] embedded urea in $\mathrm{Ti}_{3} \mathrm{C}_{2} \mathrm{~T}_{x}$ and found that urea was decomposed under the promotion of MXene, causing the $\mathrm{C}-\mathrm{N}$ bond of the molecule to break. The reason for the increasing interlayer spacing of MXene was that the decomposition of urea produced the ammonium intercalation, so that the interlayer swelled. Xu et al. [106] inserted ethylenediamine (EDA) into $\mathrm{Ti}_{3} \mathrm{C}_{2} \mathrm{~T}_{x}$ MXene nanosheets, where EDA was anchored to $\mathrm{Ti}_{3} \mathrm{C}_{2} \mathrm{~T}_{x}$ through N-Ti coordination bonds, as shown in Figure 14. The insertion of organic molecules EDA made the interlayer spacing of MXene larger and there were abundant mesopores. Due to the expansion of the layer spacing, the specific surface area of EDA- $\mathrm{Ti}_{3} \mathrm{C}_{2} \mathrm{~T}_{x}\left(59.2 \mathrm{~m}^{2} \mathrm{~g}^{-1}\right)$ was much higher than pure $\mathrm{Ti}_{3} \mathrm{C}_{2} \mathrm{~T}_{x}\left(13.6 \mathrm{~m}^{2} \mathrm{~g}^{-1}\right)$. Large interlayer spacing, abundant mesopores and large specific surface areas were beneficial to the better performance of MXene. Wang et al. [107] inserted dipicolinic acid (DC) molecules between MXene layers under the ultrasound and successfully realized the expansion of the MXene nanosheet spacing. MXene without DC had a typical accordion-like structure (Figure 15a) with small inter-layer spacing. On the other hand, DC particles appeared 
on the surface or between layers of MXene with DC (Figure 15b,c), and the layer spacing was significantly increased.
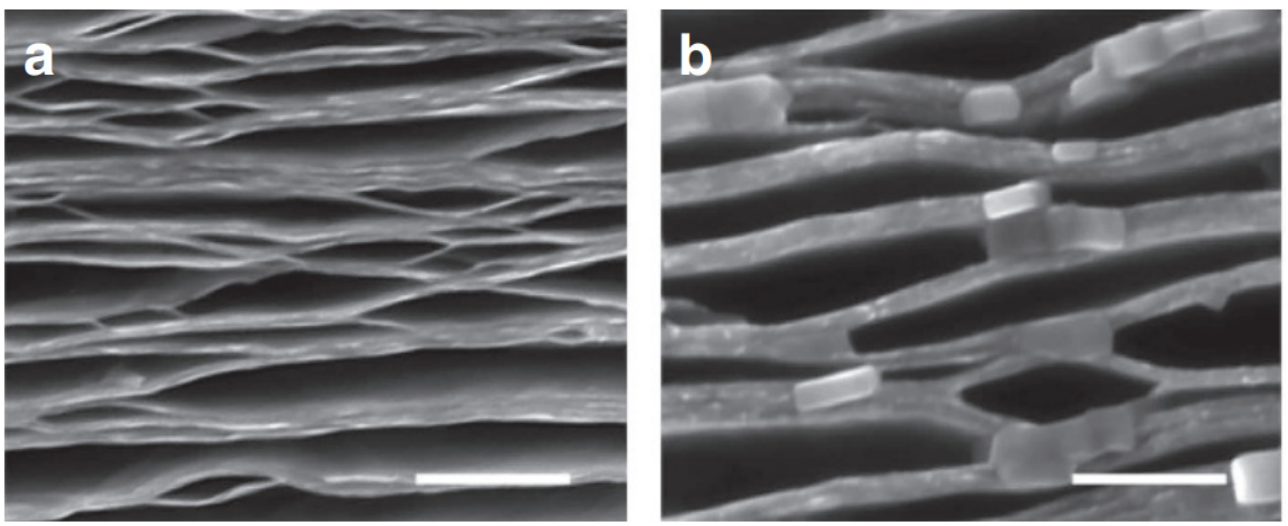

Figure 13. (a) SEM images before intercalation of $\mathrm{f}-\mathrm{Ti}_{3} \mathrm{C}_{2}$ with $\mathrm{HM}$ and DMF; (b) SEM images after intercalation of $\mathrm{f}-\mathrm{Ti}_{3} \mathrm{C}_{2}$ with $\mathrm{HM}$ and DMF (Reproduced with permission from [103]. Copyright 2013, Springer Nature).
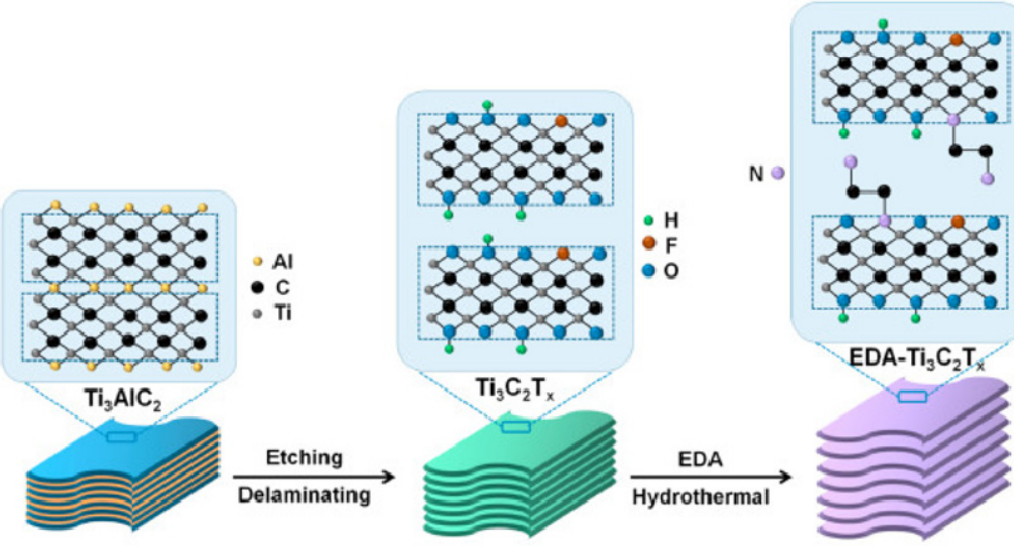

Figure 14. Schematic illustration of the preparation of $\mathrm{Ti}_{3} \mathrm{C}_{2} \mathrm{~T}_{x}$ by EDA (Reproduced with permission from [106]. Copyright 2021, Elsevier).
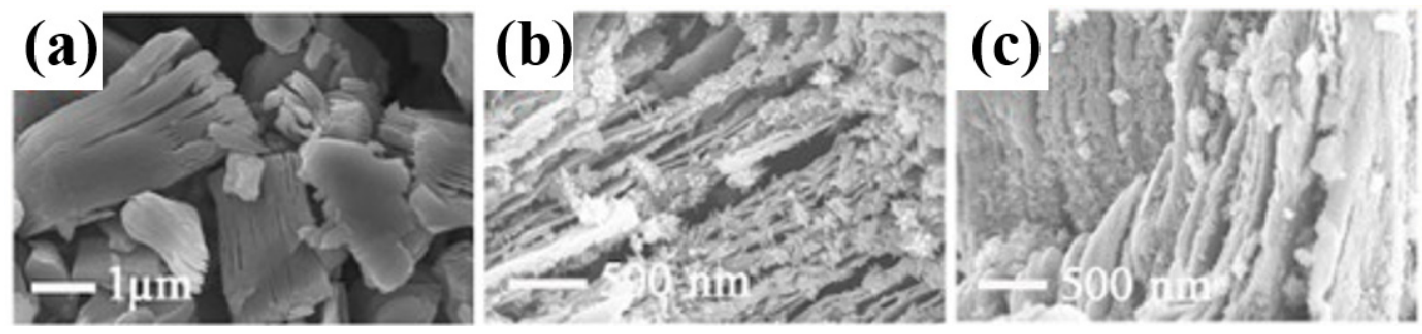

Figure 15. (a) SEM images without interacted DC; (b,c) SEM images interacted by DC (Reproduced with permission from [107]. Copyright 2020, Elsevier).

Since metal cations can be spontaneously inserted into the MXene layer, they are widely used as intercalators to increase the interlayer spacing of MXene [108]. The metal ions used as intercalators are: $\mathrm{Na}^{+}, \mathrm{K}^{+}, \mathrm{Mg}^{2+}, \mathrm{Li}^{+}, \mathrm{Sn}^{4+}, \mathrm{Mn}^{2+}$ [109-112]. For example, Kajiyama et al. [109] embedded $\mathrm{Na}^{+}$in $\mathrm{Ti}_{3} \mathrm{C}_{2} \mathrm{~T}_{x}\left(\mathrm{~T}_{x}=-\mathrm{OH},-\mathrm{O}\right.$, and $\left.-\mathrm{F}\right)$ and found that the increase of distance between layers was more than $4.0 \AA$ owing to the embedding of $\mathrm{Na}^{+}$. Additionally, $\mathrm{Na}^{+}$could be regarded as a pillar that kept distance between layers. There were two reasons for the increase of the interlayer spacing after $\mathrm{Na}^{+}$intercalation. 
On the one hand, $\mathrm{Na}$ and $\mathrm{H}$ atoms repelled each other and the existence of $-\mathrm{OH}$ terminal expanded the interlayer distance. On the other hand, $\mathrm{Na}^{+}$intercalation allowed solvent molecules to penetrate into the interlayer, resulting in a swelling effect and increasing the spacing between layers.

Zhang et al. [113] used the hydrothermal method and self-assembly to prepare $\mathrm{Co}_{3} \mathrm{O}_{4}-$ MXene (Co-MXene) composite materials. This paper found that the introduction of $\mathrm{Co}_{3} \mathrm{O}_{4}$ nanoparticles into $\mathrm{MXene}$ could effectively prevent self-weight accumulation. First, the cobalt ions were intercalated between the layers of MXene. Then, in the hydrothermal process, the cobalt ions in the MXene interlayer were transformed into volume-expanded $\mathrm{Co}_{3} \mathrm{O}_{4}$ nanoparticles. $\mathrm{Co}_{3} \mathrm{O}_{4}$ nanoparticles acted as a support for opening the laminated structure, resulting in the production of Co-MXene with a large specific surface area (Figure 16a,b).

(a)

(b)

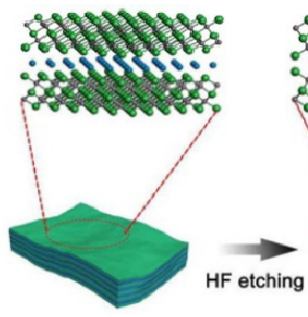

$\mathrm{Ti}_{3} \mathrm{AIC}$, MAX
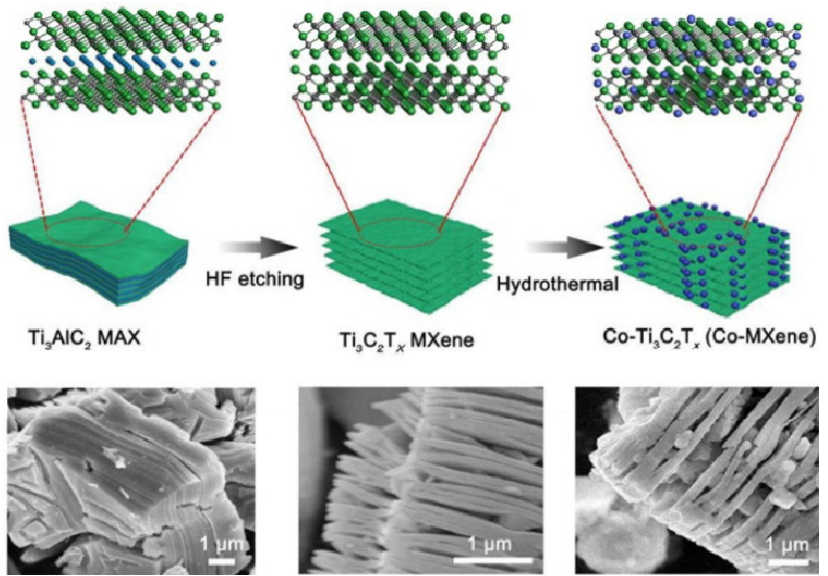

Figure 16. (a) Schematic illustration of the synthesis of the Co- $\mathrm{Ti}_{3} \mathrm{C}_{2} \mathrm{~T}_{x}$ composite; (b) FESEM images of $\mathrm{Ti}_{3} \mathrm{AlC}_{2}$, multilayer $\mathrm{Ti}_{3} \mathrm{C}_{2} \mathrm{~T}_{x}$ and $\mathrm{Co}-\mathrm{MXene}$ composite (Reproduced with permission from [113]. Copyright 2021, Elsevier).

Generally, the intercalators are added after the end of etching. However, there will happen that the interlayer spacing may decrease after the adjunction of the metal cation. Hu et al. [110] proposed a one-step method to embed metal cations in MXene, regarding the metal cations as a part of the etchant instead of as an intercalator after the etching. This method was used to solve the problem of reducing spacing between layers after the intercalation of a cation. The two-step process was as follows: The etched MXene powder was dispersed in $\mathrm{Li}, \mathrm{Na}$, or $\mathrm{Sn}$ salt and stirred, and then the product was collected. The one-step process was as follows: The $\mathrm{Ti}_{3} \mathrm{AlC}_{2}$ powder was added to the mixture of $\mathrm{HF}$ and $\mathrm{Li}, \mathrm{Na}$, and $\mathrm{Sn}$ salt to collect the product. The procedure is shown in Figure 17. The study found that: (1) When using the one-step method, the interlayer spacing of MXene increased from 18.5 to $24.84 \AA$; (2) When the embedding process occurred after the etching process, the inter-layer spacing became smaller. Because the interlayer of MXene was occupied by water after the etching, the metal cations were unevenly distributed due to static electricity after embedding. The distance between the layers where the metal ions were embedded increased. It broke the stability of the water caused the loss of water and collapsed between the layers. So the inter-layer spacing became smaller when the embedding process occurred after the etching process. For the one-step method, the cations were evenly dispersed between the layers due to etching and embedding at the same time, so there was no collapse. 


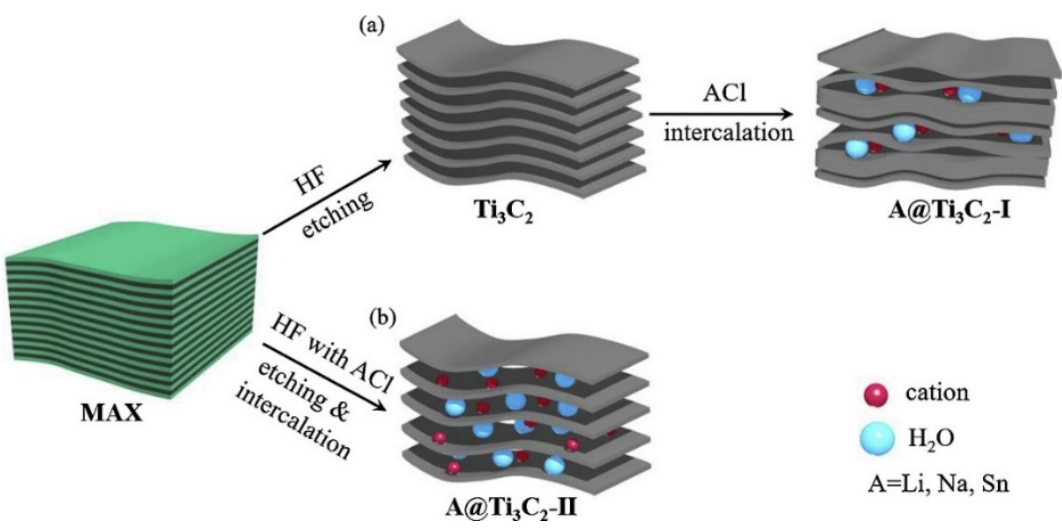

Figure 17. Schematic illustration of the preparation of $\mathrm{Ti}_{3} \mathrm{C}_{2}$ by one-step method (a) and traditional method (b) (Reproduced with permission from [110]. Copyright 2020, Elsevier).

In addition to the intercalation of organic molecules and metal cations, polymers, hydroxides, anions, and water can also be intercalated to increase the interlayer spacing of MXene. For example, Boota et al. [114] has synthesized polar charged, polar neutral, and non-polar polyfluorene derivatives (PFD) (Figure 18), and made the adjusted terminal PFD to interact with $\mathrm{Ti}_{3} \mathrm{C}_{2} \mathrm{~T}_{x}$. This study found that PFD could be embedded in the interlayer with increasing interlayer spacing. Additionally, the polar charged PFD maximized the increase in interlayer spacing. Li et al. [115] used a positively charged $\mathrm{Fe}(\mathrm{OH})_{3}$ solution as an intercalator to insert negatively charged MXene and then removed the $\mathrm{Fe}(\mathrm{OH})_{3}$ solution with $\mathrm{HCl}$. The procedure is shown in Figure 19. Then, $4 \sim 5 \mathrm{~nm} \mathrm{Fe}(\mathrm{OH})_{3}$ formed nanochannels and the nanochannels increased interlayer spacing. Srimuk et al. [116] used anion $\left(\mathrm{Cl}^{-}\right)$as an intercalator to insert MXene for the first time and at the same time inserted $\mathrm{Na}^{+}$to study its effect on seawater desalination. Fredrickson et al. [117] studied the change of the surface chemistry of $\mathrm{Ti}_{2} \mathrm{C}$ and $\mathrm{Mo}_{2} \mathrm{C}$ MXene when $\mathrm{H}_{2} \mathrm{O}$ was embedded. However, the research of these intercalators is insufficient and the applications are not extensive enough. More time should be devoted to research and develop the intercalators further in order to improve the interlayer spacing and special properties of MXene.

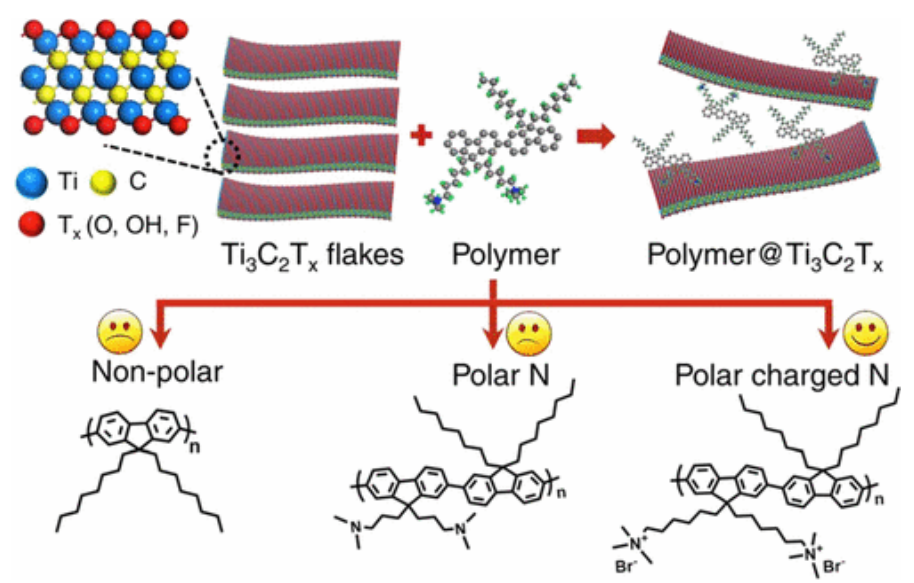

Figure 18. Schematic illustration of synthesis of the polymer and polymer@ $\mathrm{Ti}_{3} \mathrm{C}_{2} \mathrm{~T}_{x}$ (Reproduced with permission from [114]. Copyright 2017, American Chemical Society). 


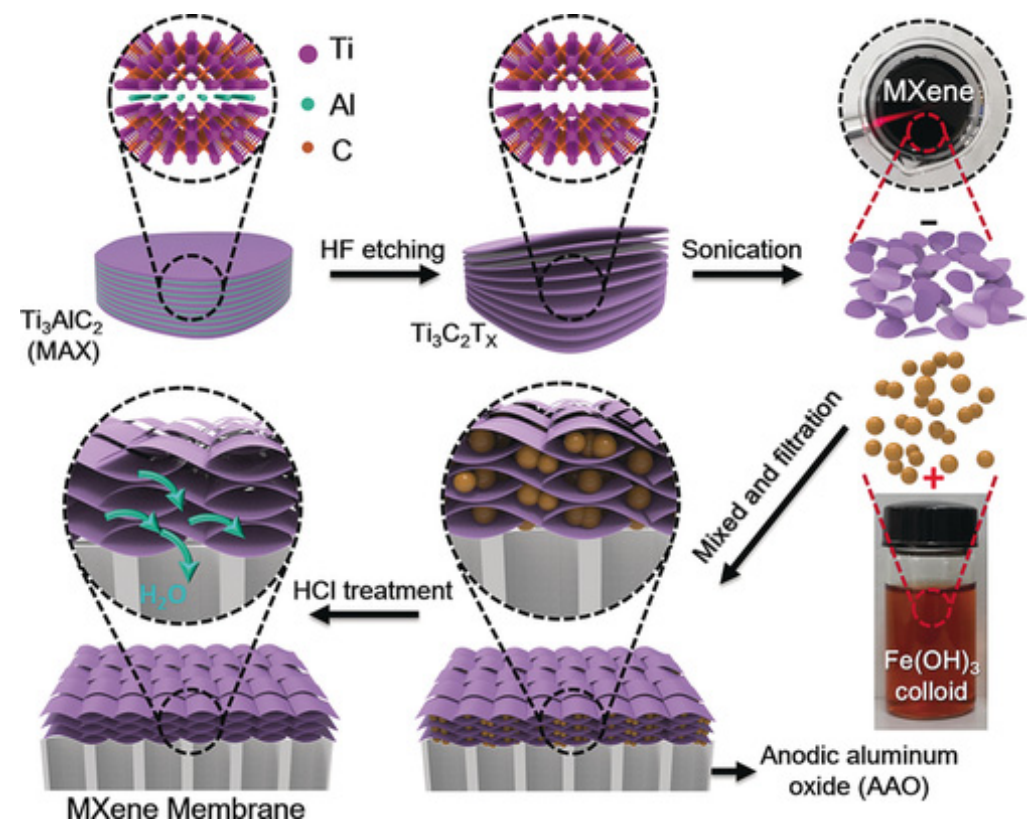

Figure 19. Schematic illustration of preparation of $\mathrm{Ti}_{3} \mathrm{C}_{2} \mathrm{~T}_{x}$ interacted by $\mathrm{Fe}(\mathrm{OH})_{3}$ (Reproduced with permission from [115]. Copyright 2017, John Wiley and Sons).

\subsection{Dispersion}

Because the van der Waals force between MXene layers can stack MXene under its weight, it leads to the extension of ion transport pathways and the lack of contact between active surface sites and electrolytic ions. Therefore, we must find a way to let MXene remain dispersed [113,118]. There are two main aspects to enhance the dispersibility of MXene: changing the dispersant and surface modification of MXene. Usually, these two aspects are applied simultaneously, not only choosing different dispersants, but also modifying MXene.

As for dispersants, organic solvents are the most studied. Maleski et al. [119] dispersed MXene in water, ethanol $(\mathrm{EtOH})$, methanol $(\mathrm{MeOH})$, acetone (ACE), etc., researching the state of dispersion and aggregation of MXene in 12 different types of solvents (Figure 20). The experiment found that MXene had poor dispersibility in HEX, TOL and DCB, and MXene ultimately precipitated after being placed for $96 \mathrm{~h}$. The higher the surface tension of the solvent, the easier the $2 \mathrm{D}$ material was to disperse. The surface tension of other organic solvents except ethanol was very high. Although the surface tension of ethanol was very low, ethanol strongly interacted with the surface terminals of MXene. Therefore, the dispersibility was also excellent.

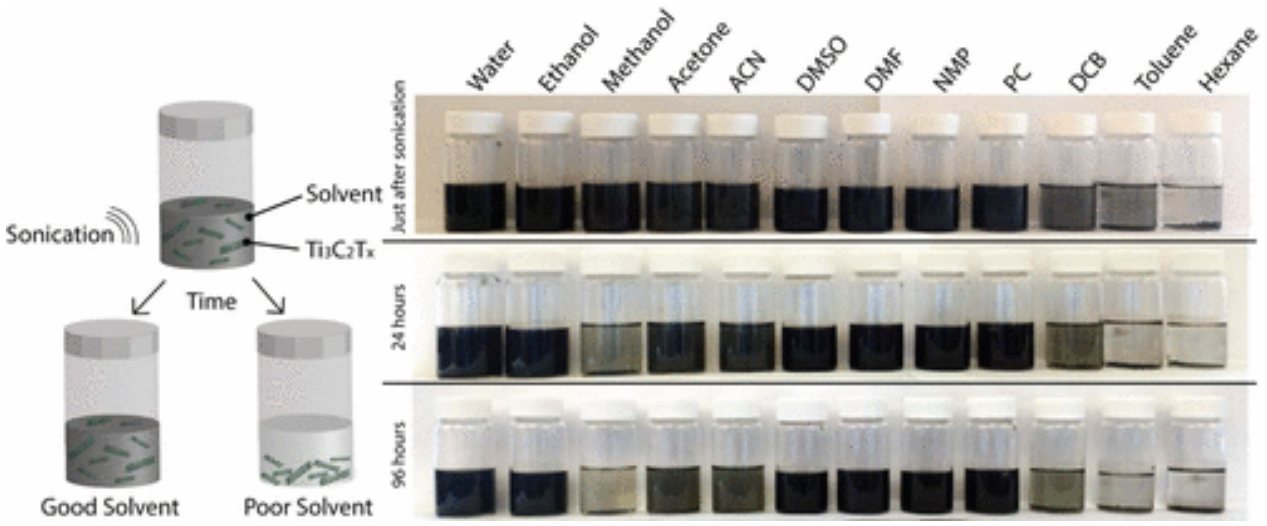

Figure 20. Dispersions of $\mathrm{Ti}_{3} \mathrm{C}_{2} \mathrm{~T}_{x}$ in the 12 solvents (Reproduced with permission from [119]. Copyright 2017, American Chemical Society). 
Zhang et al. [118] developed a high-concentration organic solvent solution of $\mathrm{Ti}_{3} \mathrm{C}_{2} \mathrm{~T}_{x}$ by adjusting the microenvironment of $\mathrm{Ti}_{3} \mathrm{C}_{2} \mathrm{~T}_{x}$, namely the tuned microenvironment method (TMM). The steps of the TMM method were: (1) Etching the MAX phase into $\mathrm{Ti}_{3} \mathrm{C}_{2} \mathrm{~T}_{x}$ MXene with HF; (2) $\mathrm{Ti}_{3} \mathrm{C}_{2} \mathrm{~T}_{x}$ was modified by the intercalation and surface modification of tetrabutylammonium hydroxide (TBAOH); (3) Stirring the modified $\mathrm{Ti}_{3} \mathrm{C}_{2} \mathrm{~T}_{x}$ powder gently or shaking it by hand to easily disperse it into the organic solvent. The procedure is shown in Figure 21. The organic solvents were propylene carbonate (PC), N,Ndimethylacetamide (DMAc), and N,N-dimethylformamide (DMF), which had high surface tension and high boiling points. The yield of the single-layer MXene obtained by the TMM method was $63.9 \%$ and the material prepared by TMM had a larger sheet size, fewer defects, and better dispersion. Special attention was that the high dispersibility of the modified $\mathrm{Ti}_{3} \mathrm{C}_{2} \mathrm{~T}_{x}$ was because of the hydrophobic surface. The hydrophobicity was caused by the insertion of $\mathrm{TBA}^{+}$between the MXene layers and the adjustment of surface groups in the TMM method.

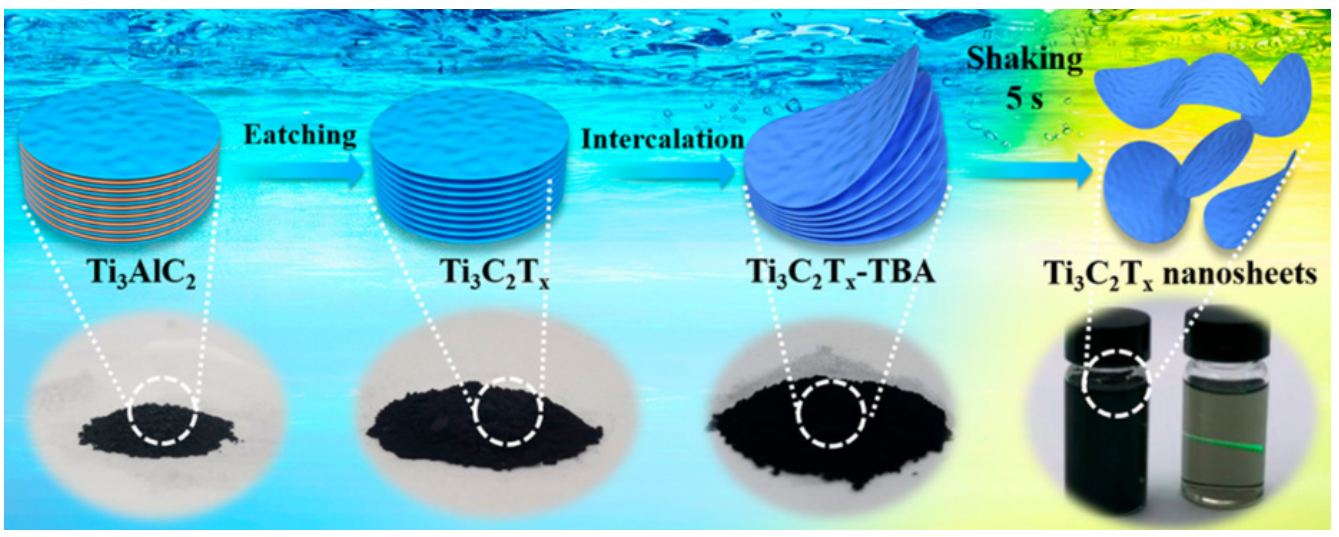

Figure 21. Schematic diagram of the synthesis of $\mathrm{Ti}_{3} \mathrm{C}_{2} \mathrm{~T}_{x}$ organic solvent dispersion via TMM (Reproduced with permission from [118]. Copyright 2021, American Chemical Society).

The dispersion of MXene in non-polar solvents has also been partially reported. However, the hydrophilicity and negative surface charge of the original $\mathrm{Ti}_{3} \mathrm{C}_{2} \mathrm{~T}_{x} \mathrm{MXene}$ limit its dispersion in non-polar solutions [120]. Scholars have researched this issue. For example, Lim et al. [121] used strong acid polyelectrolyte (PAMPS) as an emulsifier to graft octyltriethoxysilane (OTS) onto the surface of MXene, making the hydrophilic MXene become hydrophobic. The stable period of hydrophobic MXene that dispersed in non-polar hexane was more than one month. Carey et al. [122] found that when $\mathrm{Li}^{+}$exchanged with di(hydrogenated tallow) benzyl methyl ammonium chloride (DHT), the surface of MXene changed from hydrophilic to organophilic, which could be stably dispersed in non-polar solvents. McDaniel et al. [123] used isocyanate to covalently modify $\mathrm{Ti}_{3} \mathrm{C}_{2} \mathrm{~T}_{x}$ MXene for the first time and successfully obtained a large number of MXene with alkyl carbamate groups on the surface. The modified MXene could be used in hydrophobic thio amino groups and be stable dispersion in the formate matrix.

Surface modification is a common method to change the hydrophilicity of material surface and many methods have been developed based on surface modification. For example, Zhang et al. [124] used the solution-phase flocculation method to successfully prepare a large amount of low-layer $\mathrm{Ti}_{3} \mathrm{C}_{2} \mathrm{~T}_{x}$ MXene for the first time. The solution-phase flocculation method mainly used ammonium ions to solve the re-stacking of MXene nanosheets. The solution-phase flocculation method was divided into the $\mathrm{NH}_{4}{ }^{+}$method and the improved $\mathrm{NH}_{4}{ }^{+}$method. The $\mathrm{NH}_{4}{ }^{+}$method was to quickly synthesize a few-layer $\mathrm{Ti}_{3} \mathrm{C}_{2} \mathrm{~T}_{x}$ powder by freeze-drying the electrostatic flocs which was formed by MXene colloids and adding subsequent removable $\mathrm{NH}_{4}{ }^{+}$(Figure 22). In addition, all the methods discussed above are for the preparation of MXene suspension, but the solution-phase flocculation method could directly prepare MXene powder. The $\mathrm{NH}_{4}{ }^{+}$method improved the dis- 
persibility of MXene, because the negative charge on the surface of MXene was reduced after adding $\mathrm{NH}_{4}{ }^{+}$. The MXene sheets were mutually repelled by static electricity and were evenly dispersed in water. After freeze-drying and annealing, MXene nanosheets could be gathered. The improved $\mathrm{NH}_{4}{ }^{+}$method is adding step-by-step layering and auxiliary centrifugation in the electrostatic flocculation process, which was mainly to shorten the freeze-drying time further. The improved $\mathrm{NH}_{4}{ }^{+}$method shortened the preparation cycle and obtained a yield as high as $70 \%$.

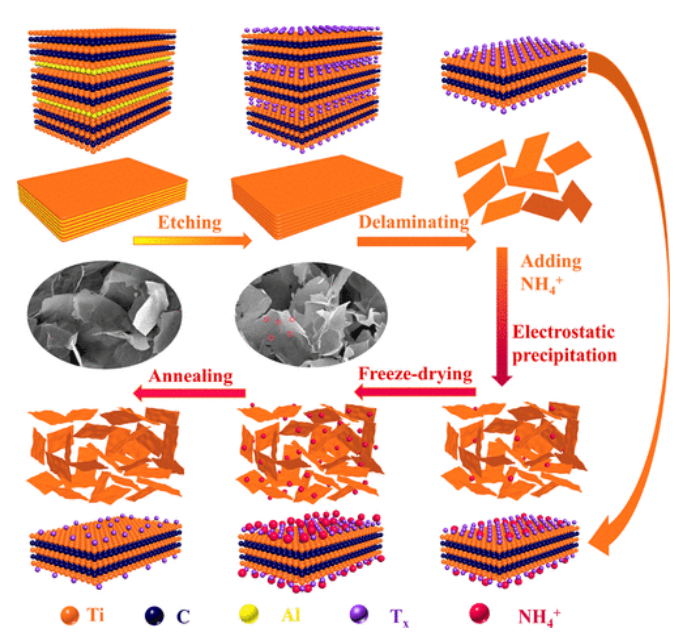

Figure 22. Schematic diagram of the synthesis of $\mathrm{Ti}_{3} \mathrm{C}_{2} \mathrm{~T}_{x}$ powders by solution-phase flocculation strategy (Reproduced with permission from [124]. Copyright 2020, American Chemical Society).

\subsection{Large-Scale Synthesis}

In most experiments of preparing MXene, the yield of MXene is deficient, which is unfavorable for putting MXene into production and widely used. However, except for the yield of less than $20 \%$ mentioned in some estimates, it has hardly been reported that the exact yield of MXene can be obtained. Therefore, it is a pity that we cannot give the yield here. It is significant to develop a method that can prepare a large amount of powder. In order to achieve the mass production of MXene, the critical technology is to swell MXene, and then use physical methods (stirring or ultrasound) to layer MXene. For example, in 2015, Naguib et al. [54] used macromolecular organic bases (tetrabutylammonium hydroxide (TBAOH), choline hydroxide, or n-butylamine) to react with MXene in order to cause the swelling of the MXene. They then used simple stirring or sonication to cause large-scale delamination of the MXene layer. In 2016, Wang et al. [125] used aryl diazonium salts to modify the surface of $\mathrm{Ti}_{3} \mathrm{C}_{2}$ MXene in order to cause swelling and large-scale delamination occurred through gentle ultrasonic treatment. In 2020, Huang et al. [126] used the different densities of water and ice to develop a new method freeze-and-thaw (FAT) auxiliary method. After etching, $\mathrm{H}_{2} \mathrm{O}$ entered the interlayers of MXene, froze to become ice, and expanded. Then, the ice thawed in order to re-embed more $\mathrm{H}_{2} \mathrm{O}$. Through multiple cycles of FAT without ultrasonic treatment, the yield of MXene could reach $39.0 \%$. After $1 \mathrm{~h}$ of ultrasonic treatment, the yield of MXene reached $81.4 \%$. In addition, large-scale MXene can be prepared through various methods developed. However, when the production volume is expanded, it must be considered whether the product obtained after expanding the dosage is the same as the small batch production. Shuck et al. [68] compared $\mathrm{Ti}_{3} \mathrm{C}_{2} \mathrm{~T}_{x}$ prepared in large batches with $\mathrm{Ti}_{3} \mathrm{C}_{2} \mathrm{~T}_{x}$ prepared in small batches and found that mass production was feasible. It is necessary to research the mass production of MXene, which is important to the actual application of MXene.

\section{MXene-Based Gas Sensors}

Because of rich surface functional groups, large specific surface area, large porosity, high conductivity, and other properties, MXene is considered as a promising sensor mate- 
rial with abundant gas adsorption active sites [127]. MXene can get fast charge transfer under low temperature conditions because of its good metal conductivity and high carrier mobility, leading the gas response to improve at room temperature [128]. For example, $\mathrm{NH}_{3}$ can interact with some oxygen terminals such as -OH and $-\mathrm{O}$. MXene with a large number of oxygen-containing terminals can strongly interact with $\mathrm{NH}_{3}$, which helps to obtain excellent gas response [129]. Here, we will describe the performance of pristine MXene and MXene composite in gas sensors in detail. MXene composite includes metal oxide composite, polymers composite and Pd-MXene.

Table 1 shows gas-sensitivity performances of MXene-based gas sensors.

Table 1. Gas sensing performances of MXene-based gas sensors.

\begin{tabular}{|c|c|c|c|c|c|c|}
\hline Material & Gas & $\begin{array}{l}\text { Conc. } \\
\text { (ppm) }\end{array}$ & $\begin{array}{l}\text { Operating } \\
\text { Temp }\left({ }^{\circ} \mathrm{C}\right)\end{array}$ & $\underset{\%}{\text { Response }}$ & $\begin{array}{c}\text { Response/Recovery } \\
\text { Time (s/s) }\end{array}$ & References \\
\hline \multirow{2}{*}{$\mathrm{Ti}_{3} \mathrm{C}_{2} \mathrm{~T}_{x}$} & Acetone & 5 & RT & 3.6 & $90 / 102$ & [130] \\
\hline & Ethanol & 100 & RT & 22.47 & $-/-$ & [131] \\
\hline $\mathrm{Mo}_{2} \mathrm{CT}_{x}$ & Toluene & 100 & $\mathrm{RT}$ & 2.65 & $-/-$ & [132] \\
\hline $\mathrm{Ti}_{3} \mathrm{C}_{2} \mathrm{~T}_{x} / \mathrm{CuO}$ & Toluene & 50 & 250 & 11.4 & $270 / 10$ & [49] \\
\hline $\mathrm{Ti}_{3} \mathrm{C}_{2} \mathrm{~T}_{x} / \mathrm{ZnO}$ & $\mathrm{NO}_{2}$ & 100 & RT & 41.93 & $34 / 105$ & [133] \\
\hline $\mathrm{Ti}_{3} \mathrm{C}_{2} \mathrm{~T}_{x} / \mathrm{SnO}_{2}$ & $\mathrm{NH}_{3}$ & 50 & RT & 40 & $36 / 44$ & [129] \\
\hline $\mathrm{Ti}_{3} \mathrm{C}_{2} \mathrm{~T}_{x} / \mathrm{SnO}-\mathrm{SnO}_{2}$ & Acetone & 100 & RT & 12.1 & $18 / 9$ & [134] \\
\hline $\mathrm{Ti}_{3} \mathrm{C}_{2} \mathrm{~T}_{x} / \mathrm{Co}_{3} \mathrm{O}_{4}$ & $\mathrm{HCHO}$ & 10 & RT & 9.2 & $83 / 5$ & [135] \\
\hline $\mathrm{Ti}_{3} \mathrm{C}_{2} \mathrm{~T}_{x} / \mathrm{WO}_{3}$ & $\mathrm{NH}_{3}$ & 1 & RT & 22.3 & $119 / 228$ & [128] \\
\hline $\mathrm{Ti}_{3} \mathrm{C}_{2} \mathrm{~T}_{x} / \mathrm{W}_{18} \mathrm{O}_{49}$ & Acetone & 0.17 & 300 & 1.4 & $5.6 / 6$ & [136] \\
\hline $\mathrm{Ti}_{3} \mathrm{C}_{2} \mathrm{~T}_{x} / \mathrm{In}_{2} \mathrm{O}_{3}$ & Methane & 5 & RT & 29.6 & $6.5 / 3.5$ & [137] \\
\hline \multirow{2}{*}{$\mathrm{Ti}_{3} \mathrm{C}_{2} \mathrm{~T}_{x} / \mathrm{PANI}$} & Ethanol & 200 & $\mathrm{RT}$ & 41.1 & $0.4 / 0.5$ & [138] \\
\hline & $\mathrm{NH}_{3}$ & 50 & $\mathrm{RT}$ & 400 & $-/-$ & [139] \\
\hline $\mathrm{Nb}_{2} \mathrm{CT}_{x} / \mathrm{PANI}$ & $\mathrm{NH}_{3}$ & 100 & $\mathrm{RT}$ & 301.31 & $105 / 143$ & [140] \\
\hline $\mathrm{Ti}_{3} \mathrm{C}_{2} \mathrm{~T}_{x} /$ PEDOT:PSS & $\mathrm{NH}_{3}$ & 100 & $\mathrm{RT}$ & 36.6 & $116 / 40$ & [141] \\
\hline \multirow{2}{*}{$\mathrm{V}_{2} \mathrm{CT}_{x}$} & $\mathrm{H}_{2}$ & 2 & RT & - & $120 / 420$ & \\
\hline & Methane & 25 & RT & - & $480 / 330$ & [85] \\
\hline \multirow{2}{*}{$\mathrm{Pd}-\mathrm{Ti}_{3} \mathrm{C}_{2} \mathrm{~T}_{x}$} & \multirow{2}{*}{$\mathrm{H}_{2}$} & 4000 & $\mathrm{RT}$ & 23 & $37 / 161$ & [142] \\
\hline & & 100 & RT & 56 & $-/-$ & [143] \\
\hline $\mathrm{SnS}_{2} / \mathrm{Ti}_{3} \mathrm{C}_{2} \mathrm{~T}_{x}$ & $\mathrm{NO}_{2}$ & 1000 & RT & 115 & $64 / 10$ & [144] \\
\hline $\mathrm{Ti}_{3} \mathrm{C}_{2} \mathrm{~T}_{x} / \mathrm{WSe}_{2}$ & Ethanol & 40 & RT & 24 & $9.7 / 6.6$ & [145] \\
\hline $\mathrm{S}-\mathrm{Ti}_{3} \mathrm{C}_{2} \mathrm{~T}_{x}$ & Toluene & 10 & $\mathrm{RT}$ & 59.1 & $-/-$ & [146] \\
\hline $\mathrm{Ti}_{3} \mathrm{C}_{2} \mathrm{~T}_{x}$ & Ethanol & 120 & RT & 14 & $39 / 139$ & [147] \\
\hline $\mathrm{Ti}_{3} \mathrm{C}_{2} \mathrm{~T}_{x} / \mathrm{Fe}_{2}\left(\mathrm{MoO}_{4}\right)_{3}$ & N-butane & 100 & $\mathrm{RT}$ & 43.1 & $18 / 24$ & [148] \\
\hline $\mathrm{Ti}_{3} \mathrm{C}_{2} \mathrm{~T}_{x}$ & $\mathrm{NH}_{3}$ & 100 & RT & 28.87 & $1 / 201$ & [149] \\
\hline $\mathrm{Ti}_{3} \mathrm{C}_{2} \mathrm{~T}_{x} / \mathrm{GO}$ & $\mathrm{NH}_{3}$ & 100 & RT & 7.21 & $-/-$ & [150] \\
\hline $\mathrm{rGO} / \mathrm{N}-\mathrm{Ti}_{3} \mathrm{C}_{2} \mathrm{~T}_{x} / \mathrm{TiO}_{2}$ & $\mathrm{HCHO}$ & 20 & RT & 132 & $-/-$ & [151] \\
\hline $\mathrm{Co}_{3} \mathrm{O}_{4} @ \mathrm{PEI} / \mathrm{Ti}_{3} \mathrm{C}_{2} \mathrm{~T}_{x}$ & $\mathrm{NO}_{x}$ & 100 & $\mathrm{RT}$ & 27.9 & $1.6 / 73.1$ & [152] \\
\hline $\mathrm{Ti}_{3} \mathrm{C}_{2} \mathrm{~T}_{x} / \mathrm{rGO} / \mathrm{CuO}$ & Acetone & 100 & RT & 52.09 & $6.5 / 7.5$ & [127] \\
\hline
\end{tabular}

\subsection{Pristine MXene}

Among various $M X e n e$ materials, $\mathrm{Ti}_{3} \mathrm{C}_{2} \mathrm{~T}_{x}$ is the most widely used and mature material, which is also the first MXene material used in gas sensors in 2017. Lee et al. [153] used a solution casting method to integrate $\mathrm{Ti}_{3} \mathrm{C}_{2} \mathrm{~T}_{x} \mathrm{MXene}$ (prepared by $\mathrm{HCl}+\mathrm{LiF}$ etching) on a flexible polyimide platform in order to make a gas sensor. The gas response to ethanol, methanol, acetone, and $\mathrm{NH}_{3}$ at room temperature was studied. The study showed that the resistance of the MXene film increased after the introduction of ethanol, methanol, acetone, and $\mathrm{NH}_{3}$. At this time, MXene possessed a p-type semiconductor gas sensing behavior. Generally speaking, MXene with high conductivity is theoretically metallic, but the abundant terminals on the surface of MXene will transform it from metallic to semiconductor. Figure 23 is the gas response of the MXene sensor exposed to 4 different gases. It could be seen from the figure that the sensor was the most sensitive to ammonia and the least sensitive to acetone. The high gas response to $\mathrm{NH}_{3}$ was mentioned above. 
$\mathrm{NH}_{3}$ gas molecules can react vigorously with $-\mathrm{O}$ and $-\mathrm{OH}$ to make a significant change in resistance. The solution casting method or vacuum-filtration (vacuum-filtration) is usually used to prepare MXene into gas sensors. The film obtained by this method is relatively thick and covers the active sites greatly, which is unfavorable for the gas response. In 2018, Yuan et al. [130] used MXene self-assembly to prepare a structurally interconnected, porous 3D MXene framework and studied its gas response to acetone. First, an electrospinning method was used to prepare a positively charged 3D frame. The 3D frame was a highly interconnected porous structure that made it easier for gas molecules to enter or spread. The positive charge on the surface could combine the subsequent MXene with the 3D frame. Then, a negatively charged MXene was added and the 3D MXene was self-assembled through the electrostatic interaction between the 3D frame and MXene (Figure 24a-c). Owing to the electrostatically attracted, the polar gas molecules could form hydrogen bonds with the terminal part of the MXene surface. It induced charge transfer between MXene and the tested molecule. This led the 3D MXene sensor to generate excellent gas response of VOCs which can generate strong hydrogen bonds. The 3D MXene sensor was placed in $50 \mathrm{ppb}-30 \mathrm{ppm}$ acetone and it was found that the sensor also had a good response to $50 \mathrm{ppb}$ acetone (Figure $25 \mathrm{a}-\mathrm{d}$ ). This was the first report that could detect ppb-level acetone. The sensitivity of the 3D MXene sensor in an environment of $5 \mathrm{ppm}$ acetone at room temperature was $3.6 \%$ and the response and recovery time was $1.5 / 1.7 \mathrm{~min}$ (Figure 25e,f). It had excellent repeatability and flexibility. After 1000 bending/extension cycles, the sensor response did not show noticeable deviation (Figure 25g). This research laid the foundation for flexible wearable VOC sensors in the future.

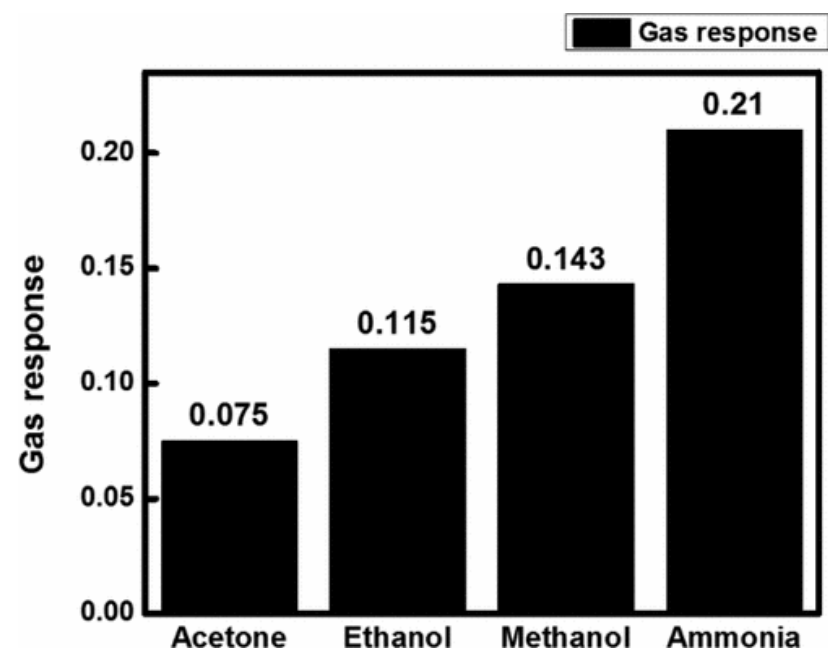

Figure 23. Gas response of $\mathrm{Ti}_{3} \mathrm{C}_{2} \mathrm{~T}_{x}$ sensor to four different gas (Reproduced with permission from [153]. Copyright 2017, American Chemical Society).

a

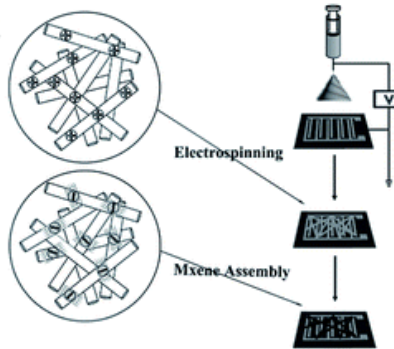

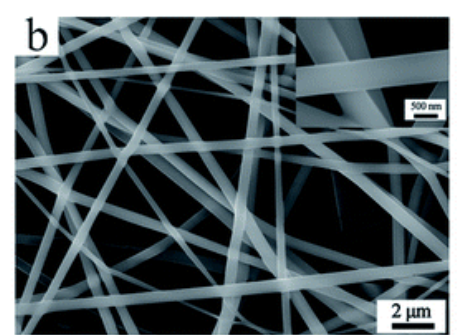

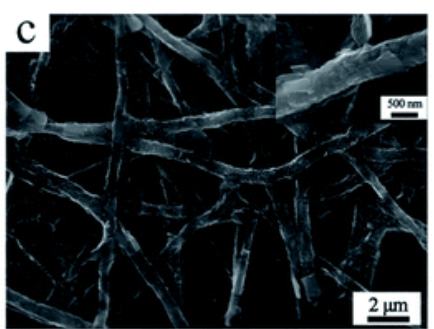

Figure 24. (a) Schematic diagram of the fabrication process of a 3D MXene; (b) SEM image of the 3D polymer scaffold; (c) SEM image of a 3D MXene (Reproduced with permission from [130]. Copyright 2018, the Royal Society of Chemistry). 

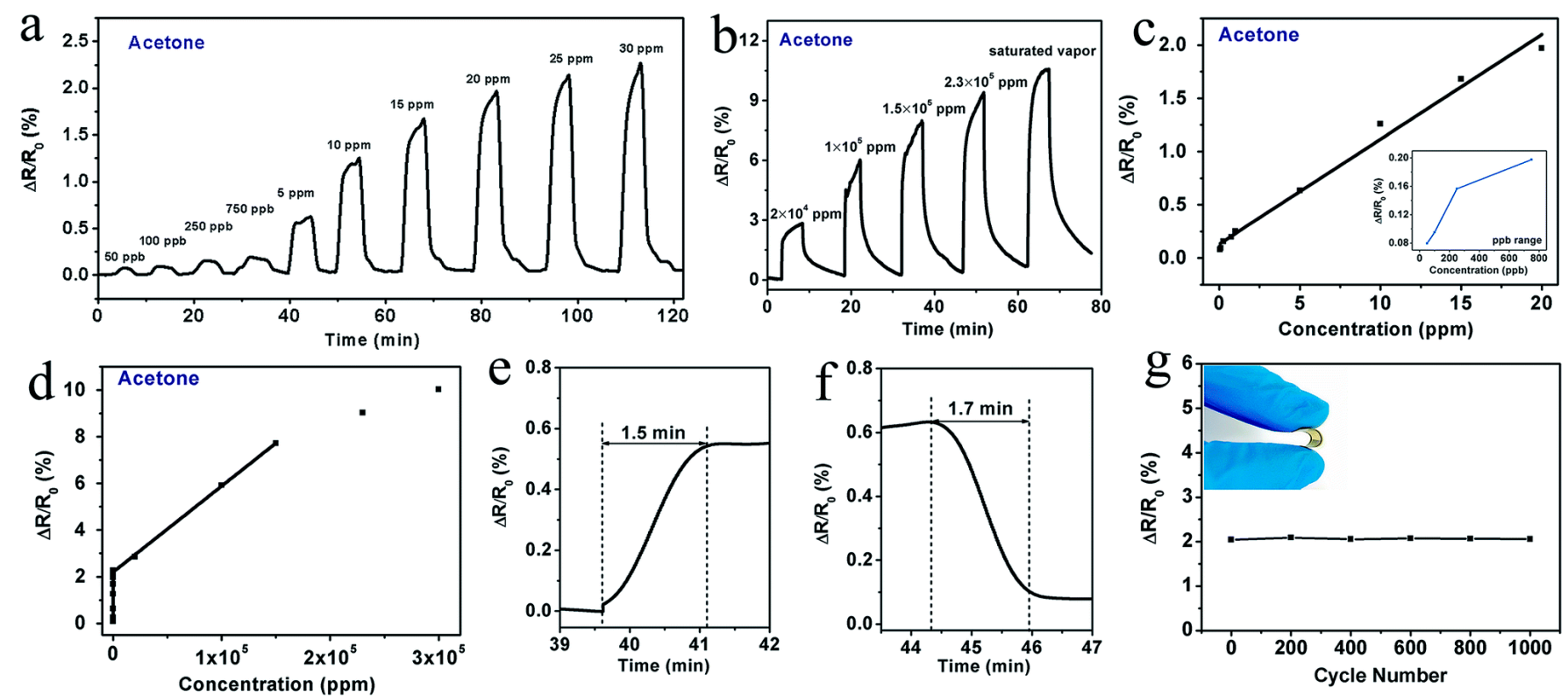

Figure 25. (a) Dynamic response curve of 3D MXene gas sensor; (b) Plot of responses versus time for a 3D-M sensor upon exposure 50 ppm acetone concentration; (c) The relationship between response and acetone concentration; (d) Relationship between response and acetone concentration in a wide range up to saturated vapor; (e,f) The curve of the response and recovery time under 5 ppm acetone; (g) Response of the 3D-M sensor under 20 ppm acetone after different bending cycles (Reproduced with permission from ref. [130]. Copyright 2018, the Royal Society of Chemistry).

Using metallic materials to prepare gas sensors, it is necessary to consider that these low-noise metallic materials lack highly active gas adsorption sites. In 2018, Kim et al. [81] transferred $\mathrm{Ti}_{3} \mathrm{C}_{2} \mathrm{~T}_{x}$ to a $\mathrm{SiO}_{2}$ wafer printed with gold sensing electrodes and fabricated a $\mathrm{Ti}_{3} \mathrm{C}_{2} \mathrm{~T}_{x} \mathrm{MXene}$ sensor with low noise, high conductivity and rich hydrophilicity on the surface. They have studied the gas response of acetone, ethanol, ammonia, propanal at room temperature. The study found that the sensor was susceptible to VOC gas and had a high response, however, it was not sensitive to other inorganic gases. The gas sensor had an excellent response to VOC gas. This was the first time that a sensor has been made to detect a variety of VOCs at room temperature. In 2019, Koh et al. [154] studied the effect of the interlayer expansion of $\mathrm{Ti}_{3} \mathrm{C}_{2} \mathrm{~T}_{x}$ film on the gas sensitivity performance. In addition, $\mathrm{Na}^{+}$was embedded in order to improve the swelling behavior. MXene was relatively insensitive to gas adsorption due to its high conductivity. However, since gas readily diffused between layers, interlayer expansion might dominate in terms of gas sensitivity. The study found that when ethanol was introduced, the interlayer spacing of MXene increased from 13.24 $\AA$ to $14.06 \AA$ and the gas response increased rapidly; when ethanol was removed, the interlayer spacing of MXene decreased to $13.55 \AA$ and the gas response decreased. This showed that the swelling behavior induced by gas was reversible and the interlayer expansion increased the gas response. The intercalation of metal ions into the interlayer of MXene would change the diffusion coefficient of $\mathrm{H}_{2} \mathrm{O}$, which lead to the change of swelling behavior. It was found that proper $\mathrm{Na}^{+}$intercalation could promote ethanol intercalation, which led to larger interlayer spacing. Because the dehydration caused by $\mathrm{Na}^{+}$intercalation provided a location for ethanol intercalation, it would lead to swelling behavior. In 2021, Hou et al. [131] used oxygen plasma activated by microwave energy to treat $\mathrm{Ti}_{3} \mathrm{C}_{2} \mathrm{~T}_{x} \mathrm{MX}$ ene and studied the gas sensitivity of activated $\mathrm{Ti}_{3} \mathrm{C}_{2} \mathrm{~T}_{x}$ to different VOC gases. Figure 26a shows the gas response of pristine $\mathrm{Ti}_{3} \mathrm{C}_{2} \mathrm{~T}_{x}$ and activated $\mathrm{Ti}_{3} \mathrm{C}_{2} \mathrm{~T}_{x}$ to different ethanol concentrations at room temperature. It could be seen that the gas sensitivity performance of activated $\mathrm{Ti}_{3} \mathrm{C}_{2} \mathrm{~T}_{x}$ was more excellent than that of pristine $\mathrm{Ti}_{3} \mathrm{C}_{2} \mathrm{~T}_{x}$. The response of activated $\mathrm{Ti}_{3} \mathrm{C}_{2} \mathrm{~T}_{x}$ increased with the concentration of ethanol gas. The sensor had good stability and selectivity. After activation, the gas-sensing performance became better, because plasma could open the interlayer of MXene and increased the interlayer spacing 
and specific surface area. Plasma could also remove the fluorine terminal and increase the oxygen-containing terminal, thereby providing more adsorption sites to improve gas sensitivity. In an environment of $100 \mathrm{ppm}$ ethanol, the response of $\mathrm{Ti}_{3} \mathrm{C}_{2} \mathrm{~T}_{x}$ activated at $500{ }^{\circ} \mathrm{C}$ was 22.47 at room temperature (Figure 26c). The sensor prepared by MXene had a strong response to various VOC gases. It is undoubtedly unfavorable for the selectivity of the VOC gas-sensing response. If a specific VOC gas is to be detected, a highly selective VOC gas sensor must be developed. Virtual sensor array (VSA) is a single sensor that can generate multi-dimensional signals and identify different VOC gases accurately. Combining with measuring impedance spectroscopy, VSA can provide multi-dimensional information for distinguishing different types of VOC. Li et al. [155] used $\mathrm{Ti}_{3} \mathrm{C}_{2} \mathrm{~T}_{x}$ to prepare a VSA, which could detect and identify different types of VOC with high accuracy and estimate the concentration of a single VOC in a VOC mixture. Based on the proposed VSA, the accuracy of ethanol concentration estimation was $93.4 \%$. This high-level, high-precision identification technology could be used in various industries in order to solve the obstacle which was caused by the low sensor selectivity in gas detecting.

(a)

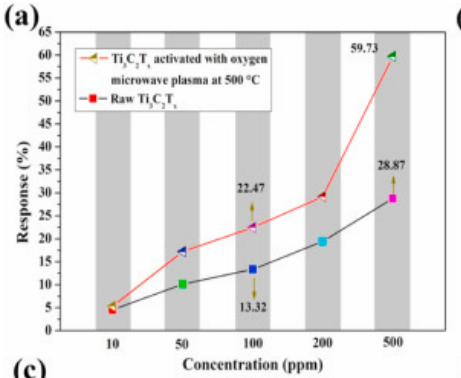

(c)

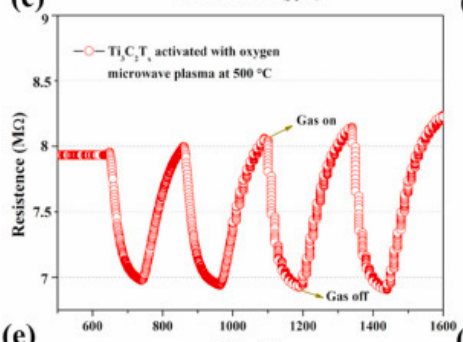

(e)

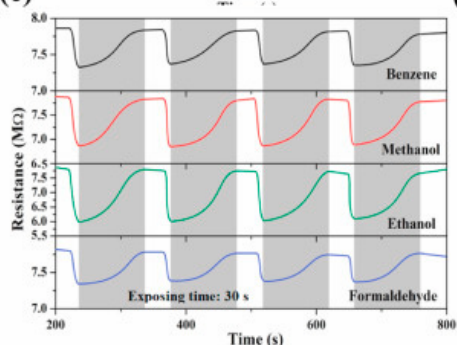

(b)

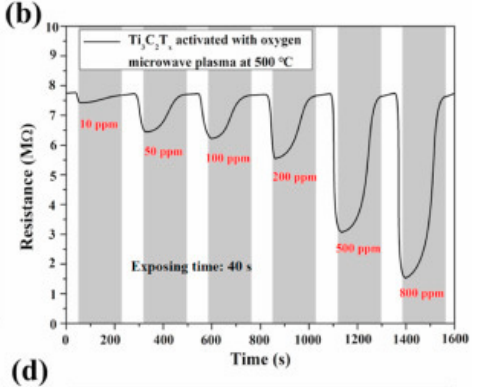

(d)
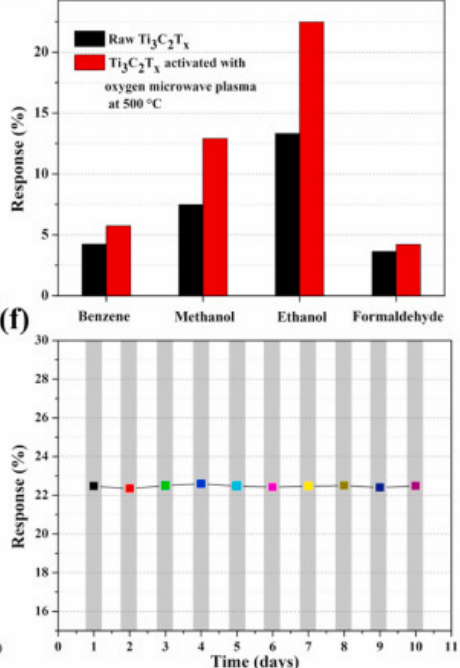

Figure 26. (a) Gas sensitivity of the pristine $\mathrm{Ti}_{3} \mathrm{C}_{2} \mathrm{~T}_{x}$ and activated $\mathrm{Ti}_{3} \mathrm{C}_{2} \mathrm{~T}_{x}$ to ethanol; (b) Responserecovery curve of activated $\mathrm{Ti}_{3} \mathrm{C}_{2} \mathrm{~T}_{x}$ under ethanol range $10 \mathrm{ppm}$ to $800 \mathrm{ppm}$; (c) Dynamic responserecovery curve of the activated $\mathrm{Ti}_{3} \mathrm{C}_{2} \mathrm{~T}_{x}$ under $100 \mathrm{ppm}$ ethanol; (d) Response of the pristine $\mathrm{Ti}_{3} \mathrm{C}_{2} \mathrm{~T}_{x}$ and activated $\mathrm{Ti}_{3} \mathrm{C}_{2} \mathrm{~T}_{x}$ under $100 \mathrm{ppm}$ different gases; (e) Dynamic response-recovery curve of the activated $\mathrm{Ti}_{3} \mathrm{C}_{2} \mathrm{~T}_{x}$ under 100 ppm different gases; (f) The stability of the activated $\mathrm{Ti}_{3} \mathrm{C}_{2} \mathrm{~T}_{x}$ under 100 ppm ethanol (Reproduced with permission from [131]. Copyright 2021, Elsevier).

In addition to $\mathrm{Ti}_{3} \mathrm{C}_{2} \mathrm{~T}_{x}$, there are some other MXene materials used in gas sensors, such as $\mathrm{V}_{2} \mathrm{CT}_{x}$ [156] and $\mathrm{Mo}_{2} \mathrm{CT}_{x}$ [132]. Lee et al. [156] coated a small layer of $\mathrm{V}_{2} \mathrm{CT}_{x}$ on a polyimide film to make a gas sensor and studied the gas sensitivity to polar gas $\left(\mathrm{H}_{2}\right)$ and non-polar gas (methane), respectively. Compared with other 2D materials, this study found that $\mathrm{V}_{2} \mathrm{CT}_{x}$ MXene had a highly oxygen-functionalized surface and its conductive carbide core, which was conducive to its realization of trace detection and high signal-to-noise ratio. The sensor prepared by $\mathrm{V}_{2} \mathrm{CT}_{x}$ had the most enormous response to $\mathrm{H}_{2}$. It was 
different from $\mathrm{Ti}_{3} \mathrm{C}_{2} \mathrm{~T}_{x}$ that had the largest response to $\mathrm{NH}_{3}$ reported in the past. Based on the previous vanadium-containing gas sensors, the selectivity to hydrogen was very high. It was believed that the $\mathrm{V}$ atoms of $\mathrm{V}_{2} \mathrm{CT}_{x}$ mainly caused this difference. At the same time, the detection limits of $\mathrm{V}_{2} \mathrm{CT}_{x}$ for $\mathrm{H}_{2}$ and methane at room temperature were $2 \mathrm{ppm}$ and $25 \mathrm{ppm}$, respectively. This paper showed that the sensitivity of the MXene sensor to different gases could be different by changing the surface transition metal elements. This paper provided a new method to develop accurate MXene gas sensors in the future.

Guo et al. [132] obtained $\mathrm{Mo}_{2} \mathrm{CT}_{x}$ MXene from $\mathrm{Mo}_{2} \mathrm{Ga}_{2} \mathrm{C}$ by etching. They used photolithography to fabricate $\mathrm{Mo}_{2} \mathrm{CT}_{x}$ gas sensors on $\mathrm{Si} / \mathrm{SiO}_{2}$ substrates and studied its gas response to VOC gas. When the $\mathrm{Mo}_{2} \mathrm{CT}_{x}$ sensor was exposed to toluene and benzene gas, the resistance changed positively. This was because the adsorption of VOC increased the channel resistance. The $\mathrm{Mo}_{2} \mathrm{CT}_{x}$ sensor showed a high response to toluene. Because the benzene ring with high activity had a strong interaction with $\mathrm{Mo}_{2} \mathrm{CT}_{x}$, toluene could be readily adsorbed to the sensor surface and was more sensitive to changes in resistance. In addition, compared with benzene, the methyl group with electron-donating properties in toluene increased the activity of the benzene ring, so the sensor's response to toluene was higher than that of benzene. The application of $\mathrm{Mo}_{2} \mathrm{CT}_{x}$ on the sensor provides another way of thinking for future MXene gas sensors, which are significant for developing more different MXene gas sensors in the future.

\subsection{MXene/Metal Oxide Gas Sensors}

Metal oxides are often prepared as gas sensors owing to their high sensitivity, good selectivity, and mature technology. At the same time, they are often used to composite with other gas-sensitive materials to enhance gas-sensing performance, such as carbon nanotubes [157]. There have been many reports on the 2d MXene/metal oxide materials, including $\mathrm{CuO}$ [49], $\mathrm{ZnO}$ [133], $\mathrm{SnO}$ [129,134], $\mathrm{Co}_{3} \mathrm{O}_{4}$ [135], $\mathrm{WO}_{3}$ [128], $\mathrm{W}_{18} \mathrm{O}_{49}$ [136], and $\operatorname{In}_{2} \mathrm{O}_{3}$ [137]. Using metal oxide and MXene to prepare gas sensors, most of the performance of composites is better than the pristine MXene and pure metal oxide. The main reason for the improved performance is combining two different materials to form a heterojunction or p-n junction. Therefore, when the sensor captures the measured gas molecules, a depletion layer and a hole accumulation layer that can regulate electrons' transfer are formed.

Hermawan et al. [49] used electrostatic interaction between $\mathrm{CuO}$ and $\mathrm{Ti}_{3} \mathrm{C}_{2} \mathrm{~T}_{x}$ in an ultrasonic bath to self-assemble the two materials into a $\mathrm{CuO} / \mathrm{Ti}_{3} \mathrm{C}_{2} \mathrm{~T}_{x} \mathrm{MXene} \mathrm{heterostructure}$ and studied the gas response of the sensor to detect toluene (see Figure 27a). After $\mathrm{CuO}$ has compounded with $\mathrm{Ti}_{3} \mathrm{C}_{2} \mathrm{~T}_{x}, \mathrm{CuO}$ was not inserted between the layers of $\mathrm{Ti}_{3} \mathrm{C}_{2} \mathrm{~T}_{x}$ but inserted between the gaps of the layered plate composed of multiple layers. So the layer spacing of $\mathrm{Ti}_{3} \mathrm{C}_{2} \mathrm{~T}_{x}$ did not increase. The $\mathrm{CuO} / \mathrm{Ti}_{3} \mathrm{C}_{2} \mathrm{~T}_{x}$ MXene composite sensor had an excellent gas response to toluene (The response value to $50 \mathrm{ppm}$ toluene at $250{ }^{\circ} \mathrm{C}$ was 11.4 and the response and recovery time was $270 / 10$ s, shown in Figure $27 \mathrm{~b}, \mathrm{c}$ ). The reason for the improved gas response of the composite was that a Schottky barrier was formed between $\mathrm{CuO}$ and MXene. When the sensor was placed in toluene gas, $-\mathrm{O}$ would be removed from the $\mathrm{CuO}$ surface, leading the depletion area (HAL) to thin and the resistance of sensors to increase. Therefore, the gas sensitive response increased. At the same time, the conductive layer $\mathrm{Ti}_{3} \mathrm{C}_{2} \mathrm{~T}_{x}$ allowed charge carriers to migrate faster in the $\mathrm{CuO}$ nanoparticles. This fact helped to reduce response and recovery time. 
(a)

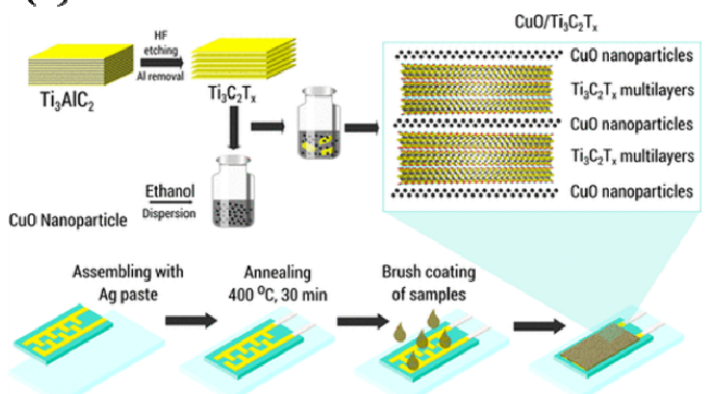

(c)

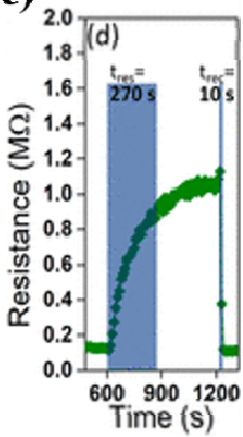

(b)

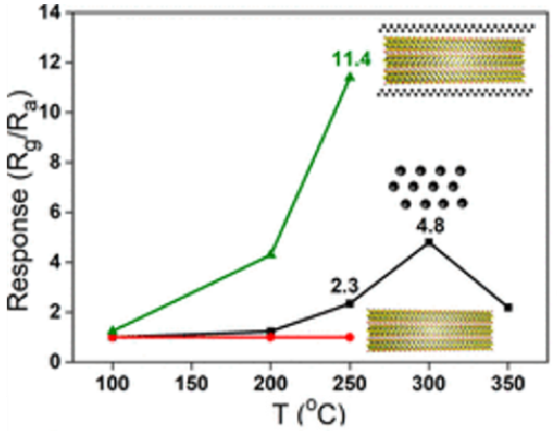

(d)

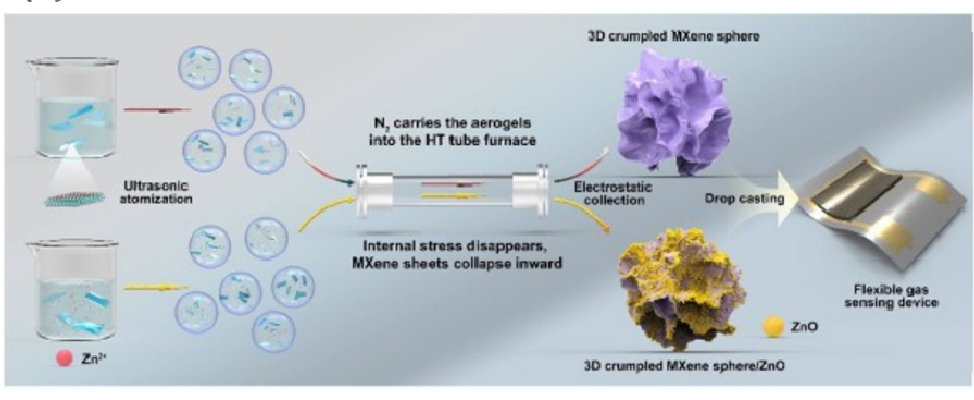

Figure 27. (a) Schematic diagram of the fabrication process of $\mathrm{CuO}$ Nanoparticles $/ \mathrm{Ti}_{3} \mathrm{C}_{2} \mathrm{~T}_{x}$ and gas sensor device (Reproduced with permission from [49]. Copyright 2020, American Chemical Society); (b) Gas response of $\mathrm{CuO}_{1} \mathrm{Ti}_{3} \mathrm{C}_{2} \mathrm{~T}_{x} \mathrm{MXene}$, and $\mathrm{CuO} / \mathrm{Ti}_{3} \mathrm{C}_{2} \mathrm{~T}_{x} \mathrm{MXene}$ at different operating temperatures (Reproduced with permission from [49]. Copyright 2020, American Chemical Society); (c) Response and recovery times of $\mathrm{CuO} / \mathrm{Ti}_{3} \mathrm{C}_{2} \mathrm{~T}_{x}$ MXene under 50 ppm of toluene (Reproduced with permission from [49]. Copyright 2020, American Chemical Society); (d) Schematic diagram of the fabrication of 3D MXene sphere and the flexible gas sensing device (Reproduced with permission from [133]. Copyright 2021, Elsevier).

The common problem of 2D materials is the stacking of layers, leading to a smaller specific surface area. The decrease of active sites is detrimental to gas-sensing performance. A 2D material layer can be inserted on a spherical substrate to form a 3D ball with reference to metal oxide nanoflowers. Yang et al. [133] prepared a three-dimensional corrugated MXene sphere. Although this sphere was not formed by inserting it on the substrate, preparing a 2D material into a 3D sphere was beneficial to increase its surface area. This report described using ultrasonic spray pyrolysis technology to prepare three-dimensional corrugated MXene spheres and then composite the MXene spheres with $\mathrm{ZnO}$ to form a composite material. The process of preparing 3D MXene spheres was as follows: (1) $\mathrm{The} \mathrm{Ti}_{3} \mathrm{C}_{2} \mathrm{~T}_{x}$ precursor was dispersed with ultrasound, and the $\mathrm{Ti}_{3} \mathrm{C}_{2} \mathrm{~T}_{x}$, at this time, was a single micromist particle. (2) The water of the dispersed aerogel evaporated and the internal stress disappeared. So that all MXene sheets collapsed inward isotropically to self-assemble into a 3D shrinking MXene. Figure $27 \mathrm{~d}$ is a route map of the preparation process. The prepared composite material showed excellent gas sensitivity to $\mathrm{NO}_{2}$. In the environment of 100 ppm $\mathrm{NO}_{2}$ at room temperature, the response was $41.93 \%$, and the response and recovery time was 34/105 s (The response of the original material was $27.27 \%$ and the response and recovery time was $53 \mathrm{~s} / 5 \mathrm{~min}$ ). There were three reasons that the gas sensitivity of this 3D MXene/ $\mathrm{ZnO}$ composite was enhanced. First, there formed more line defects with more adsorption sites because of the breaking of the internal chemical bonds. Second, a great amount of $\mathrm{O}_{2}{ }^{-}$adsorbed on the surface of $\mathrm{ZnO}$ nanoparticles at room temperature, and $\mathrm{O}_{2}{ }^{-}$played a crucial role in the gas response. Third, the oxygen-containing terminals of MXene sphere/ $\mathrm{ZnO}$ increased and formed a p-n heterojunction with $\mathrm{ZnO}$.

He et al. [129] used a hydrothermal method to synthesize a 2D MXene decorated with $\mathrm{SnO}_{2}$ nanoparticles successfully and studied the gas response of $\mathrm{SnO}_{2} / \mathrm{MXene}$ sensors to $\mathrm{NH}_{3}$. The study found that the introduction of $\mathrm{SnO}_{2}$ increased the content of adsorbed 
oxygen, which tended to get more adsorption sites in order to enhance the sensing ability. Since the C-F bond was easily affected by temperature, most fluorine terminals were removed and made the surface hydrophilic better when the composite material was prepared by hydrothermal. When a pristine MXene sensor detected $\mathrm{NH}_{3}$, the resistance of the sensor increased (Figure 28a). Because the author believed that MXene showed p-type semiconductor characteristics in this paper. The oxygen-containing terminals of MXene and $\mathrm{NH}_{3}$ interacted strongly. $\mathrm{NH}_{3}$ provided electrons to MXene due to its electron-donating properties. The electrons and holes recombined to make the carrier in MXene decrease. These electrons interfered with the metal conductivity of the Ti-C core channel, resulting in a decrease in conductivity. However, the resistance of the sensor under $\mathrm{NH}_{3}$ decreased, indicating that the $\mathrm{SnO}_{2} / \mathrm{MXene}$ was a n-type semiconductor. When the $\mathrm{SnO}_{2} / \mathrm{MXene} \mathrm{sen-}$ sor worked at different temperatures, the gas sensor response decreased and the response time increased as the operating temperature increased (Figure 28b,c). It was the opposite of the gas sensor made of metal oxide. The reason was that the - $\mathrm{OH}$ terminal amount of MXene decreased in the higher temperature, which led to the decrease of gas adsorption active sites. Figure $28 \mathrm{~d}$ is the influence of humidity on the gas sensor. It was seen that the gas sensor response reached the highest when the humidity was $45 \%$, which met the needs of daily gas detection. Compared with the pristine MXene sensor, the gas performance of the $\mathrm{SnO}_{2} / \mathrm{MXene}$ sensor has been improved (The response to $50 \mathrm{ppm} \mathrm{NH}_{3}$ was $40 \%$ and the response and recovery time was $36 / 44 \mathrm{~s}$ at room temperature). There were two reasons for the enhancement of gas sensitivity. First, MXene had a strong interaction with $\mathrm{NH}_{3}$. Secondly, $\mathrm{MXene}$ and $\mathrm{SnO}_{2}$ formed a heterojunction and the charge transfer in the heterojunction enriched the electrons in the surface area, thereby leading to the increase of the sensitivity. In addition to the above-mentioned research on recombination with n-type semiconductor $\mathrm{SnO}_{2}$, a type of $\mathrm{SnO}_{2}$ partially oxidized by p-type $\mathrm{SnO}$ was used to form a p-n junction in situ and then $\mathrm{SnO}-\mathrm{SnO}_{2}$ combined with MXene. Wang et al. [134] used a hydrothermal method to synthesize in-situ $\mathrm{p}-\mathrm{n}$ junction $\mathrm{SnO}-\mathrm{SnO}_{2}$ (Figure 28e is a schematic diagram of $\mathrm{SnO}-\mathrm{SnO}_{2}$ ). Then, $\mathrm{SnO}-\mathrm{SnO}_{2}$ was composited with $\mathrm{Ti}_{3} \mathrm{C}_{2} \mathrm{~T}_{x}$ in order to form a $\mathrm{SnO}-\mathrm{SnO}_{2} / \mathrm{Ti}_{3} \mathrm{C}_{2} \mathrm{~T}_{x}$ sensor and studied the effect of this composite sensor on the acetone response. Figure $28 \mathrm{f}$ is the response curve of $\mathrm{MXene}, \mathrm{SnO}-\mathrm{SnO}_{2}$, and $\mathrm{SnO}-\mathrm{SnO}_{2} / \mathrm{Ti}_{3} \mathrm{C}_{2} \mathrm{~T}_{x}$ to $10 \sim 100 \mathrm{ppm}$ acetone gas. The figure showed that the response of the $\mathrm{SnO}-\mathrm{SnO}_{2} / \mathrm{Ti}_{3} \mathrm{C}_{2} \mathrm{~T}_{x}$ composite sensor was more excellent than the other two materials (The response of the composite sensor to $100 \mathrm{ppm}$ acetone at room temperature was 12.1 and the response and recovery time was $18 / 9 \mathrm{~s}$ ). The reason for the improved sensing performance was the different work function, so that a Schottky barrier was formed between $\mathrm{SnO}$ and $\mathrm{Ti}_{3} \mathrm{C}_{2} \mathrm{~T}_{x}$, which acted as a hole accumulation layer (HAL) in the composite sensor. At the same time, $\mathrm{SnO}-\mathrm{SnO}_{2}$ was embedded in the interlayer of MXene. It increased the interlayer spacing, so the surface area increased and the gas response enhanced.

As mentioned in Section 2.3, embedding $\mathrm{Co}_{3} \mathrm{O}_{4}$ as an intercalant in MXene can increase the interlayer spacing of MXene and obtain a larger specific surface area. This is beneficial to more gas adsorption sites and excellent gas sensitivity. Zhang et al. [135] successfully prepared $\mathrm{MXene} / \mathrm{Co}_{3} \mathrm{O}_{4}$ composite materials and studied the gas-sensitive response of $\mathrm{MXene} / \mathrm{Co}_{3} \mathrm{O}_{4}$ sensors to formaldehyde. In the composite material, $\mathrm{Co}_{3} \mathrm{O}_{4}$ existed on the surface and between layers of MXene. The MXene $/ \mathrm{Co}_{3} \mathrm{O}_{4}$ sensor had a high gas response to formaldehyde and a short recovery time (At room temperature, the response to $10 \mathrm{ppm}$ formaldehyde was $9.2 \%$ and the response and recovery time was $83 / 5 \mathrm{~s}$ ). Furthermore, it showed an extremely low detection limit (10 ppb formaldehyde could be detected). The MXene $/ \mathrm{Co}_{3} \mathrm{O}_{4}$ sensor could also be used as a flexible sensor. The bending angle of the flexible electrode was proportional to the resistance change, that was, the response increased with the increase of the bending angle. The response was speedy and it could instantly return to the baseline resistance. The enhancement of gas response was attributed to the cooperative interface interaction between $\mathrm{MXene}$ and $\mathrm{Co}_{3} \mathrm{O}_{4}$. 
(a)

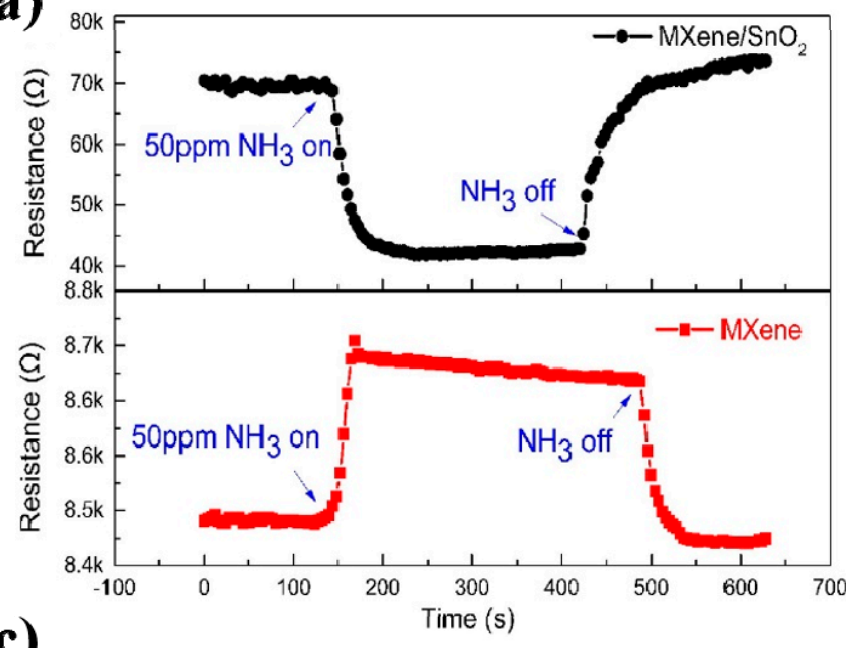

(c)

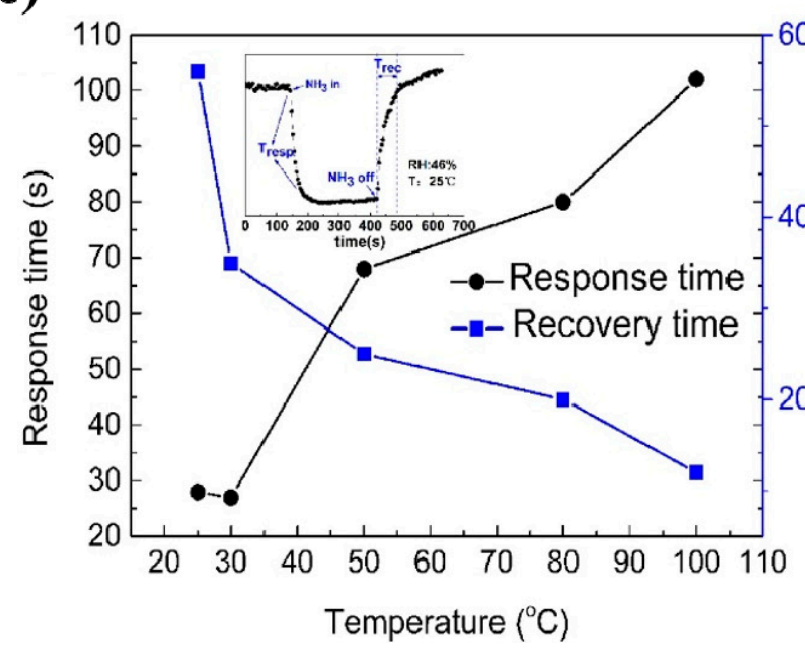

(e)

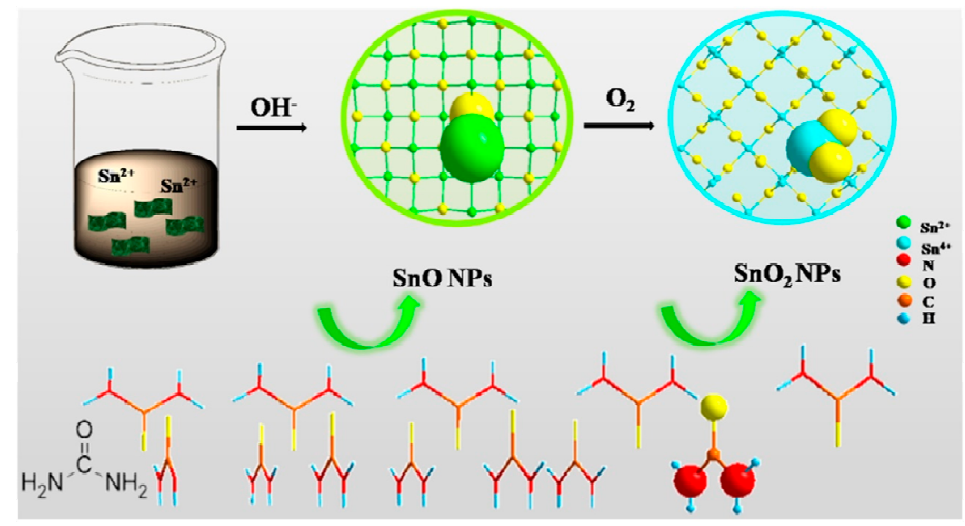

(b)

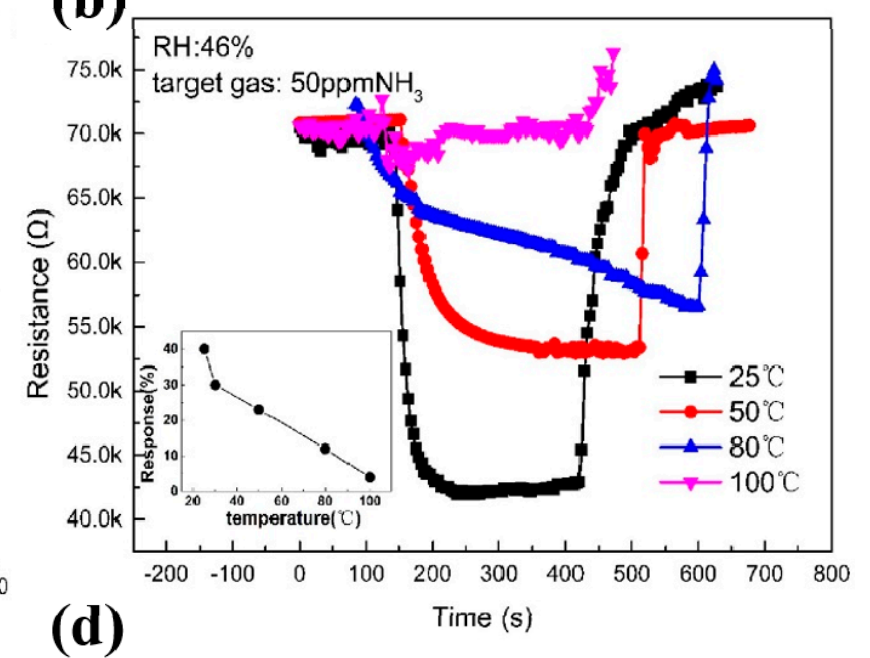

60

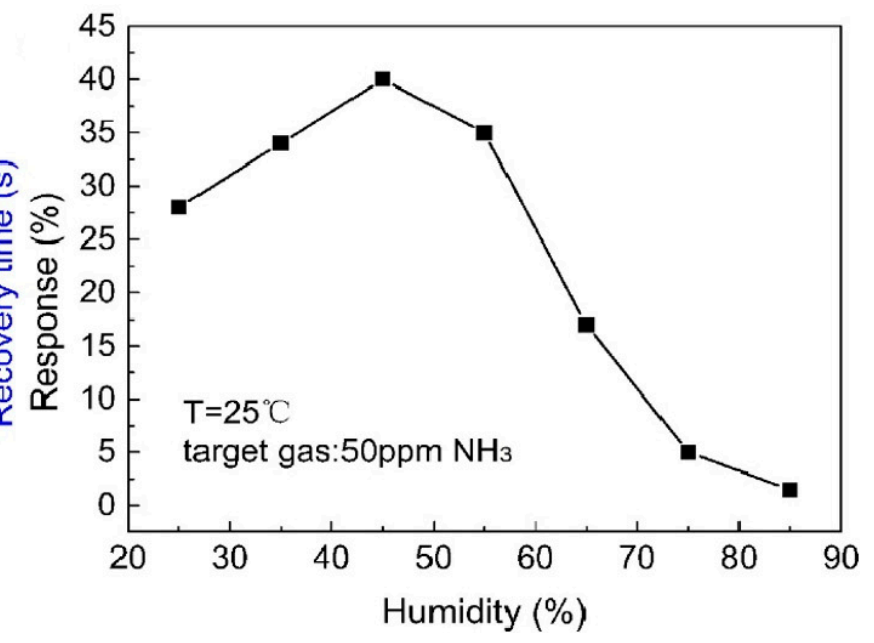

(f)

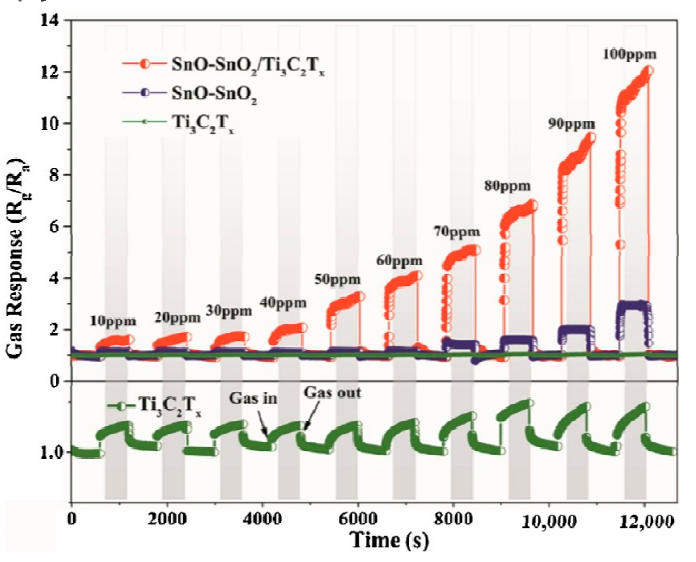

Figure 28. (a) The response of the $\mathrm{MXene} / \mathrm{SnO}_{2}$ and $\mathrm{MXene}$ under $50 \mathrm{ppm}$ ammonia; (b) The relationship of responses and operating temperatures of $\mathrm{MXene} / \mathrm{SnO}_{2} ;$ (c) The relationship of response and recovery time and operating temperatures of $\mathrm{MXene} / \mathrm{SnO}_{2} ;$ (d) The relationship of responses and humidity of $\mathrm{MXene} / \mathrm{SnO}_{2}$ (Reproduced with permission from [129]. Copyright 2021, Elsevier); (e) Schematic of the preparation of $\mathrm{SnO}-\mathrm{SnO}_{2} / \mathrm{Ti}_{3} \mathrm{C}_{2} \mathrm{~T}_{x}$ nanocomposites; (f) Gas response of acetone of $\mathrm{Ti}_{3} \mathrm{C}_{2} \mathrm{~T}_{x}, \mathrm{SnO}-\mathrm{SnO}_{2} \mathrm{NPs}$ and $\mathrm{SnO}-\mathrm{SnO}_{2} / \mathrm{Ti}_{3} \mathrm{C}_{2} \mathrm{~T}_{x}$ nanocomposites) at 10-100 ppm (Reproduced with permission from [134]. Copyright 2021, Elsevier). 
Guo et al. [128] used the ultrasonic method to composite $\mathrm{Ti}_{3} \mathrm{C}_{2} \mathrm{~T}_{x}$ and $\mathrm{WO}_{3}$ into a sensor and studied the relationship of contents of $\mathrm{WO}_{3}$ with the gas sensitivity of $\mathrm{NH}_{3}$ at room temperature. Figure 29a shows the relationship between the gas sensitivity response and the $\mathrm{WO}_{3}$ content. It could be seen that when the $\mathrm{WO}_{3}$ content was $50 \mathrm{wt} \%$, the response was the largest $(22.3 \%)$, which was much higher than the original $\mathrm{Ti}_{3} \mathrm{C}_{2} \mathrm{~T}_{x}$ sensor $(1.45 \%)$. Figure $29 \mathrm{~b}$ is the response time and recovery time of the original $\mathrm{Ti}_{3} \mathrm{C}_{2} \mathrm{~T}_{x}$ and $\mathrm{Ti}_{3} \mathrm{C}_{2} \mathrm{~T}_{x} / \mathrm{WO}_{3}$ to 1 ppm $\mathrm{NH}_{3}$. It could be seen that the response and recovery speed of the $\mathrm{Ti}_{3} \mathrm{C}_{2} \mathrm{~T}_{x} / \mathrm{WO}_{3}$ sensor was faster than that of the original $\mathrm{Ti}_{3} \mathrm{C}_{2} \mathrm{~T}_{x}$, which meant that the participation of $\mathrm{WO}_{3}$ improved the gas performance of MXene. There were three reasons for improved gas sensitivity. First, $\mathrm{WO}_{3}$ was distributed on $\mathrm{Ti}_{3} \mathrm{C}_{2} \mathrm{~T}_{x}$ in order to obtain a porous structure that was conducive to the entry and diffusion of gas molecules. Second, the defects of $\mathrm{WO}_{3}$ became adsorption sites for the measured gas on the surface of the composite material. Third, the metal phase $\mathrm{Ti}_{3} \mathrm{C}_{2} \mathrm{~T}_{x}$ and the n-type semiconductor $\mathrm{WO}_{3}$ combined to form a metal-semiconductor contact. Schottky barrier and depletion layer were formed in order to improve the gas sensitivity at the same time. $\mathrm{Ti}_{3} \mathrm{C}_{2} \mathrm{~T}_{x} / \mathrm{WO}_{3}$ had excellent gas response, short response and recovery time and great selectivity to $\mathrm{NH}_{3}$ (Figure 29c). It was a potential $\mathrm{NH}_{3}$ sensor.

(a)

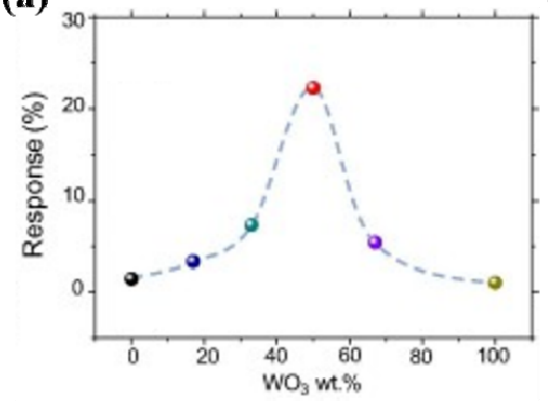

(b)

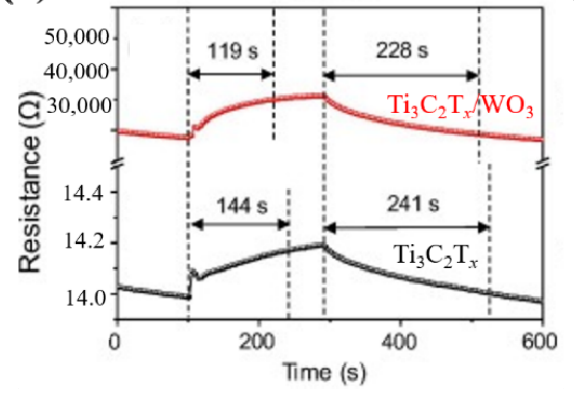

(c)

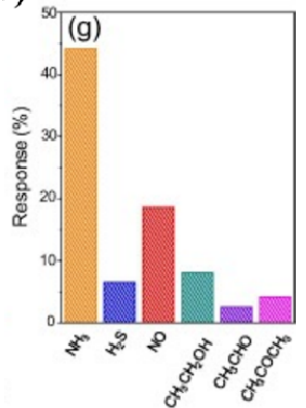

Figure 29. (a) The relationship of the gas response and $\mathrm{WO}_{3}$ content; (b) Response and recovery time of $\mathrm{Ti}_{3} \mathrm{C}_{2} \mathrm{~T}_{x} / \mathrm{WO}_{3}$ and $\mathrm{Ti}_{3} \mathrm{C}_{2} \mathrm{~T}_{x}$ sensor under 1 ppm NH${ }_{3}$; (c) Gas response of $\mathrm{Ti}_{3} \mathrm{C}_{2} \mathrm{~T}_{x} / \mathrm{WO}_{3}$ exposed to different gas (Reproduced with permission from [128]. Copyright 2021, Elsevier).

In addition to single metal oxides, the composite of bimetallic oxides with MXene has also been reported. Iron molybdate $\left(\mathrm{Fe}_{2}\left(\mathrm{MoO}_{4}\right)_{3}\right)$ is used as a sensing material because of its abundant oxygen vacancies. Zou et al. [148] prepared a sensor composed of $\mathrm{Fe}_{2}\left(\mathrm{MoO}_{4}\right)_{3}$ and $\mathrm{Ti}_{3} \mathrm{C}_{2} \mathrm{~T}_{\mathrm{x}}$ to detect $\mathrm{n}$-butanol. The composite structure was composed of MXene layers and loosely stacked $\mathrm{Fe}_{2}\left(\mathrm{MoO}_{4}\right)_{3}$ nano-layers, with a high surface area $\left(47.0 \mathrm{~m}^{2} / \mathrm{g}\right)$. The large surface area of the composite increased the adsorption and diffusion of gas molecules. Therefore, the sensor had excellent gas sensing properties (The response to $100 \mathrm{ppm} \mathrm{n}$ butanol was $43.1 \%$ and the response and recovery time was $18 / 24 \mathrm{~s})$. The recombination of bimetallic oxides expands the way to improve the gas sensing performance of MXene, and it is expected to obtain gas sensors with better performance.

\subsection{MXene/Polymer Gas Sensors}

The conductive polymer is considered one of the promising gas sensors materials due to its advantages-low resistance, low cost, and adjustable functions. The conductive polymers which was used in gas sensors include polyaniline (PANI) [29,158-160], polypyrrole (PPy) [6,161,162], and polythiophene (PTh) [163,164]. PPy and PTh have not been reported to be combined with MXene and applied in gas sensors, so there will not be details. Polyaniline (PANI) is one of the most widely used polymers in gas sensors [159]. PANI has three states: fully reduced state (leucoemeraldine), semi-oxidized state (emeraldine), and fully oxidized state (pernigraniline) [158]. Due to the amine group of the polyaniline molecule, PANI shows great gas sensitivity to nitrogen-containing substances, so PANI is often used as a $\mathrm{NH}_{3}$ sensor [29]. The protonation and deprotonation process of PANI is the root of $\mathrm{NH}_{3}$ 
sensing behavior. When the protonated PANI is placed in the environment of $\mathrm{NH}_{3}$, the protons in the PANI are transferred to the $\mathrm{NH}_{3}$ molecule, causing the state of PANI to change (The conductive emerald salt (ES) state change to the emerald base (EB) state), thereby increasing electrical resistance [139]. For example, Kulkarni et al. [160] synthesized PANI nanofibers using an in-situ chemical oxidation polymerization process and studied the gas-sensitive response of sensors made of PANI nanofibers to $\mathrm{NH}_{3}$. The PANI nanofiber sensor showed good selectivity for $\mathrm{NH}_{3}$ (The response of $62 \%$ under $100 \mathrm{ppm} \mathrm{NH}_{3}$ ) and could detect 1 ppm $\mathrm{NH}_{3}$ at room temperature. Aiming at further improving the gas-sensing performance of PANI, it was often compounded with metal oxides [165,166], carbon nanotubes, etc. [167,168], to become a composite sensor. For example, Liu et al. [165] used electrospinning, hydrothermal and in-situ polymerization techniques to synthesis a gas sensor composed of polyaniline (PANI) and $\mathrm{SnO}_{2}$ nanotubes (PMS) coated with $\mathrm{MoS}_{2}$ nanosheets. The gas response to $\mathrm{NH}_{3}$ was studied. The sensitivity of $\mathrm{PANI} / \mathrm{MoS}_{2} / \mathrm{SnO}_{2}$ under $100 \mathrm{ppm} \mathrm{NH} \mathrm{N}_{3}$ at room temperature was 10.9 , which had a low detection limit (200 ppb).

The combination of MXene and PANI into composite sensors has been studied. For example, Zhao et al. [138] used low-temperature in-situ polymerization to anchor the aniline monomer in situ on $\mathrm{Ti}_{3} \mathrm{C}_{2} \mathrm{~T}_{x}$ MXene nanosheets, and then dropped the PANI/ $\mathrm{Ti}_{3} \mathrm{C}_{2} \mathrm{~T}_{x}$ solution onto flexible polyethylene terephthalate (PET). The sensor was formed on the substrate (Figure 30a) and its gas sensitivity to ethanol was studied. The study found that PANI anchored on MXene nanosheets could prevent MXene from gathering in order to exert the maximum gas sensitivity. The gas sensitivity of the PANI/ $\mathrm{Ti}_{3} \mathrm{C}_{2} \mathrm{~T}_{x}$ composite sensor to ethanol was better than that of the original $\mathrm{Ti}_{3} \mathrm{C}_{2} \mathrm{~T}_{x}$ (Figure $30 \mathrm{~b}$ ). The response of the PANI/ $\mathrm{Ti}_{3} \mathrm{C}_{2} \mathrm{~T}_{x}$ composite sensor to $200 \mathrm{ppm}$ ethanol was $41.1 \%$ and the response and recovery time was $0.4 / 0.5 \mathrm{~s}$ at room temperature. There were three reasons for the enhancement of gas sensitivity of composite sensors. (1) The unique structure and large specific surface area of composite materials resulted in a large number of target gas adsorption sites. (2) $\mathrm{Ti}_{3} \mathrm{C}_{2} \mathrm{~T}_{x}$ had a large number of functional groups on its surface, which increased the number of active sites. (3) The excellent metal conductivity of $\mathrm{Ti}_{3} \mathrm{C}_{2} \mathrm{~T}_{x}$ ensured effective charge carrier transfer in the composite material. The PANI/ $\mathrm{Ti}_{3} \mathrm{C}_{2} \mathrm{~T}_{x}$ sensor was very flexible, so bending it to $120^{\circ}$ still maintained high sensitivity very well (Figure 30c).

(a)
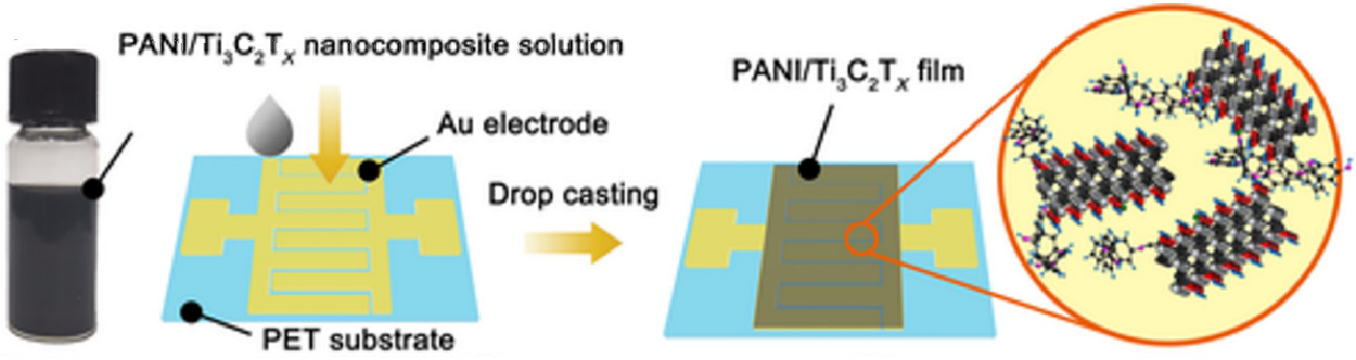

(b)

(c)
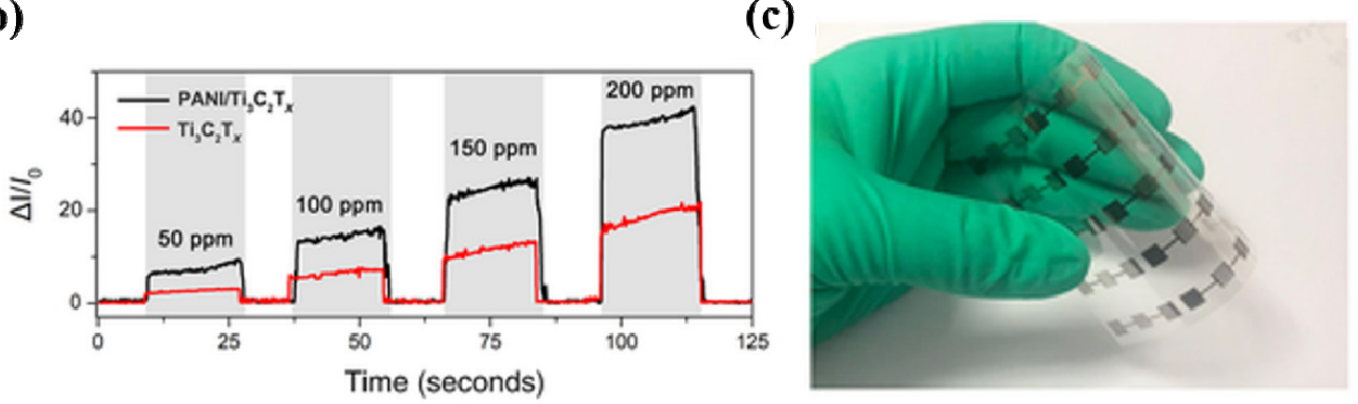

Figure 30. (a) Schematic illustration of coating the PANI/ $\mathrm{Ti}_{3} \mathrm{C}_{2} \mathrm{~T}_{x}$ nanocomposites on the interdigital electrode; (b) Dynamic transient Figure 3. $\mathrm{C}_{2} \mathrm{~T}_{x}$ and PANI/ $\mathrm{Ti}_{3} \mathrm{C}_{2} \mathrm{~T}_{x}$-based flexible sensors under ethanol gas range from $50 \mathrm{ppm}$ to $200 \mathrm{ppm}$; (c) The image of PANI $/ \mathrm{Ti}_{3} \mathrm{C}_{2} \mathrm{~T}_{x}$-based flexible sensors. (Reproduced with permission from [138]. Copyright 2019, John Wiley and Sons). 
In addition to the commonly used $\mathrm{Ti}_{3} \mathrm{C}_{2} \mathrm{~T}_{x}$ and PANI polymerization, some scholars predict that niobium carbide MXene $\left(\mathrm{Nb}_{2} \mathrm{CT}_{x}\right)$, which has fewer atomic layers, is a potential gas-sensitive material. Wang et al. [140] made the composite material $\mathrm{Nb}_{2} \mathrm{CT}_{x} / \mathrm{PANI}$ composed of polyaniline (PANI) and $\mathrm{Nb}_{2} \mathrm{CT}_{x}$ into a sensor-driven by a simple friction nanogenerator (TENG) and studied its gas sensitivity to $\mathrm{NH}_{3}$. This simple triboelectric nanogenerator (TENG) comprised two aluminum electrodes and two triboelectric films connected to a PET substrate. It could be used as a power source to drive the $\mathrm{NH}_{3}$ sensor. Figure 31a-c is the preparation process of the $\mathrm{Nb}_{2} \mathrm{CT}_{x}$ /PANI sensor. $\mathrm{Nb}_{2} \mathrm{CT}_{x} / \mathrm{PANI}$ had better gas sensitivity than the original PANI (Figure 31d). As the $\mathrm{Nb}_{2} \mathrm{CT}_{x}$ content in PANI increased, the gas response increased first and then decreased. Because when the $\mathrm{Nb}_{2} \mathrm{CT}_{x}$ nanosheets were densely coated, it would hinder $\mathrm{NH}_{3}$ molecules to adsorb on the PANI. When the sensor was placed in $100 \mathrm{ppm} \mathrm{NH}_{3}$ at room temperature, the response was 301.31\% and the response and recovery time was $105 / 143 \mathrm{~s}$. The $\mathrm{Nb}_{2} \mathrm{CT}_{x} / \mathrm{PANI}$ sensor showed high selectivity to $\mathrm{NH}_{3}$, and the sensor achieved the highest gas response when the ambient humidity reached $70 \%$ (Figure 31e,f). This meant that the $\mathrm{Nb}_{2} \mathrm{CT}_{x}$ /PANI sensor could be used as an $\mathrm{NH}_{3}$ sensor in a high humidity environment to achieve $\mathrm{NH}_{3}$ detection.

(a)

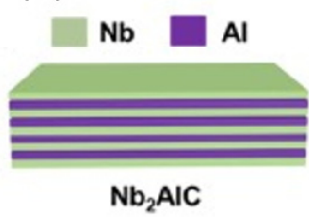

HF etching

$\mathrm{Nb}_{2} \mathrm{AlC}$

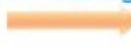

(b)

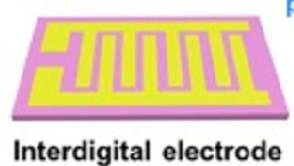

In-situ polymerization of PANI

Interdigital electrode

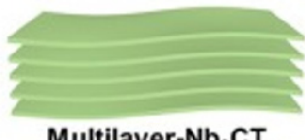

TPAOH

intercalated

Multilayer- $\mathrm{Nb}_{2} \mathrm{CT}_{x}$

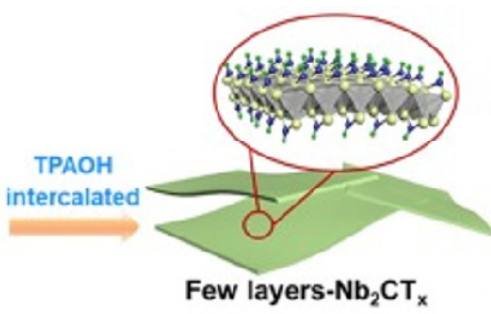

(c)
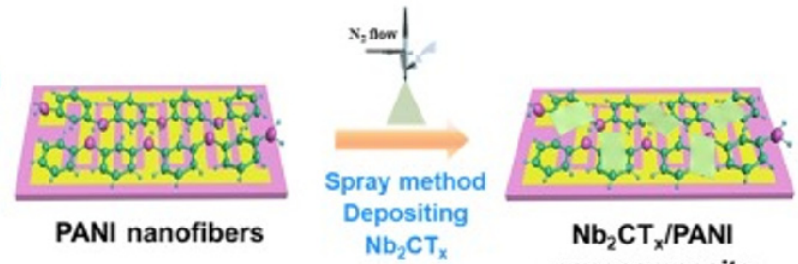

$\mathrm{Nb}_{2} \mathrm{CT}_{x} / \mathrm{PANI}$

nanocomposite

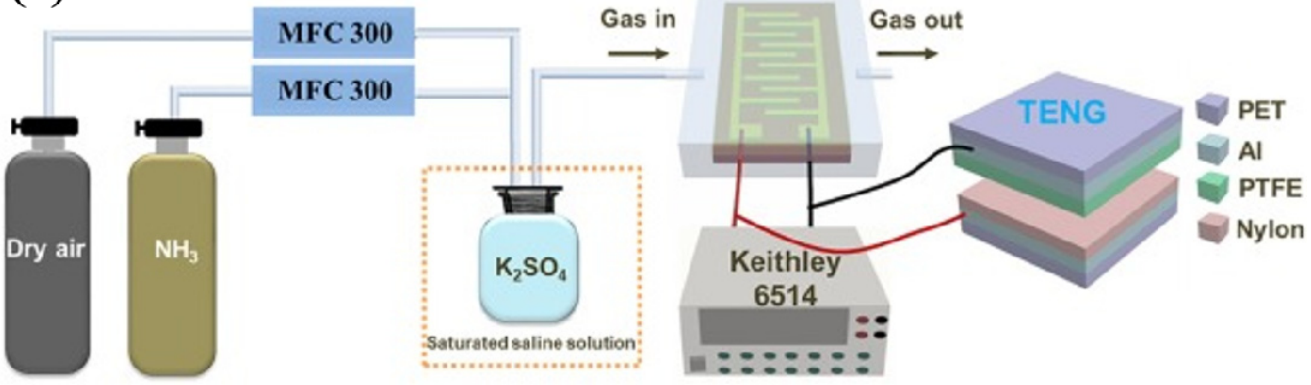

(d)

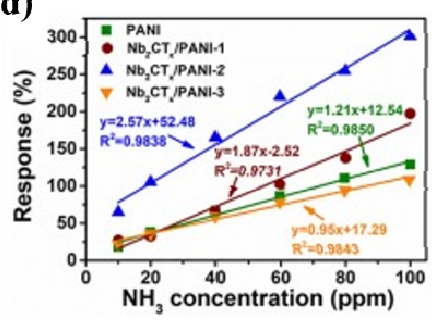

(e)

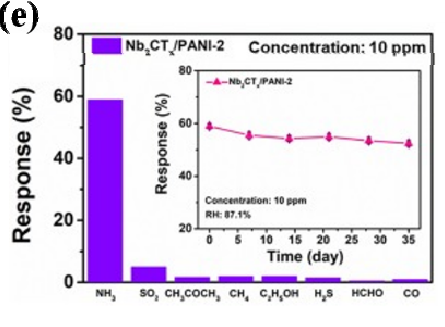

(f)

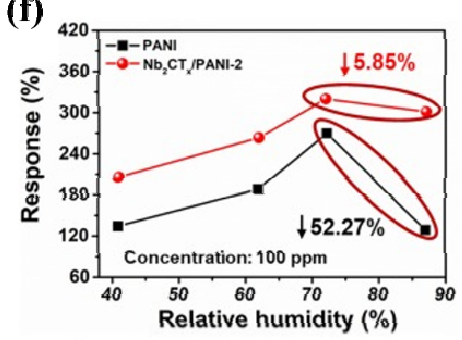

Figure 31. (a) Schematic illustration of preparation of the ultrathin $2 \mathrm{D} \mathrm{Nb} \mathrm{CT}_{x}$ nanosheets; (b) Schematic illustration of preparation of the $\mathrm{Nb}_{2} \mathrm{CT}_{x}$ /PANI sensor; (c) Schematic illustration of preparation of the TENG-driven gas sensing system; (d) The relationship of response and $\mathrm{NH}_{3}$ concentration fitting curves of the different sensors toward 10-100 $\mathrm{ppm} \mathrm{NH}_{3}$; (e) Selectivity of the $\mathrm{Nb}_{2} \mathrm{CT}_{x}$ / PANI-2 sensor; (f) The relationship of response and humidity of PANI and $\mathrm{Nb}_{2} \mathrm{CT}_{x} / \mathrm{PANI}_{2}$ sensor for $100 \mathrm{ppm} \mathrm{NH}_{3}$. (Reproduced with permission from [140]. Copyright 2021, Elsevier). 
PEDOT:PSS, which is a composite of poly(3,4-ethylene dioxythiophene) (short for PEDOT) and poly(4-styrenesulfonic acid) (short for PSS), has been popular because of its simple synthesis process and high conductivity. The PEDOT:PSS gas sensor could detect nitrogen-containing gas at room temperature [169,170]. For instance, Lin et al. [171] made a PEDOT:PSS gas sensor and studied its gas response to NO. The PEDOT:PSS sensor had excellent gas-sensitivity performance (The response time was $527 \mathrm{~s}$ and the recovery time was $1780 \mathrm{~s}$ ), with a detection limit of $350 \mathrm{ppb}$ for NO. The study also found that when the sensor detected $10 \mathrm{ppm} \mathrm{NO}$, it was significantly affected by $\mathrm{O}_{2}$ or CO. PEDOT:PSS is often used to compound graphene to improve gas sensitivity. Some scholars thought of compounding PEDOT:PSS with MXene, which is also a 2D material. For example, the $\mathrm{Ti}_{3} \mathrm{C}_{2} \mathrm{~T}_{x}$ /PEDOT:PSS prepared by Jin et al. [141] showed good gas sensitivity to $\mathrm{NH}_{3}$ (When the amount of MXene was $15 \mathrm{wt} \%$, the response to $100 \mathrm{ppm} \mathrm{NH} \mathrm{N}_{3}$ was $36.3 \%$ and the response and recovery time was $116 / 40 \mathrm{~s}$ ). MXene itself was very sensitive to $\mathrm{NH}_{3}$ and there was a synergistic effect between PEDOT:PSS and $\mathrm{Ti}_{3} \mathrm{C}_{2} \mathrm{~T}_{x}$, which lead to further enhance gas sensitivity.

In addition to detecting nitrogen gas, $\mathrm{Ti}_{3} \mathrm{C}_{2} \mathrm{~T}_{x}$ combined with PEDOT:PSS can also detect VOC gas. Wang et al. [172] combined $\mathrm{Ti}_{3} \mathrm{C}_{2} \mathrm{~T}_{x}$ and PEDOT:PSS to prepare a composite sensor and studied the gas sensitivity of the sensor to VOC gas. The obtained sensors showed the most sensitive to methanol. When the mass ratio between PEDOT:PSS and $\mathrm{Ti}_{3} \mathrm{C}_{2} \mathrm{~T}_{x}$ was $4: 1$, the gas response was the highest. Because the conductive path in the sensor at this time was contributed by PEDOT:PSS instead of MXene. After combination, it destroyed the conductive path of MXene and increased the distance between the PEDOT chains, which made the electronic jumping process difficult and made the resistance increase, bringing about the increase of gas response. However, the study found that the response and recovery time of $\mathrm{Ti}_{3} \mathrm{C}_{2} \mathrm{~T}_{x} / \mathrm{PEDOT}$ :PSS was slightly longer than that of traditional sensors. This still needs to be solved, and it also pointed out a direction for the future development of sensors.

\subsection{Pd-MXene Gas Sensor}

Noble metal particles are widely used as modified gas sensors, such as $\mathrm{Pd}, \mathrm{Pt}, \mathrm{Au}$, etc. [173-175]. Pd has an affinity for $\mathrm{H}_{2}$ and can absorb up to 900 times its own volume in hydrogen, so scholars generally use Pd particles to compound with gas-sensitive materials to improve its gas response to $\mathrm{H}_{2}[175,176]$. For example, Wang et al. [177] obtained $\mathrm{Pd}-\mathrm{SnO}_{2}$ sensors by electrospinning and magnet sputtering in order to detect $\mathrm{H}_{2}$ at low temperatures. Experiments showed that Pd enhanced the sensor's response to $\mathrm{H}_{2}$ at low temperatures. The $\mathrm{Pd}-\mathrm{SnO}_{2}$ sensor showed a detection limit of $\sim 0.25 \mathrm{ppm}$ under $100 \mathrm{ppm}$ $\mathrm{H}_{2}$ and a short response time of $4 \mathrm{~s}$. At present, it has been reported that gas sensors made by introducing Pd particles into MXene materials are all detecting $\mathrm{H}_{2}$.

Zhu et al. [142] combined $\mathrm{Ti}_{3} \mathrm{C}_{2} \mathrm{~T}_{x}$ nanosheets and Pd colloidal nanoclusters to form a paper membrane $\mathrm{H}_{2}$ sensor using a full solution vacuum filtration method. The study found that the sensor could detect $0.5 \%$ of $\mathrm{H}_{2}$ and it still had high resolution when the $\mathrm{H}_{2}$ content reached $40 \%$ (Figure 32a). As the $\mathrm{H}_{2}$ content increased, the obtained gas response and response and recovery time increased (Figure 32c). At the same time, the $\mathrm{Pd}-\mathrm{Ti}_{3} \mathrm{C}_{2} \mathrm{~T}_{x}$ sensor had good stability and flexibility (Figure $32 \mathrm{~d}-\mathrm{f}$ ). Loading $\mathrm{Pd}$ was the reason why the gas-sensing performance of MXene was improved. When the $\mathrm{Pd}-\mathrm{Ti}_{3} \mathrm{C}_{2} \mathrm{~T}_{x}$ sensor was placed in $\mathrm{H}_{2}, \mathrm{H}_{2}$ was preferentially adsorbed on the surface of $\mathrm{Pd}$ and then dissociated into $\mathrm{H}$ atoms, resulting in $\mathrm{Pd}$ to being converted to $\mathrm{PdH} x$. Because the work function of $\mathrm{PdH} x$ was lower than that of $\mathrm{Pd}$, it caused electrons to move to $\mathrm{Ti}_{3} \mathrm{C}_{2} \mathrm{~T}_{x}$. The $\mathrm{Ti}_{3} \mathrm{C}_{2} \mathrm{~T}_{x}$ in this paper was metallic and the loading of electrons led to an increase in carrier concentration, thereby reducing resistance. In addition, Doan et al. [143] used the polyol method to grow $\mathrm{Pd}$ particles on the surface of $\mathrm{Ti}_{3} \mathrm{C}_{2} \mathrm{~T}_{x}$ directly and successfully synthesized $\mathrm{Pd}-$ $\mathrm{Ti}_{3} \mathrm{C}_{2} \mathrm{~T}_{x}$. At room temperature, the $\mathrm{Pd}-\mathrm{Ti}_{3} \mathrm{C}_{2} \mathrm{~T}_{x}$ sensor showed excellent gas response to $\mathrm{H}_{2}$ (The response of $\mathrm{H}_{2}$ was $56 \%$ to $100 \mathrm{ppm}$ ). 
(a)

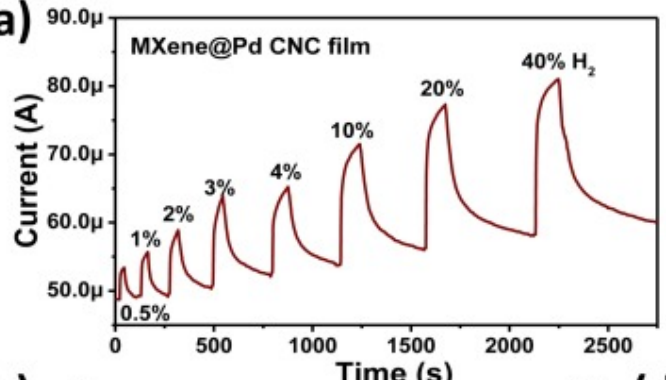

(c)

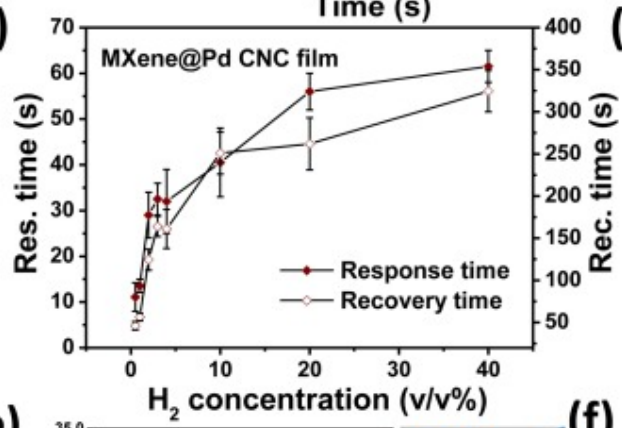

(e)
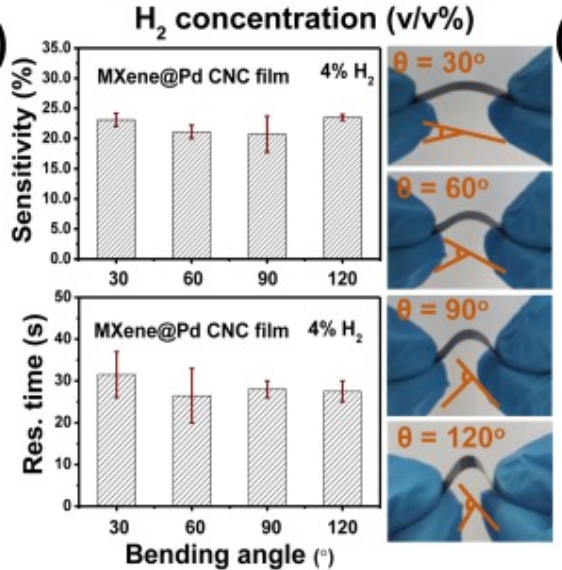

(b)

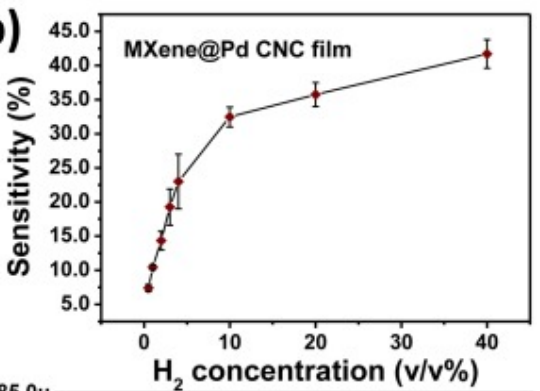

(d)

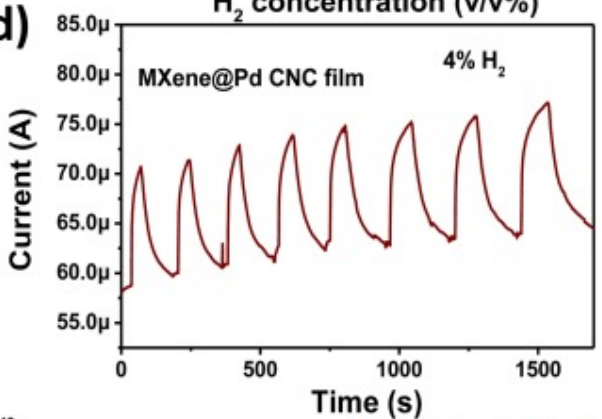

f)
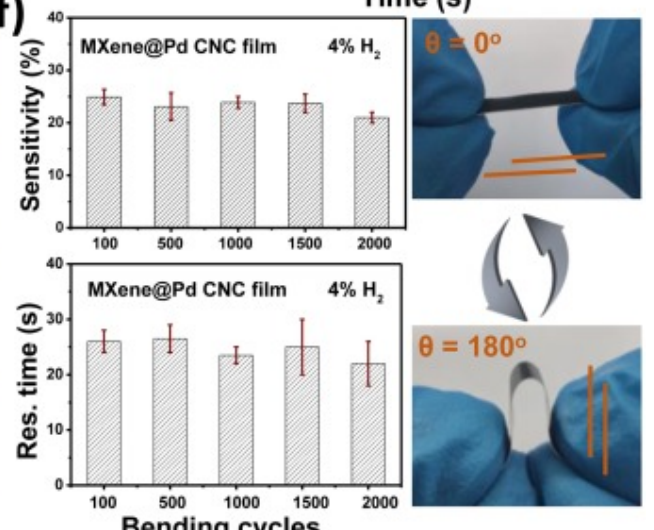

Bending cycles

Figure 32. (a) Response/recovery curves of MXene@Pd CNC sensor to $\mathrm{H}_{2}(0.5 \sim 40 v / v \%)$; (b) The relationship of sensitivities and $\mathrm{H}_{2}$ concentration; (c) The relationship of the response and recovery times and $\mathrm{H}_{2}$ concentration; (d) Repeatability of the MXene@Pd CNC film sensor under $4 \% \mathrm{H}_{2}$; (e) Response and response times of MXene@Pd CNC film sensor under $4 \% \mathrm{H}_{2}$ under different bending angles; (f) Response and response times of MXene@Pd CNC film sensor under $4 \% \mathrm{H}_{2}$ after n-time bending cycles from $\theta=0^{\circ}$ to $180^{\circ}$ and back to $0^{\circ}$ (Reproduced with permission from [142]. Copyright 2020, Elsevier).

So far, only Pd particles loaded with MXene as a gas sensor have been reported. Loading metal ions on gas-sensitive materials have great prospects. In the future, more gas sensors loaded with MXene and other metal particles can be developed, further expanding the family of gas sensor materials, and contributing to the gas sensor industry.

\subsection{Miscellaneous Sensors}

In addition to the MXene gas sensor described above, MXene is also modified by twodimensional transition metal dichalcogenides (TMD) [144,145], S doping [146], surface treatment [147], alkali treatment [149], carbon-based materials [150], two compounds [127,151,152]. They are prepared into sensors for detecting various gases. Since these reports on the modification or compounding of MXene materials are too few, we focus on the discussion here rather than specific classification.

TMD is considered as a candidate material for $\mathrm{NO}_{2}$ detection. Zhang et al. [144] combined $\mathrm{SnS}_{2}$ with MXene and MXene's derivative $\mathrm{TiO}_{2}$ to prepare $\mathrm{NO}_{2}$ sensors with a large response and ultra-fast reaction in seconds. The recombination process in this work was as follows: the negative charge on the surface of MXene reacted with $\mathrm{Sn}^{4+}$, which led to the derivation of $\mathrm{TiO}_{2}$ from $\mathrm{MXene}$ and the formation of $\mathrm{SnS}_{2}$ during the formation of 
$\mathrm{TiO}_{2}$. It could also be said that $\mathrm{TiO}_{2}$ derived from MXene provided a platform which $\mathrm{SnS}_{2}$ was recombined in order to form heterojunctions and increase its surface area. The sensor showed a strong response to $\mathrm{NO}_{2}$, but the low response to other interfering gases such as $\mathrm{H}_{2}, \mathrm{NH}_{3}$, and $\mathrm{HCHO}$. Therefore, this sensor could detect $\mathrm{NO}_{2}$ and had excellent gassensing performance (The response to $1000 \mathrm{ppm} \mathrm{NO}$ gas at room temperature was $115 \%$ and the response and recovery time was $64 / 10 \mathrm{~s}$ ). There were two reasons for the enhancement of the performance of the composite sensor: (1) The heterojunction was formed between $\mathrm{SnS}_{2} / \mathrm{TiO}_{2}$, which might improve the sensing performance; (2) The specific surface area increased, which increased the total number of gas adsorption sites, leading to the enhancement of gas sensitivity.

Doping ions are of great significance to improve the properties of materials, and it is one of the most commonly used methods to improve the properties. Scholars also try to adulterate MXene. Shuvo et al. [146] introduced S ion into MXene for the first time and studied the gas sensing performance of the sensor for toluene. It was found that the response of S-doped MXene was higher than that of pure MXene (The response was $214 \%$ to $1 \mathrm{ppm}$ toluene and the response to $50 \mathrm{ppm}$ toluene was $312 \%$ ). The gas sensing performance was greatly improved. The doped MXene sensor could also detect toluene as low as $500 \mathrm{ppb}$ with a very low detection limit. The reason for the improvement of sensing performance was that sulfur had the affinity to obtain two electrons, resulting in a greater change in resistance. Sulfur doping increased the binding ability of MXene to toluene, which was why it had a better selectivity to toluene. Doping is a very effective method to improve performance, and it is hoped that more reports about doping will emerge in the future.

The water absorption of the MXene surface will affect the life of MXene. Surface modification can be used to prolong the life of MXene and ensure its stability. Chen et al. [147] used fluoroalkylsilane (FOTS) to modify the surface of $\mathrm{Ti}_{3} \mathrm{C}_{2} \mathrm{~T}_{x}$ and studied its gas sensing properties for ethanol. The modified $\mathrm{Ti}_{3} \mathrm{C}_{2} \mathrm{~T}_{x}$ MXene had a hydrophobic surface and excellent gas sensing properties (The response to $120 \mathrm{ppm}$ ethanol was $14 \%$ and the response and recovery time was 39/139 s). The hydrophobicity was obtained because FOTS molecules fixed $-\mathrm{OH}$ on the surface of MXene to avoid its reaction with $\mathrm{H}_{2} \mathrm{O}$, and reduced the surface energy. Therefore, MXene had better stability. On the other hand, FOTS molecules could also act as intercalators to increase the interlayer spacing of MXene and improve the gas sensing properties.

Yang et al. [149] prepared $\mathrm{NH}_{3}$ sensors by alkaline treatment of MXene with $\mathrm{NaOH}$ solution. The essence of $\mathrm{NaOH}$ alkali treatment was that the embedding of $\mathrm{Na}^{+}$lead to the increase of surface area. In addition, alkali treatment could effectively remove $-\mathrm{F}$ terminal and increased $-\mathrm{O}$, that was, increasing the ratio of oxygen to fluorine atoms $([\mathrm{O}] /[\mathrm{F}])$. The increase of $[\mathrm{O}] /[\mathrm{F}]$ led to the increase in gas response. The response of alkalized $\mathrm{Ti}_{3} \mathrm{C}_{2} \mathrm{~T}_{x}$ sensor to $100 \mathrm{ppm} \mathrm{NH}(28.87 \%)$ was twice that of pure $\mathrm{Ti}_{3} \mathrm{C}_{2} \mathrm{~T}_{x}$ and the response time was as low as 1s. The alkali-treated MXene sensor was expected to be a sensor for overspeed response.

Lee et al. [150] prepared graphene-based fibers (GFs) and $\mathrm{Ti}_{3} \mathrm{C}_{2} \mathrm{~T}_{x}$ composites by wet spinning process, and studied the gas sensing properties of the sensor to $\mathrm{NH}_{3}$. The response of the composite to $50 \mathrm{ppm} \mathrm{NH}$ was 7.9 times higher than that of pure MXene. When the detection concentration was as low as $10 \mathrm{ppm}$, the composite sensor still showed $4.26 \%$ gas response. Owing to the excellent flexibility and the high bending of fibrous material, GFs was very suitable to be made into a flexible sensor. Because the GFs/MXene flexible sensor was more flexible and stable than the simple MXene sensor, the change of resistance was only $\pm 0.2 \%$ after being bent more than 2000 times. This laid the foundation for future wearable sensors.

In addition to compounding MXene with a single other material, scholars also composite the two materials with MXene simultaneously to improve the gas sensing properties. Sun et al. [150] first functionalized $\mathrm{Ti}_{3} \mathrm{C}_{2} \mathrm{~T}_{x}$ with polyethyleneimine (PEI), and then riveted $\mathrm{Co}_{3} \mathrm{O}_{4}$ to form $\mathrm{Co}_{3} \mathrm{O}_{4} @ \mathrm{PEI} / \mathrm{Ti}_{3} \mathrm{C}_{2} \mathrm{~T}_{x}$ composites. The gas sensing properties of the sensor to 
$\mathrm{NO}_{x}$ gas were studied. In the composite, the active site $\mathrm{Co}_{3} \mathrm{O}_{4}$ was uniformly dispersed on $\mathrm{Ti}_{3} \mathrm{C}_{2} \mathrm{~T}_{x}$ and formed a heterostructure. The electron transfer channel PEI connected $\mathrm{Co}_{3} \mathrm{O}_{4}$ and $\mathrm{Ti}_{3} \mathrm{C}_{2} \mathrm{~T}_{x}$. Because of this unique structure, $\mathrm{Co}_{3} \mathrm{O}_{4} @ \mathrm{PEI} / \mathrm{Ti}_{3} \mathrm{C}_{2} \mathrm{~T}_{x}$ had a mesoporous structure and high selectivity, low detection limit, high response, and short response time for $\mathrm{NO}_{x}$ gas. At room temperature, the composite sensor had a response of 27.9 to 100 ppm $\mathrm{NO}_{x}$ and a response and recovery time of $1.6 / 73.1 \mathrm{~s}$. There were two reasons for enhancing sensing performance: (1) Heterojunction and synergism improved the diffusivity and carrier velocity of $\mathrm{NO}_{x}$ molecules; (2) There were oxygen vacancies on the surface of the composites, which could improve the efficiency of electron transport.

\section{Sensing Mechanism of MXene-Based Gas Sensors}

Since MXene has high conductivity, MXene generally exhibits metallic properties. The gas-sensing mechanism of other semiconductor materials is that the increase or decrease of resistance depends on the type of gas molecules (donor or acceptor) and the type of channel material (p-type or n-type). Nevertheless, the resistance changes of MXene always increase regardless of the MXene gas sensor detects both electron donor gas and the electron acceptor gas. It is indicated that the concentration of electrons in the MXene gas sensor always decreases or the transportation of electrons is always hindered [81,130,147,154,178]. Chen et al. [147] used the MXene sensor to detect ethanol and acetone and found that the changes of resistance were always positive. They interpreted this phenomenon as that the carriers in MXene decreased when gas molecules adsorbed on the surface of the metallic MXene. Therefore, the resistance of MXene increased. For two-dimensional materials, the gap between layers is an essential channel for electronic transportation. The gap between layers of 2D MXene is relatively large, which is the primary channel for electron transportation. The expansion of the lamellae is one of the main reasons why MXene consistently exhibits a positive resistance phenomenon. Junkaew et al. [178] researched the effect of interlayer expansion on gas-sensing performance and found that interlayer expansion would affect the conductivity of the channel. Because the expansion of the two-dimensional material sheet layer reduced the interlayer spacing and electrons were easily affected. Because of the obstacles of the surface, the transmission of electrons became more difficult. Therefore, MXene appeared as an increase in resistance. The gas sensing mechanism of other 2D materials is the same as that of semiconductor materials. Because their interlayer spacing is too small, which hinders the embedding of gas molecules in a non-pressurized environment. So interlayer expansion will not affect their gas response.

In the etching process of $\mathrm{Ti}_{3} \mathrm{C}_{2} \mathrm{~T}_{x}$ MXene, the adsorbed molecules $\left(\mathrm{H}_{2} \mathrm{O}\right.$ and $\left.\mathrm{O}\right)$ are $\mathrm{p}$ type $\mathrm{Ti}_{3} \mathrm{C}_{2} \mathrm{~T}_{x}$ doping, resulting in the transformation of metallic $\mathrm{Ti}_{3} \mathrm{C}_{2} \mathrm{~T}_{x}$ into semiconductor characteristics [153]. At this time, the gas-sensing mechanism of MXene is consistent with that of semiconductor materials. When the $\mathrm{Ti}_{3} \mathrm{C}_{2} \mathrm{~T}_{x}$ sensor is placed in the air, the surface will be adsorbed by $\mathrm{O}_{2}$ molecules. $\mathrm{O}_{2}$ molecules can obtain electrons from semiconductors and change them into chemically adsorbed molecular oxygen $\left(\mathrm{O}_{2}^{-}, \mathrm{O}^{-}, \mathrm{O}^{2-}\right) . \mathrm{O}_{2}{ }^{-}$which was generated on the surface leads the hole accumulation layer (HAL) to form, reducing electrical resistance. When the sensor is placed in the tested gas, the gas reacts with $\mathrm{O}_{2}{ }^{-}$on the surface. The electrons captured by $\mathrm{O}_{2}$ are released back into $\mathrm{Ti}_{3} \mathrm{C}_{2} \mathrm{~T}_{x}$ and the electrons and holes recombine in order to reduce the carrier of the $\mathrm{Ti}_{3} \mathrm{C}_{2} \mathrm{~T}_{x}$ sensor, resulting in an increase in resistance [127,129,134,135].

$$
\begin{gathered}
\mathrm{O}_{2} \text { (gas) } \rightarrow \mathrm{O}_{2} \text { (ads) } \\
\mathrm{O}_{2} \text { (ads) }+\mathrm{e}^{-} \rightarrow \mathrm{O}_{2}{ }^{-}
\end{gathered}
$$

The work function of MXene is different from that of other n-type semiconductors. When p-type MXene and n-type semiconductors are recombined, in order to keep the Fermi level at the same level, electron transfer occurs between them, thus forming a built-in electric field and Schottky barrier. The heterogeneous $\mathrm{p}-\mathrm{n}$ junction formed by this interface 
greatly affects the gas sensing mechanism of the gas sensor $[127,133,139,140,152,179,180]$. At this time, the positive change or negative change of the sensor resistance depends on the electron donor and acceptor characteristics of the target gas molecule. For example, the work function of MXene $(4.79 \mathrm{eV})$ is lower than $\mathrm{Co}_{3} \mathrm{O}_{4}(6.48 \mathrm{eV})$, so the electrons of MXene migrate to $\mathrm{Co}_{3} \mathrm{O}_{4}$. Then, an electron depletion layer with a positive zone is formed on the MXene side and the negative one is formed on the $\mathrm{Co}_{3} \mathrm{O}_{4}$ side. A built-in electric field was built. The built-in electric field counters the transfer of electrons until the Fermi level reaches the same level and a Schottky barrier is created (Figure 33a,b). When the composite material is placed in $\mathrm{NO}_{2}$, gas molecules adsorb on the surface and capture electrons from the sensor. The built-in electric field is destroyed and more electrons are transferred from $\mathrm{MXene}$ to $\mathrm{Co}_{3} \mathrm{O}_{4}$. It will cause the conductivity of the sensor to increase (Figure 33c) [152]. In addition to p-type $\mathrm{Ti}_{3} \mathrm{C}_{2} \mathrm{~T}_{x}$ MXene, there is also n-type MXene. For example, the $\mathrm{Nb}_{2} \mathrm{CT}_{x}$ studied by Wang et al. [140] behaved as an n-type semiconductor. When it was compounded with p-type PANI, it resulted in forming a $\mathrm{p}-\mathrm{n}$ heterojunction (Figure 33d). Additionally, the hetero interface generated a narrow depletion layer. The electrons in the $\mathrm{NH}_{3}$ molecule were transferred to PANI when the sensor was placed in $\mathrm{NH}_{3}$. It would reduce the hole concentration, which caused the depletion layer on the PANI side to widen, thereby narrowing the conductive path of PANI and changing the resistance.

(a)

(b)

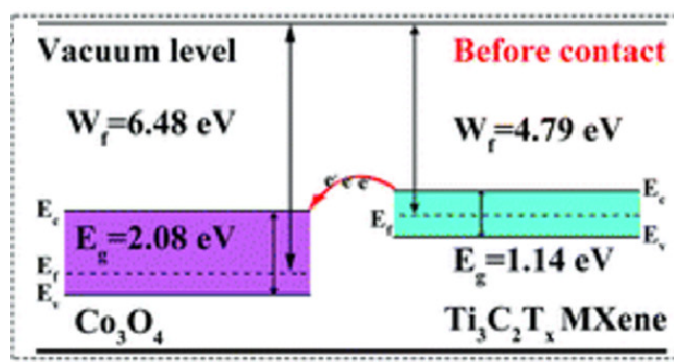

(c)

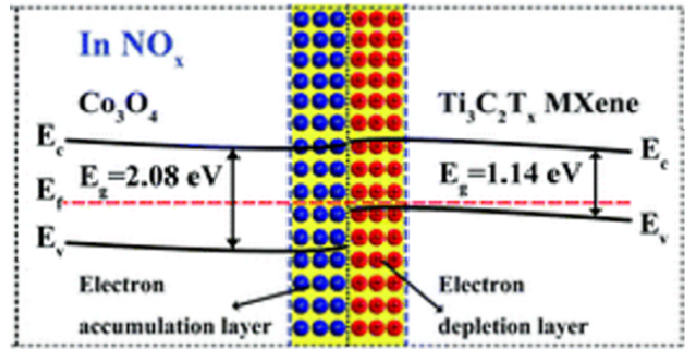

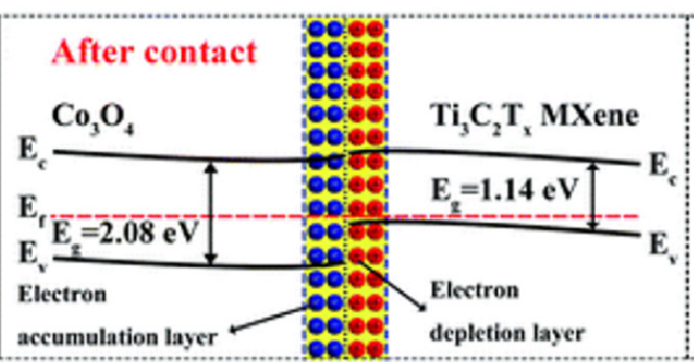

(d)

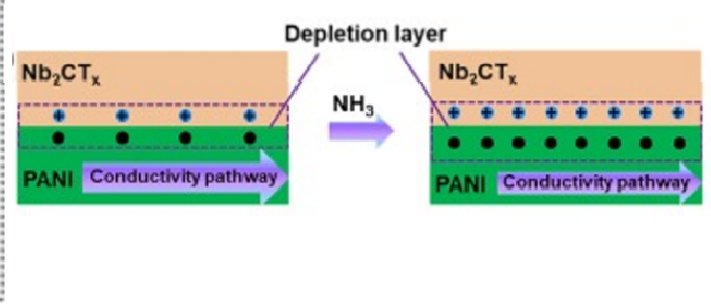

Figure 33. (a) Band diagram of $\mathrm{Ti}_{3} \mathrm{C}_{2} \mathrm{~T}_{x}$ and $\mathrm{Co}_{3} \mathrm{O}_{4}$ before contact; (b) Band diagram of $\mathrm{Ti}_{3} \mathrm{C}_{2} \mathrm{~T}_{x}$ and $\mathrm{Co}_{3} \mathrm{O}_{4}$ after contact; (c) Energy band structure of the composites in different atmosphere (Reproduced with permission from [152]. Copyright 2021, the Royal Society of Chemistry); (d) The change of depletion layer and conductivity pathway of the $\mathrm{Nb}_{2} \mathrm{CT}_{x} / \mathrm{PANI}$ film (Reproduced with permission from [140]. Copyright 2021, Elsevier).

\section{Conclusions and Outlook}

This paper reviews the effects of etching method (HF etching, in-situ HF etching, fluorine-free etching), intercalator, dispersion, and oxidation resistance and large-scale preparation of MXene on the morphology and performance of the new two-dimensional material MXene. Fluorine-containing etching makes MXene have more fluorine terminals that are unfavorable to performance. However, etching with HF and fluoride to obtain MXene is still the most widely used method. We should continue to develop more mature and feasible fluorine-free etching vigorously. Corrosion methods to avoid problems caused by fluorine terminal should be researched. This paper describes the application of original 
MXene and its composite materials in gas sensors and explains the gas sensing mechanism of MXene as a gas sensor to detect gases. The formation of composite materials by MXene can increase the surface area, the spacing between layers and the active sites for gas adsorption. The gas-sensing mechanism of metallic MXene is affected by the expansion of the lamellae. MXene will be doped with $\mathrm{H}_{2} \mathrm{O}$ and $\mathrm{O}$ during the etching process to become a p-type semiconductor. In order to regulate and control the gas sensitivity of composite materials, the semiconductor MXene was combined with other type semiconductors to form a $\mathrm{p}-\mathrm{n}$ heterojunction and a Schottky barrier. Although there are still few reports on the application of MXene materials to gas sensors, MXene and its composite materials possessing sizeable specific surface area, large porosity and high conductivity are expected to become materials that can effectively detect gases at room temperature, especially for the detection of $\mathrm{NH}_{3}$ and $\mathrm{VOC}$ gas.

Author Contributions: Writing, Q.L.; Supervision, Y.L.; Review and editing, W.Z. All authors have read and agreed to the published version of the manuscript.

Funding: This work was financially supported by the Graduate Scientific Research and Innovation Foundation of Chongqing, China (No. CYS20001) and the Science and Technology Research Program of Chongqing Municipal Education Commission (No. KJQN201801320).

Institutional Review Board Statement: Not applicable.

Informed Consent Statement: Not applicable.

Data Availability Statement: No new data were created or analyzed in this study. Data sharing is not applicable to this article.

Conflicts of Interest: The authors declare no conflict of interest.

\section{References}

1. Hao, M.; Zeng, W.; Li, Y.-Q.; Wang, Z.-C. Three-dimensional graphene and its composite for gas sensors. Rare Met. 2021, 40, 1494-1514. [CrossRef]

2. Wang, C.; Wang, Y.; Yang, Z.; Hu, N. Review of recent progress on graphene-based composite gas sensors. Ceram. Int. 2021, 47, 16367-16384. [CrossRef]

3. Bai, S.; Han, J.; Meng, J.C.; Sun, L.; Sun, J.; Zhao, Y.; Tang, P.; Luo, R.; Li, D.; Chen, A. NiO/ZnO composite decorated on rGO for detection of $\mathrm{NO}_{2}$. Sens. Actuators $B$ Chem. 2021, 339, 129720. [CrossRef]

4. Yao, X.; Zhao, J.; Jin, Z.; Jiang, Z.; Xu, D.; Wang, F.; Zhang, X.; Song, H.; Pan, D.; Chen, Y.; et al. Flower-like hydroxyfluoride-sensing platform toward $\mathrm{NO}_{2}$ detection. ACS Appl. Mater. Interfaces 2021, 13, 26278-26287. [CrossRef]

5. Raj, I.L.P.; Gobalakrishnan, S.; Praseetha, P.K.; Chidhambaram, N.; Saravanakumar, S.; Ganesh, V.; AlFaify, S.; Algarni, H.; Yahia, I.S. Improved ammonia vapor sensing properties of Al-doped $\mathrm{ZnO}$ nanoparticles prepared by sol-gel process. Phys. Scr. 2021, 96, 085802. [CrossRef]

6. Hien, H.T.; Ngan, P.Q.; Thai, G.H.; Trung, T.; Tan, M.M.; Giang, H.T. High $\mathrm{NH}_{3}$ sensing performance of NiO/PPy hybrid nanostructures. Sens. Actuators B Chem. 2021, 340, 129986. [CrossRef]

7. Maheswari, S.; Karunakaran, M.; Hariprasad, K.; Kasirajan, K.; Raj, I.L.P.; Chandrasekar, L.B.; Alshahrani, T.; Shkir, M.; Aifaify, S. Noticeable enhancement in $\mathrm{NH}_{3}$ sensing performance of nebulizer spray pyrolysis deposited $\mathrm{SnO}_{2}$ thin films: An effect of Tb doping. Superlattices Microstruct. 2021, 154, 106868. [CrossRef]

8. Chang, J.; Deng, Z.; Fang, X.; Hu, C.; Shi, L.; Dai, T.; Li, M.; Wang, S.; Meng, G. Heterostructural $\left(\mathrm{Sr}_{0.6} \mathrm{Bi}_{0.305}\right)_{(2)} \mathrm{Bi}_{2} \mathrm{O}_{7} / \mathrm{ZnO}_{0}$ for novel high-performance $\mathrm{H}_{2} \mathrm{~S}$ sensor operating at low temperature. J. Hazard. Mater. 2021, 414, 125500. [CrossRef] [PubMed]

9. Wang, H.; Luo, Y.; Liu, B.; Gao, L.; Duan, G. CuO nanoparticle loaded $\mathrm{ZnO}$ hierarchical heterostructure to boost $\mathrm{H}_{2} \mathrm{~S}$ sensing with fast recovery. Sens. Actuators B Chem. 2021, 338, 129806. [CrossRef]

10. Luo, Y.; An, B.; Bai, J.; Wang, Y.; Cheng, X.; Wang, Q.; Li, J.; Yang, Y.; Wu, Z.; Xie, E. Ultrahigh-response hydrogen sensor based on $\mathrm{PdO} / \mathrm{NiO}$ co-doped $\mathrm{In}_{2} \mathrm{O}_{3}$ nanotubes. J. Colloid Interface Sci. 2021, 599, 533-542. [CrossRef]

11. Kasapoglu, A.E.; Habashyani, S.; Baltakesmez, A.; Iskenderoglu, D.; Gur, E. The effect of the change in the amount of Sb doping in $\mathrm{ZnO}$ nanorods for hydrogen gas sensors. Int. J. Hydrogen Energy 2021, 46, 21715-21725. [CrossRef]

12. Hu, K.; Wang, F.; Shen, Z.; Yan, Y.; Liu, H. Enhancement methods of hydrogen sensing for one-dimensional nanomaterials: A review. Int. J. Hydrogen Energy 2021, 46, 20119-20138. [CrossRef]

13. Gonzalez-Garnica, M.; Galdamez-Martinez, A.; Malagon, F.; Ramos, C.D.; Santana, G.; Abolhassani, R.; Panda, P.K.; Kaushik, A.; Mishra, Y.K.; Karthik, T.V.K.; et al. One dimensional Au-ZnO hybrid nanostructures based $\mathrm{CO}_{2}$ detection: Growth mechanism and role of the seed layer on sensing performance. Sens. Actuators B Chem. 2021, 337, 129765. [CrossRef] 
14. Van Tong, P.; Minh, L.H.; Van Duy, N.; Hung, C.M. Porous $\operatorname{In}_{2} \mathrm{O}_{3}$ nanorods fabricated by hydrothermal method for an effective CO gas sensor. Mater. Res. Bull. 2021, 137, 111179. [CrossRef]

15. Hung, N.M.; Hung, C.M.; Van Duy, N.; Hoa, N.D.; Hong, H.S.; Dang, T.K.; Viet, N.N.; Thong, L.T.; Phuoc, P.H.; Van Hieu, N. Significantly enhanced $\mathrm{NO}_{2}$ gas-sensing performance of nanojunction-networked $\mathrm{SnO}_{2}$ nanowires by pulsed UV-radiation. Sens. Actuators A Phys. 2021, 327, 112759. [CrossRef]

16. Pi, M.; Zheng, L.; Luo, H.; Duan, S.; Li, C.; Yang, J.; Zhang, D.; Chen, S. Improved acetone gas sensing performance based on optimization of a transition metal doped $\mathrm{WO}_{3}$ system at room temperature. J. Phys. D Appl. Phys. 2021, 54, 155107. [CrossRef]

17. Harathi, N.; Sarkar, A. $\mathrm{TiO}_{2}$ based surface acoustic wave gas sensor with modified electrode dimensions for enhanced $\mathrm{H}_{2}$ sensing application. Int. J. Nano Dimens. 2021, 12, 83-89.

18. Yang, J.; Han, W.; Ma, J.; Wang, C.; Shimanoe, K.; Zhang, S.; Sun, Y.; Cheng, P.; Wang, Y.; Zhang, H.; et al. Sn doping effect on NiO hollow nanofibers based gas sensors about the humidity dependence for triethylamine detection. Sens. Actuators B Chem. 2021, 340, 129971. [CrossRef]

19. Bai, H.; Guo, H.; Wang, J.; Dong, Y.; Liu, B.; Xie, Z.; Guo, F.; Chen, D.; Zhang, R.; Zheng, Y. A room-temperature $\mathrm{NO}_{2}$ gas sensor based on $\mathrm{CuO}$ nanoflakes modified with rGO nanosheets. Sens. Actuators B Chem. 2021, 337, 129783. [CrossRef]

20. Umar, A.; Ibrahim, A.A.; Kumar, R.; Albargi, H.; Zeng, W.; Alhmami, M.A.M.; Alsaiari, M.A.; Baskoutas, S. Gas sensor device for high-performance ethanol sensing using alpha- $\mathrm{MnO}_{2}$ nanoparticles. Mater. Lett. 2021, 286, 129232. [CrossRef]

21. Xu, T.-T.; Zhang, X.-F.; Dong, X.; Deng, Z.-P.; Huo, L.-H.; Gao, S. Enhanced $\mathrm{H}_{2} \mathrm{~S}$ gas-sensing performance of $\mathrm{Zn}_{2} \mathrm{SnO}_{4}$ hierarchical quasi-microspheres constructed from nanosheets and octahedra. J. Hazard. Mater. 2019, 361, 49-55. [CrossRef] [PubMed]

22. Subramanian, M.; Dhayabaran, V.V.; Shanmugavadivel, M. Fiber optic gas sensing properties of $\mathrm{Ni}_{2} \mathrm{~V}_{2} \mathrm{O}_{7}$ nanorods operable at room temperature. Mater. Sci. Eng. B 2020, 259, 114604. [CrossRef]

23. Wang, B.; Yu, Q.; Zhang, S.; Wang, T.; Sun, P.; Chuai, X.; Lu, G. Gas sensing with yolk-shell $\mathrm{LaFeO}_{3}$ microspheres prepared by facile hydrothermal synthesis. Sens. Actuators B Chem. 2018, 258, 1215-1222. [CrossRef]

24. Yao, D.; Dong, C.; Bing, Q.; Liu, Y.; Qu, F.; Yang, M.; Liu, B.; Yang, B.; Zhang, H. Oxygen-defective ultrathin BiVO 4 nanosheets for enhanced gas sensing. ACS Appl. Mater. Interfaces 2019, 11, 23495-23502. [CrossRef] [PubMed]

25. Kim, J.K.; Han, M.; Kim, Y.; An, H.K.; Lee, S.; Kong, S.H.; Jung, D. Pd-decorated multi-walled carbon nanotube sensor for hydrogen detection. J. Nanosci. Nanotechnol. 2021, 21,3707-3710. [CrossRef] [PubMed]

26. Ridhi, R.; Neeru; Gautam, S.; Saini, G.S.S.; Tripathi, S.K.; Rawat, J.S.; Jha, P. Study of the effect of orbital on interaction behaviour of SWCNT- metal phthalocyanines composites with ammonia gas. Sens. Actuators B Chem. 2021, 337, 129767. [CrossRef]

27. Jeong, D.-W.; Kim, K.H.; Kim, B.S.; Byun, Y.T. Characteristics of highly sensitive and selective nitric oxide gas sensors using defect-functionalized single-walled carbon nanotubes at room temperature. Appl. Surf. Sci. 2021, 550, 149250. [CrossRef]

28. Matatagui, D.; Lopez-Sanchez, J.; Pena, A.; Serrano, A.; del Campo, A.; de la Fuente, O.R.; Carmona, N.; Navarro, E.; Marin, P.; Carmen Horrillo, M.D. Ultrasensitive $\mathrm{NO}_{2}$ gas sensor with insignificant $\mathrm{NH}_{3}$-interference based on a few-layered mesoporous graphene. Sens. Actuators B Chem. 2021, 335, 129657. [CrossRef]

29. Qu, C.; Zhao, P.; Wu, C.; Zhuang, Y.; Liu, J.; Li, W.; Liu, Z.; Liu, J. Electrospun PAN/PANI fiber film with abundant active sites for ultrasensitive trimethylamine detection. Sens. Actuators B Chem. 2021, 338, 129822. [CrossRef]

30. Thangamani, G.J.; Deshmukh, K.; Nambiraj, N.A.; Pasha, S.K.K. Chemiresistive gas sensors based on vanadium pentoxide reinforced polyvinyl alcohol/polypyrrole blend nanocomposites for room temperature LPG sensing. Synth. Met. 2021, 273, 116687. [CrossRef]

31. Yuan, Y.; Wu, H.; Bu, X.; Wu, Q.; Wang, X.; Han, C.; Li, X.; Wang, X.; Liu, W. Improving ammonia detecting performance of polyaniline decorated rGO composite membrane with GO Doping. Materials 2021, 14, 2829. [CrossRef]

32. Zhang, Z.; Du, H.; Yi, W.; Sun, Y.; Zheng, Y.; Wu, Y.; Sun, S.; Xu, S. Investigation of Ammonia-sensing mechanism on polypyrrole gas sensor based on experimental and theoretical evidence. Sens. Mater. 2021, 33, 1443-1454. [CrossRef]

33. Chen, J.; Lv, H.; Bai, X.; Liu, Z.; He, L.; Wang, J.; Zhang, Y.; Sun, B.; Kan, K.; Shi, K. Synthesis of hierarchically porous $\mathrm{Co}_{3} \mathrm{O}_{4}$ / Biomass carbon composites derived from MOFs and their highly $\mathrm{NO}_{2}$ gas sensing performance. Microporous Mesoporous Mater. 2021, 321, 111108. [CrossRef]

34. Mi, Q.; Zhang, D.; Zhang, X.; Wang, D. Highly sensitive ammonia gas sensor based on metal-organic frameworks-derived $\mathrm{CoSe}_{2} @$ nitrogen-doped amorphous carbon decorated with multi-walled carbon nanotubes. J. Alloys Compd. 2021, 860, 158252. [CrossRef]

35. Li, X.; Zhang, Y.; Cheng, Y.; Chen, X.; Tan, W. MOF-derived porous hierarchical $\mathrm{ZnCo}_{2} \mathrm{O}_{4}$ microflowers for enhanced performance gas sensor. Ceram. Int. 2021, 47, 9214-9224. [CrossRef]

36. Michel, C.R.; Martinez-Preciado, A.H.; Lopez Contreras, N.L. Gas sensing properties of $\mathrm{Nd}_{2} \mathrm{O}_{3}$ nanostructured microspheres. Sens. Actuators B Chem. 2013, 184, 8-14. [CrossRef]

37. Michel, C.R.; Martinez-Preciado, A.H. CO sensing properties of novel nanostructured $\mathrm{La}_{2} \mathrm{O}_{3}$ microspheres. Sens. Actuators $B$ Chem. 2015, 208, 355-362. [CrossRef]

38. Bi, H.; Zhang, L.-X.; Xing, Y.; Zhang, P.; Chen, J.-J.; Yin, J.; Bie, L.-J. Morphology-controlled synthesis of CeO 2 nanocrystals and their facet-dependent gas sensing properties. Sens. Actuators B Chem. 2021, 330, 129374. [CrossRef]

39. Lei, G.; Lou, C.; Liu, X.; Xie, J.; Li, Z.; Zheng, W.; Zhang, J. Thin films of tungsten oxide materials for advanced gas sensors. Sens. Actuators B Chem. 2021, 341, 129996. [CrossRef]

40. Wang, Y.; Zhang, S.; Huang, C.; Qu, F.; Yao, D.; Guo, H.; Xu, H.; Jiang, C.; Yang, M. Mesoporous WO $\mathrm{W}_{3}$ modified by Au nanoparticles for enhanced trimethylamine gas sensing properties. Dalton Trans. 2021, 50, 970-978. [CrossRef] [PubMed] 
41. Chaloeipote, G.; Prathumwan, R.; Subannajui, K.; Wisitsoraat, A.; Wongchoosuk, C. 3D printed CuO semiconducting gas sensor for ammonia detection at room temperature. Mater. Sci. Semicond. Process. 2021, 123, 105546. [CrossRef]

42. Ma, J.; Fan, H.; Li, Z.; Jia, Y.; Yadav, A.K.; Dong, G.; Wang, W.; Dong, W.; Wang, S. Multi-walled carbon nanotubes/polyaniline on the ethylenediamine modified polyethylene terephthalate fibers for a flexible room temperature ammonia gas sensor with high responses. Sens. Actuators B Chem. 2021, 334, 129677. [CrossRef]

43. Yan, D.; Xia, S.; Li, S.; Wang, S.; Tan, M.; Liu, S. Electrophoretic deposition of multiwalled carbon nanotubes onto porous silicon with enhanced $\mathrm{NO}_{2}$-sensing characteristics. Mater. Res. Bull. 2021, 134, 111109. [CrossRef]

44. Gupta, M.; Hawari, H.F.; Kumar, P.; Burhanudin, Z.A.; Tansu, N. Functionalized Reduced Graphene oxide thin films for ultrahigh $\mathrm{CO}_{2}$ gas sensing performance at room temperature. Nanomaterials 2021, 11, 623. [CrossRef]

45. Adhikari, A.; Tiwary, P.; Rana, D.; Halder, A.; Nath, J.; Basu, A.; Ghoshal, D.; Kar, P.; Chakraborty, A.K.; Chattopadhyay, D. Na-cholate micelle mediated synthesis of polypyrrole nanoribbons for ethanol sensing. J. Environ. Chem. Eng. 2020, 8, 104249. [CrossRef]

46. Fu, Y.; Xin, M.; Chong, J.; Li, R.; Huang, M. Plasmonic gold nanostars@ZIF-8 nanocomposite for the ultrasensitive detection of gaseous formaldehyde. J. Mater. Sci. 2021, 56, 4151-4160. [CrossRef]

47. Zhan, M.; Hussain, S.; AlGarni, T.S.; Shah, S.; Liu, J.; Zhang, X.; Ahmad, A.; Javed, M.S.; Qiao, G.; Liu, G. Facet controlled polyhedral ZIF-8 MOF nanostructures for excellent $\mathrm{NO}_{2}$ gas-sensing applications. Mater. Res. Bull. 2021, 136, 111133. [CrossRef]

48. Qin, Y.; Wang, X. Experiments combined with first-principles calculations to compare the enhancement of Ag-doping and -functionalization on the sensing properties of two-dimensional SnS. Phys. E Low-Dimens. Syst. Nanostruct. 2021, 131, 114752. [CrossRef]

49. Hermawan, A.; Zhang, B.; Taufik, A.; Asakura, Y.; Hasegawa, T.; Zhu, J.; Shi, P.; Yin, S. CuO nanoparticles $/ \mathrm{Ti}_{3} \mathrm{C}_{2} \mathrm{~T}_{x} \mathrm{MXene} \mathrm{hybrid}$ nanocomposites for detection of toluene Gas. ACS Appl. Nano Mater. 2020, 3, 4755-4766. [CrossRef]

50. Naguib, M.; Kurtoglu, M.; Presser, V.; Lu, J.; Niu, J.; Heon, M.; Hultman, L.; Gogotsi, Y.; Barsoum, M.W. Two-dimensional nanocrystals produced by exfoliation of $\mathrm{Ti}_{3} \mathrm{AlC}_{2}$. Adv. Mater. 2011, 23, 4248-4253. [CrossRef] [PubMed]

51. Wu, Y.; Sun, Y.; Zheng, J.; Rong, J.; Li, H.; Niu, L. Exploring MXene-based materials for next-generation rechargeable batteries. J. Phys. Energy 2021, 3, 032009. [CrossRef]

52. Qi, Z.; Wang, S.; Li, Y.; Wang, L.; Zhao, L.; Ge, Q.; Zhang, J.Z. Scavenging activity and reaction mechanism of Ti $3 \mathrm{C}_{2} \mathrm{~T}_{x} \mathrm{MXene}$ as a novel free radical scavenger. Ceram. Int. 2021, 47, 16555-16561. [CrossRef]

53. Iravani, S.; Varma, R.S. MXenes for cancer therapy and diagnosis: Recent advances and current challenges. ACS Biomater. Sci. Eng. 2021, 7, 1900-1913. [CrossRef]

54. Naguib, M.; Unocic, R.R.; Armstrong, B.L.; Nanda, J. Large-scale delamination of multi-layers transition metal carbides and carbonitrides "MXenes". Dalton Trans. 2015, 44, 9353-9358. [CrossRef]

55. Naguib, M.; Mochalin, V.N.; Barsoum, M.W.; Gogotsi, Y. 25th Anniversary Article: MXenes: A new family of Two-dimensional materials. Adv. Mater. 2014, 26, 992-1005. [CrossRef]

56. Zhang, M.; Wang, Y.; Gao, F.; Wang, Y.; Shen, X.; He, N.; Zhu, J.; Chen, Y.; Wan, X.; Lian, X.; et al. Formation of new MXene film using spinning coating method with DMSO solution and its application in advanced memristive device. Ceram. Int. 2019, 45, 19467-19472. [CrossRef]

57. Wu, X.; Ma, P.; Sun, Y.; Du, F.; Song, D.; Xu, G. Application of MXene in electrochemical sensors: A Review. Electroanal 2021, 33, 1827-1851. [CrossRef]

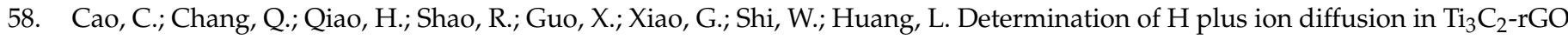
glucose sensor. Sens. Actuators B Chem. 2021, 340, 129943. [CrossRef]

59. Wang, J.; Gong, J.; Zhang, H.; Lv, L.; Liu, Y.; Dai, Y. Construction of hexagonal nickel-cobalt oxide nanosheets on metal-organic frameworks based on MXene interlayer ion effect for hybrid supercapacitors. J. Alloys Compd. 2021, 870, 159466. [CrossRef]

60. Mei, J.; Ayoko, G.A.; Hu, C.; Bell, J.M.; Sun, Z. Two-dimensional fluorine-free mesoporous $\mathrm{Mo}_{2} \mathrm{C}$ MXene via UV-induced selective etching of $\mathrm{Mo}_{2} \mathrm{Ga}_{2} \mathrm{C}$ for energy storage. Sustain. Mater. Technol. 2020, 25, e00156. [CrossRef]

61. Ghasali, E.; Orooji, Y.; Azarniya, A.; Alizadeh, M.; Kazem-zad, M.; Ebadzadeh, T. Production of $\mathrm{V}_{2} \mathrm{C}$ MXene using a repetitive pattern of $\mathrm{V}_{2} \mathrm{AlC}$ MAX phase through microwave heating of $\mathrm{Al}-\mathrm{V}_{2} \mathrm{O}_{5}-\mathrm{C}$ system. Appl. Surf. Sci. 2021, 542, 148538. [CrossRef]

62. Zhang, Y.; Yu, J.; Lu, J.; Zhu, C.; Qi, D. Facile construction of $2 \mathrm{D}$ MXene $\left(\mathrm{Ti}_{3} \mathrm{C}_{2} \mathrm{~T}_{x}\right)$ based aerogels with effective fire-resistance and electromagnetic interference shielding performance. J. Alloys Compd. 2021, 870, 159442. [CrossRef]

63. Wang, H.; Li, X.; Luo, B.; Wei, K.; Zeng, G. The MXene/water nanofluids with high stability and photo-thermal conversion for direct absorption solar collectors: A comparative study. Energy 2021, 227, 120483. [CrossRef]

64. Aghaei, S.M.; Aasi, A.; Panchapakesan, B. Experimental and theoretical advances in MXene-based gas sensors. ACS Omega 2021, 6, 2450-2461. [CrossRef]

65. Pei, Y.; Zhang, X.; Hui, Z.; Zhou, J.; Huang, X.; Sun, G.; Huang, W. $\mathrm{Ti}_{3} \mathrm{C}_{2} \mathrm{~T}_{x}$ MXene for sensing applications: Recent progress, design principles, and future perspectives. ACS Nano 2021, 15, 3996-4017. [CrossRef]

66. Deshmukh, K.; Kovarik, T.; Pasha, S.K.K. State of the art recent progress in two dimensional MXenes based gas sensors and biosensors: A comprehensive review. Coord. Chem. Rev. 2020, 424, 213514. [CrossRef]

67. Zhao, Q.-N.; Zhang, Y.-J.; Duan, Z.-H.; Wang, S.; Liu, C.; Jiang, Y.-D.; Tai, H.-L. A review on $\mathrm{Ti}_{3} \mathrm{C}_{2} \mathrm{~T}_{x}$-based nanomaterials: Synthesis and applications in gas and humidity sensors. Rare Met. 2021, 40, 1459-1476. [CrossRef]

68. Shuck, C.E.; Sarycheva, A.; Anayee, M.; Levitt, A.; Zhu, Y.; Uzun, S.; Balitskiy, V.; Zahorodna, V.; Gogotsi, O.; Gogotsi, Y. Scalable synthesis of $\mathrm{Ti}_{3} \mathrm{C}_{2} \mathrm{~T}_{x}$ MXene. Adv. Eng. Mater. 2020, 22, 1901241. [CrossRef] 
69. Chen, B.; Feng, A.; Liu, K.; Wu, J.; Yu, Y.; Song, L. Subsize $\mathrm{Ti}_{3} \mathrm{C}_{2} \mathrm{~T}_{x}$ derived from molten-salt synthesized $\mathrm{Ti}_{3} \mathrm{AlC}_{2}$ for enhanced capacitive deionization. Ceram. Int. 2021, 47, 3665-3670. [CrossRef]

70. Han, M.; Liu, Y.; Rakhmanov, R.; Israel, C.; Tajin, M.A.S.; Friedman, G.; Volman, V.; Hoorfar, A.; Dandekar, K.R.; Gogotsi, Y. SolutionProcessed $\mathrm{Ti}_{3} \mathrm{C}_{2} \mathrm{~T}_{x} \mathrm{MXene}$ antennas for radio-frequency communication. Adv. Mater. 2021, 33, e2003225. [CrossRef] [PubMed]

71. Li, Z.; Wang, L.; Sun, D.; Zhang, Y.; Liu, B.; Hu, Q.; Zhou, A. Synthesis and thermal stability of two-dimensional carbide MXene $\mathrm{Ti}_{3} \mathrm{C}_{2}$. Mater. Sci. Eng. B 2015, 191, 33-40. [CrossRef]

72. Su, X.; Zhang, J.; Mu, H.; Zhao, J.; Wang, Z.; Zhao, Z.; Han, C.; Ye, Z. Effects of etching temperature and ball milling on the preparation and capacitance of $\mathrm{Ti}_{3} \mathrm{C}_{2}$ MXene. J. Alloys Compd. 2018, 752, 32-39. [CrossRef]

73. Alhabeb, M.; Maleski, K.; Anasori, B.; Lelyukh, P.; Clark, L.; Sin, S.; Gogotsi, Y. Guidelines for synthesis and processing of two-dimensional titanium carbide $\left(\mathrm{Ti}_{3} \mathrm{C}_{2} \mathrm{~T}_{x}\right.$ MXene). Chem. Mater. 2017, 29, 7633-7644. [CrossRef]

74. Li, Y.; Shao, H.; Lin, Z.; Lu, J.; Liu, L.; Duployer, B.; Persson, P.O.A.; Eklund, P.; Hultman, L.; Li, M.; et al. A general Lewis acidic etching route for preparing MXenes with enhanced electrochemical performance in non-aqueous electrolyte. Nat. Mater. 2020, 19, 894-899. [CrossRef]

75. Kumar, S.; Kang, D.; Hong, H.; Rehman, M.A.; Lee, Y.-J.; Lee, N.; Seo, Y. Effect of $\mathrm{Ti}_{3} \mathrm{C}_{2} \mathrm{~T}_{x}$ MXenes etched at elevated temperatures using concentrated acid on binder-free supercapacitors. RSC Adv. 2020, 10, 41837-41845. [CrossRef]

76. Sun, J.; Kong, W.; Jin, Z.; Han, Y.; Ma, L.; Ding, X.; Niu, Y.; Xu, Y. Recent advances of MXene as promising catalysts for electrochemical nitrogen reduction reaction. Chin. Chem. Lett. 2020, 31, 953-960. [CrossRef]

77. Ghidiu, M.; Lukatskaya, M.R.; Zhao, M.-Q.; Gogotsi, Y.; Barsoum, M.W. Conductive two-dimensional titanium carbide 'clay' with high volumetric capacitance. Nature 2014, 516, 78-81. [CrossRef] [PubMed]

78. Sinha, A.; Ma, K.; Zhao, H. 2D Ti ${ }_{3} \mathrm{C}_{2} \mathrm{~T}_{x}$ flakes prepared by in-situ HF etchant for simultaneous screening of carbamate pesticides. J. Colloid Interface Sci. 2021, 590, 365-374. [CrossRef]

79. Gajdosova, V.; Lorencova, L.; Prochazka, M.; Omastova, M.; Micusik, M.; Prochazkova, S.; Kveton, F.; Jerigova, M.; Velic, D.; Kasak, P.; et al. Remarkable differences in the voltammetric response towards hydrogen peroxide, oxygen and $\mathrm{Ru}\left(\mathrm{NH}_{3}\right)_{(6)}{ }^{(3+)}$ of electrode interfaces modified with $\mathrm{HF}$ or LiF-HCl etched $\mathrm{Ti}_{3} \mathrm{C}_{2} \mathrm{~T}_{x}$ MXene. Microchim. Acta 2020, 187, 1-8. [CrossRef]

80. Gao, L.; Li, C.; Huang, W.; Mei, S.; Lin, H.; Ou, Q.; Zhang, Y.; Guo, J.; Zhang, F.; Xu, S.; et al. MXene/Polymer membranes: Synthesis, properties, and emerging applications. Chem. Mater. 2020, 32, 1703-1747. [CrossRef]

81. Kim, S.J.; Koh, H.-J.; Ren, C.E.; Kwon, O.; Maleski, K.; Cho, S.-Y.; Anasori, B.; Kim, C.-K.; Choi, Y.-K.; Kim, J.; et al. Metallic $\mathrm{Ti}_{3} \mathrm{C}_{2} \mathrm{~T}_{x} \mathrm{MXene}$ gas sensors with ultrahigh signal-to-noise ratio. ACS Nano 2018, 12, 986-993. [CrossRef] [PubMed]

82. Akinola, O.; Chakraborty, I.; Celio, H.; Akinwande, D.; Incorvia, J.A.C. Synthesis and characterization of Cr $\mathrm{C}_{2} \mathrm{C} \mathrm{MXenes.} \mathrm{J.} \mathrm{Mater.}$ Res. 2021, 36, 1980-1989. [CrossRef]

83. Wang, X.; Garnero, C.; Rochard, G.; Magne, D.; Morisset, S.; Hurand, S.; Chartier, P.; Rousseau, J.; Cabioc'h, T.; Coutanceau, C.; et al. A new etching environment $\left(\mathrm{FeF}_{3} / \mathrm{HCl}\right)$ for the synthesis of two-dimensional titanium carbide MXenes: A route towards selective reactivity vs. water. J. Mater. Chem. A 2017, 5, 22012-22023. [CrossRef]

84. Liu, F.; Zhou, A.; Chen, J.; Jin, J.; Zhou, W.; Wang, L.; Hu, Q. Preparation of $\mathrm{Ti}_{3} \mathrm{C}_{2}$ and $\mathrm{Ti}_{2} \mathrm{C}$ MXenes by fluoride salts etching and methane adsorptive properties. Appl. Surf. Sci. 2017, 416, 781-789. [CrossRef]

85. He, H.; Xia, Q.; Wang, B.; Wang, L.; Hu, Q.; Zhou, A. Two-dimensional vanadium carbide $\left(\mathrm{V}_{2} \mathrm{CT}_{x}\right) \mathrm{MXene}$ as supercapacitor electrode in seawater electrolyte. Chin. Chem. Lett. 2020, 31, 984-987. [CrossRef]

86. Handoko, A.D.; Chen, H.; Lum, Y.; Zhang, Q.; Anasori, B.; Seh, Z.W. Two-dimensional titanium and molybdenum carbide MXenes as electrocatalysts for $\mathrm{CO}_{2}$ reduction. iScience 2020, 23, 101181. [CrossRef]

87. Feng, A.; Yu, Y.; Jiang, F.; Wang, Y.; Mi, L.; Yu, Y.; Song, L. Fabrication and thermal stability of $\mathrm{NH}_{4} \mathrm{HF}_{2}$-etched $\mathrm{Ti}_{3} \mathrm{C}_{2} \mathrm{MXene}$ Ceram. Int. 2017, 43, 6322-6328. [CrossRef]

88. Feng, A.; Yu, Y.; Wang, Y.; Jiang, F.; Yu, Y.; Mi, L.; Song, L. Two-dimensional MXene Ti3C2 produced by exfoliation of Ti $3 \mathrm{AlC}_{2}$. Mater. Des. 2017, 114, 161-166. [CrossRef]

89. Sun, Z.; Yuan, M.; Lin, L.; Yang, H.; Nan, C.; Li, H.; Sun, G.; Yang, X. Selective Lithiation-Expansion-Microexplosion synthesis of two-dimensional fluoride-free Mxene. ACS Mater. Lett. 2019, 1, 628-632. [CrossRef]

90. Wang, C.; Shou, H.; Chen, S.; Wei, S.; Lin, Y.; Zhang, P.; Liu, Z.; Zhu, K.; Guo, X.; Wu, X.; et al. HCl-based hydrothermal etching strategy toward fluoride-free MXenes. Adv. Mater. 2021, 33, 2101015. [CrossRef]

91. Li, T.; Yao, L.; Liu, Q.; Gu, J.; Luo, R.; Li, J.; Yan, X.; Wang, W.; Liu, P.; Chen, B.; et al. Fluorine-free synthesis of high-purity Ti ${ }_{3} \mathrm{C}_{2} \mathrm{~T}_{x}$ $(\mathrm{T}=\mathrm{OH}, \mathrm{O})$ via alkali treatment. Angew. Chem. Int. Ed. 2018, 57, 6115-6119. [CrossRef] [PubMed]

92. Zhang, B.; Zhu, J.; Shi, P.; Wu, W.; Wang, F. Fluoride-free synthesis and microstructure evolution of novel two-dimensional Ti ${ }_{3} \mathrm{C}_{2}(\mathrm{OH})_{(2)}$ nanoribbons as high-performance anode materials for lithium-ion batteries. Ceram. Int. 2019, 45, 8395-8405. [CrossRef]

93. Xue, N.; Li, X.; Zhang, M.; Han, L.; Liu, Y.; Tao, X. Chemical-combined ball-milling synthesis of fluorine-free porous MXene for high-performance lithium ion batteries. ACS Appl. Energy Mater. 2020, 3, 10234-10241. [CrossRef]

94. Rafieerad, A.; Amiri, A.; Sequiera, G.L.; Yan, W.; Chen, Y.; Polycarpou, A.A.; Dhingra, S. Development of fluorine-free tantalum carbide MXene hybrid structure as a biocompatible material for supercapacitor electrodes. Adv. Funct. Mater. 2021, 31, 2100015. [CrossRef]

95. Sun, W.; Shah, S.A.; Chen, Y.; Tan, Z.; Gao, H.; Habib, T.; Radovic, M.; Green, M.J. Electrochemical etching of Ti ${ }_{2} \mathrm{AlC} \mathrm{to} \mathrm{Ti}_{2} \mathrm{CT}_{x}$ (MXene) in low-concentration hydrochloric acid solution. J. Mater. Chem. A 2017, 5, 21663-21668. [CrossRef]

96. Yang, S.; Zhang, P.; Wang, F.; Ricciardulli, A.G.; Lohe, M.R.; Blom, P.W.M.; Feng, X. Fluoride-free synthesis of two-dimensional titanium carbide (MXene) using a binary aqueous system. Angew. Chem. Int. Ed. 2018, 57, 15491-15495. [CrossRef] 
97. Song, M.; Pang, S.-Y.; Guo, F.; Wong, M.-C.; Hao, J. Fluoride-free 2D niobium carbide MXenes as stable and biocompatible nanoplatforms for electrochemical biosensors with ultrahigh sensitivity. Adv. Sci. 2020, 7, 7. [CrossRef] [PubMed]

98. Jawaid, A.; Hassan, A.; Neher, G.; Nepal, D.; Pachter, R.; Kennedy, W.J.; Ramakrishnan, S.; Vaia, R.A. Halogen etch of Ti ${ }_{3} \mathrm{AlC}_{2}$ MAX phase for MXene fabrication. ACS Nano 2021, 15, 2771-2777. [CrossRef] [PubMed]

99. Shi, H.; Zhang, P.; Liu, Z.; Park, S.; Lohe, M.R.; Wu, Y.; Shaygan Nia, A.; Yang, S.; Feng, X. Ambient-stable two-dimensional titanium carbide (MXene) enabled by iodine etching. Angew. Chem. Int. Ed. 2021, 60, 8689-8693. [CrossRef] [PubMed]

100. Han, F.; Luo, S.; Xie, L.; Zhu, J.; Wei, W.; Chen, X.; Liu, F.; Chen, W.; Zhao, J.; Dong, L.; et al. Boosting the yield of MXene 2D sheets via a facile hydrothermal-assisted intercalation. ACS Appl. Mater. Interfaces 2019, 11, 8443-8452. [CrossRef]

101. Xiu, L.-Y.; Wang, Z.-Y.; Qiu, J.-S. General synthesis of MXene by green etching chemistry of fluoride-free Lewis acidic melts. Rare Met. 2020, 39, 1237-1238. [CrossRef]

102. Wu, S.; Wang, H.; Li, L.; Guo, M.; Qi, Z.; Zhang, Q.; Zhou, Y. Intercalated MXene-based layered composites: Preparation and application. Chin. Chem. Lett. 2020, 31, 961-968. [CrossRef]

103. Mashtalir, O.; Naguib, M.; Mochalin, V.N.; Dall'Agnese, Y.; Heon, M.; Barsoum, M.W.; Gogotsi, Y. Intercalation and delamination of layered carbides and carbonitrides. Nat. Commun. 2013, 4, 1716. [CrossRef] [PubMed]

104. Qian, A.; Seo, J.Y.; Shi, H.; Lee, J.Y.; Chung, C.-H. Surface functional groups and electrochemical behavior in dimethyl sulfoxidedelaminated $\mathrm{Ti}_{3} \mathrm{C}_{2} \mathrm{~T}_{x}$ MXene. Chemsuschem 2018, 11, 3719-3723. [CrossRef] [PubMed]

105. Overbury, S.H.; Kolesnikov, A.I.; Brown, G.M.; Zhang, Z.; Nair, G.S.; Sacci, R.L.; Lotfi, R.; van Duin, A.C.T.; Naguib, M. Complexity of intercalation in MXenes: Destabilization of urea by two-dimensional titanium carbide. J. Am. Chem. Soc. 2018, 140, 10305-10314. [CrossRef]

106. Xu, P.; Xiao, H.; Liang, X.; Zhang, T.; Zhang, F.; Liu, C.; Lang, B.; Gao, Q. A MXene-based EDA-Ti ${ }_{3} \mathrm{C}_{2} \mathrm{~T}_{x}$ intercalation compound with expanded interlayer spacing as high performance supercapacitor electrode material. Carbon 2021, 173, 135-144. [CrossRef]

107. Wang, H.; Wu, X. High capacitance of dipicolinic acid-intercalated MXene in neutral water-based electrolyte. Chem. Eng. J. 2020, 399, 125850. [CrossRef]

108. Husmann, S.; Budak, O.; Shim, H.; Liang, K.; Aslan, M.; Kruth, A.; Quade, A.; Naguib, M.; Presser, V. Ionic liquid-based synthesis of MXene. Chem. Commun. 2020, 56, 11082-11085. [CrossRef]

109. Kajiyama, S.; Szabova, L.; Sodeyama, K.; Iinuma, H.; Morita, R.; Gotoh, K.; Tateyama, Y.; Okubo, M.; Yamada, A. Sodium-ion intercalation mechanism in MXene nanosheets. ACS Nano 2016, 10, 3334-3341. [CrossRef] [PubMed]

110. Hu, A.; Yu, J.; Zhao, H.; Zhang, H.; Li, W. One-step synthesis for cations intercalation of two-dimensional carbide crystal Ti ${ }_{3} \mathrm{C}_{2}$ MXene. Appl. Surf. Sci. 2020, 505, 144538. [CrossRef]

111. Feng, X.; Ning, J.; Wang, B.; Guo, H.; Xia, M.; Wang, D.; Zhang, J.; Wu, Z.-S.; Hao, Y. Functional integrated electromagnetic interference shielding in flexible micro-supercapacitors by cation-intercalation typed $\mathrm{Ti}_{3} \mathrm{C}_{2} \mathrm{~T}_{x} \mathrm{MXene.} \mathrm{Nano} \mathrm{Energy} \mathrm{2020,} \mathrm{72,}$ 104741. [CrossRef]

112. Gao, Q.; Come, J.; Naguib, M.; Jesse, S.; Gogotsi, Y.; Balke, N. Synergetic effects of $\mathrm{K}^{+}$and $\mathrm{Mg}^{2+}$ ion intercalation on the electrochemical and actuation properties of the two-dimensional $\mathrm{Ti}_{3} \mathrm{C}_{2}$ MXene. Faraday Discuss. 2017, 199, 393-403. [CrossRef] [PubMed]

113. Zhang, Y.; Cao, J.; Yuan, Z.; Zhao, L.; Wang, L.; Han, W. Assembling $\mathrm{Co}_{3} \mathrm{O}_{4}$ nanoparticles into MXene with enhanced electrochemical performance for advanced asymmetric supercapacitors. J. Colloid Interface Sci. 2021, 599, 109-118. [CrossRef]

114. Boota, M.; Pasini, M.; Galeotti, F.; Porzio, W.; Zhao, M.-Q.; Halim, J.; Gogotsi, Y. Interaction of polar and nonpolar polyfluorenes with layers of two-dimensional titanium carbide (MXene): Intercalation and pseudocapacitance. Chem. Mater. 2017, 29, 2731-2738. [CrossRef]

115. Ding, L.; Wei, Y.; Wang, Y.; Chen, H.; Caro, J.; Wang, H. A two-dimensional lamellar membrane: MXene nanosheet stacks. Angew. Chem. Int. Ed. 2017, 56, 1825-1829. [CrossRef]

116. Srimuk, P.; Halim, J.; Lee, J.; Tao, Q.; Rosen, J.; Presser, V. Two-dimensional molybdenum carbide (MXene) with divacancy ordering for brackish and seawater desalination via cation and anion intercalation. ACS Sustain. Chem. Eng. 2018, 6, 3739-3747. [CrossRef]

117. Fredrickson, K.D.; Anasori, B.; Seh, Z.W.; Gogotsi, Y.; Vojvodic, A. Effects of applied potential and water intercalation on the surface chemistry of $\mathrm{Ti}_{2} \mathrm{C}$ and $\mathrm{Mo}_{2} \mathrm{C}$ MXenes. J. Phys. Chem. C 2016, 120, 28432-28440. [CrossRef]

118. Zhang, Q.; Lai, H.; Fan, R.; Ji, P.; Fu, X.; Li, H. High concentration of $\mathrm{Ti}_{3} \mathrm{C}_{2} \mathrm{~T}_{x} \mathrm{MXene}$ in organic solvent. ACS Nano 2021, 15, 5249-5262. [CrossRef]

119. Maleski, K.; Mochalin, V.N.; Gogotsi, Y. Dispersions of two-dimensional titanium carbide MXene in organic solvents. Chem. Mater. 2017, 29, 1632-1640. [CrossRef]

120. Kim, D.; Ko, T.Y.; Kim, H.; Lee, G.H.; Cho, S.; Koo, C.M. Nonpolar organic dispersion of $2 \mathrm{D} \mathrm{Ti}_{3} \mathrm{C}_{2} \mathrm{~T}_{x}$ MXene flakes via simultaneous interfacial chemical grafting and phase transfer method. ACS Nano 2019, 13, 13818-13828. [CrossRef]

121. Lim, S.; Park, H.; Yang, J.; Kwak, C.; Lee, J. Stable colloidal dispersion of octylated $\mathrm{Ti}_{3} \mathrm{C}_{2}$-MXenes in a nonpolar solvent. Colloid Surf. A 2019, 579, 579. [CrossRef]

122. Carey, M.; Hinton, Z.; Natu, V.; Pai, R.; Sokol, M.; Alvarez, N.J.; Kalra, V.; Barsoum, M.W. Dispersion and stabilization of alkylated 2D MXene in nonpolar solvents and their pseudocapacitive behavior. Cell Rep. Phys. Sci. 2020, 1, 100042. [CrossRef]

123. McDaniel, R.M.; Carey, M.S.; Wilson, O.R.; Barsoum, M.W.; Magenau, A.J.D. Well-dispersed nanocomposites using covalently modified, multilayer, 2D titanium carbide (MXene) and in-situ "Click" polymerization. Chem. Mater. 2021, 33, 1648-1656. [CrossRef]

124. Zhang, S.; Huang, P.; Wang, J.; Zhuang, Z.; Zhang, Z.; Han, W.-Q. Fast and universal Solution-Phase flocculation strategy for scalable synthesis of various few-layered MXene powders. J. Phys. Chem. Lett. 2020, 11, 1247-1254. [CrossRef]

125. Wang, H.; Zhang, J.; Wu, Y.; Huang, H.; Li, G.; Zhang, X.; Wang, Z. Surface modified MXene $\mathrm{Ti}_{3} \mathrm{C}_{2}$ multilayers by aryl diazonium salts leading to large-scale delamination. Appl. Surf. Sci. 2016, 384, 287-293. [CrossRef] 
126. Huang, X.; Wu, P. A Facile, High-yield, and freeze-and-thaw-assisted approach to fabricate MXene with plentiful wrinkles and its application in on-chip micro-supercapacitors. Adv. Funct. Mater. 2020, 30, 1910048. [CrossRef]

127. Liu, M.; Wang, Z.; Song, P.; Yang, Z.; Wang, Q. Flexible MXene/rGO/CuO hybrid aerogels for high performance acetone sensing at room temperature. Sens. Actuators B Chem. 2021, 340. [CrossRef]

128. Guo, X.; Ding, Y.; Kuang, D.; Wu, Z.; Sun, X.; Du, B.; Liang, C.; Wu, Y.; Qu, W.; Xiong, L.; et al. Enhanced ammonia sensing performance based on MXene- $\mathrm{Ti}_{3} \mathrm{C}_{2} \mathrm{~T}_{x}$ multilayer nanoflakes functionalized by tungsten trioxide nanoparticles. J. Colloid Interface Sci. 2021, 595, 6-14. [CrossRef] [PubMed]

129. He, T.; Liu, W.; Lv, T.; Ma, M.; Liu, Z.; Vasiliev, A.; Li, X. MXene/SnO 2 heterojunction based chemical gas sensors. Sens. Actuators B Chem. 2021, 329. [CrossRef]

130. Yuan, W.; Yang, K.; Peng, H.; Li, F.; Yin, F. A flexible VOCs sensor based on a 3D Mxene framework with a high sensing performance. J. Mater. Chem. A 2018, 6, 18116-18124. [CrossRef]

131. Hou, M.; Guo, S.; Yang, L.; Gao, J.; Hu, T.; Wang, X.; Li, Y. Improvement of gas sensing property for two-dimensional Ti ${ }_{3} \mathrm{C}_{2} \mathrm{~T}_{x}$ treated with oxygen plasma by microwave energy excitation. Ceram. Int. 2021, 47, 7728-7737. [CrossRef]

132. Guo, W.; Surya, S.G.; Babar, V.; Ming, F.; Sharma, S.; Alshareef, H.N.; Schwingenschlogl, U.; Salama, K.N. Selective toluene detection with $\mathrm{Mo}_{2} \mathrm{CT}_{x} \mathrm{MXene}$ at room temperature. ACS Appl. Mater. Interfaces 2020, 12, 57218-57227. [CrossRef]

133. Yang, Z.; Jiang, L.; Wang, J.; Liu, F.; He, J.; Liu, A.; Lv, S.; You, R.; Yan, X.; Sun, P.; et al. Flexible resistive $\mathrm{NO}_{2}$ gas sensor of three-dimensional crumpled $\mathrm{MXene} \mathrm{Ti}_{3} \mathrm{C}_{2} \mathrm{~T}_{x} / \mathrm{ZnO}$ spheres for room temperature application. Sens. Actuators B Chem. 2021, 326, 128828. [CrossRef]

134. Wang, Z.; Wang, F.; Hermawan, A.; Asakura, Y.; Hasegawa, T.; Kumagai, H.; Kato, H.; Kakihana, M.; Zhu, J.; Yin, S. SnO-SnO 2 modified two-dimensional MXene $\mathrm{Ti}_{3} \mathrm{C}_{2} \mathrm{~T}_{x}$ for acetone gas sensor working at room temperature. J. Mater. Sci. Technol. 2021, 73, 128-138. [CrossRef]

135. Zhang, D.; Mi, Q.; Wang, D.; Li, T. MXene/ $\mathrm{Co}_{3} \mathrm{O}_{4}$ composite based formaldehyde sensor driven by ZnO/MXene nanowire arrays piezoelectric nanogenerator. Sens. Actuators B Chem. 2021, 339, 129923. [CrossRef]

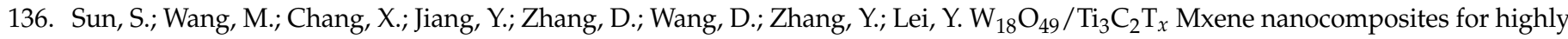
sensitive acetone gas sensor with low detection limit. Sens. Actuators B Chem. 2020, 304, 127274. [CrossRef]

137. Liu, M.; Wang, Z.; Song, P.; Yang, Z.; Wang, Q.J.C.I. $\mathrm{In}_{2} \mathrm{O}_{3}$ nanocubes $/ \mathrm{Ti}_{3} \mathrm{C}_{2} \mathrm{~T}_{x} \mathrm{MXene}$ composites for enhanced methanol gas sensing properties at room temperature. Ceram. Int. 2021, 47, 23028-23037. [CrossRef]

138. Zhao, L.; Wang, K.; Wei, W.; Wang, L.; Han, W. High-performance flexible sensing devices based on polyaniline/MXene nanocomposites. InfoMat 2019, 1, 407-416. [CrossRef]

139. Li, X.; Xu, J.; Jiang, Y.; He, Z.; Liu, B.; Xie, H.; Li, H.; Li, Z.; Wang, Y.; Tai, H. Toward agricultural ammonia volatilization monitoring: A flexible polyaniline $/ \mathrm{Ti}_{3} \mathrm{C}_{2} \mathrm{~T}_{x}$ hybrid sensitive films based gas sensor. Sens. Actuators B Chem. 2020, 316, 128144. [CrossRef]

140. Wang, S.; Liu, B.; Duan, Z.; Zhao, Q.; Zhang, Y.; Xie, G.; Jiang, Y.; Li, S.; Tai, H. PANI nanofibers-supported Nb ${ }_{2} \mathrm{CT}_{x}$ nanosheetsenabled selective $\mathrm{NH}_{3}$ detection driven by TENG at room temperature. Sens. Actuators B Chem. 2021, 327, 128923. [CrossRef]

141. Jin, L.; Wu, C.; Wei, K.; He, L.; Gao, H.; Zhang, H.; Zhang, K.; Asiri, A.M.; Alamry, K.A.; Yang, L.; et al. Polymeric Ti ${ }_{3} \mathrm{C}_{2} \mathrm{~T}_{x} \mathrm{MX}_{\mathrm{X}} \mathrm{Hen}$ composites for room temperature ammonia sensing. ACS Appl. Nano Mater. 2020, 3, 12071-12079. [CrossRef]

142. Zhu, Z.; Liu, C.; Jiang, F.; Liu, J.; Ma, X.; Liu, P.; Xu, J.; Wang, L.; Huang, R. Flexible and lightweight Ti $3 \mathrm{C}_{2} \mathrm{~T}_{x} \mathrm{MXene@Pd} \mathrm{colloidal}$ nanoclusters paper film as novel $\mathrm{H}_{2}$ sensor. J. Hazard. Mater. 2020, 399, 123054. [CrossRef]

143. Doan, T.H.P.; Hong, W.G.; Noh, J.-S. Palladium nanoparticle-decorated multi-layer $\mathrm{Ti}_{3} \mathrm{C}_{2} \mathrm{~T}_{x}$ dual-functioning as a highly sensitive hydrogen gas sensor and hydrogen storage. Rsc Adv. 2021, 11, 7492-7501. [CrossRef]

144. Chen, T.; Yan, W.; Wang, Y.; Li, J.; Hu, H.; Ho, D. $\mathrm{SnS}_{2} / \mathrm{MXene}$ derived $\mathrm{TiO}_{2}$ hybrid for ultra-fast room temperature $\mathrm{NO}_{2}$ gas sensing. J. Mater. Chem. C 2021, 9, 7407-7416. [CrossRef]

145. Chen, W.Y.; Jiang, X.; Lai, S.-N.; Peroulis, D.; Stanciu, L. Nanohybrids of a MXene and transition metal dichalcogenide for selective detection of volatile organic compounds. Nat. Commun. 2020, 11, 1-10. [CrossRef]

146. Shuvo, S.N.; Gomez, A.M.U.; Mishra, A.; Chen, W.Y.; Dongare, A.M.; Stanciu, L.A. Sulfur-doped titanium carbide MXenes for room-temperature gas sensing. ACS Sens. 2020, 5, 2915-2924. [CrossRef] [PubMed]

147. Chen, W.Y.; Lai, S.-N.; Yen, C.-C.; Jiang, X.; Peroulis, D.; Stanciu, L.A. Surface functionalization of $\mathrm{Ti}_{3} \mathrm{C}_{2} \mathrm{~T}_{x} \mathrm{MXene}$ with highly reliable superhydrophobic protection for volatile organic compounds sensing. ACS Nano 2020, 14, 11490-11501. [CrossRef] [PubMed]

148. Zou, S.; Gao, J.; Liu, L.; Lin, Z.; Fu, P.; Wang, S.; Chen, Z. Enhanced gas sensing properties at low working temperature of iron molybdate/MXene composite. J. Alloys Compd. 2020, 817, 152785. [CrossRef]

149. Yang, Z.; Liu, A.; Wang, C.; Liu, F.; He, J.; Li, S.; Wang, J.; You, R.; Yan, X.; Sun, P.; et al. Improvement of gas and humidity sensing properties of organ-like MXene by alkaline treatment. ACS Sens. 2019, 4, 1261-1269. [CrossRef]

150. Lee, S.H.; Eom, W.; Shin, H.; Ambade, R.B.; Bang, J.H.; Kim, H.W.; Han, T.H. Room-temperature, highly durable Ti ${ }_{3} \mathrm{C}_{2} \mathrm{~T}_{x}$ MXene/graphene hybrid fibers for $\mathrm{NH}_{3}$ gas sensing. ACS Appl. Mater. Interfaces 2020, 12, 10434-10442. [CrossRef]

151. Wang, Y.; Zhou, Y.; Wang, Y. Humidity activated ionic-conduction formaldehyde sensing of reduced graphene oxide decorated nitrogen-doped MXene/titanium dioxide composite film. Sens. Actuators B Chem. 2020, 323, 128695. [CrossRef]

152. Sun, B.; Lv, H.; Liu, Z.; Wang, J.; Bai, X.; Zhang, Y.; Chen, J.; Kan, K.; Shi, K. $\mathrm{Co}_{3} \mathrm{O}_{4} @ \mathrm{PEI} / \mathrm{Ti}_{3} \mathrm{C}_{2} \mathrm{~T}_{x}$ MXene nanocomposites for a highly sensitive NOx gas sensor with a low detection limit. J. Mater. Chem. A 2021, 9, 6335-6344. [CrossRef]

153. Lee, E.; Mohammadi, A.V.; Prorok, B.C.; Yoon, Y.S.; Beidaghi, M.; Kim, D.-J. Room temperature gas sensing of two-dimensional titanium carbide (MXene). ACS Appl. Mater. Interfaces 2017, 9, 37184-37190. [CrossRef] [PubMed] 
154. Koh, H.-J.; Kim, S.J.; Maleski, K.; Cho, S.-Y.; Kim, Y.-J.; Ahn, C.W.; Gogotsi, Y.; Jung, H.-T. Enhanced selectivity of MXene gas sensors through metal ion intercalation: In situ X-ray diffraction study. ACS Sens. 2019, 4, 1365-1372. [CrossRef]

155. Li, D.; Liu, G.; Zhang, Q.; Qu, M.; Fu, Y.Q.; Liu, Q.; Xie, J. Virtual sensor array based on MXene for selective detections of VOCs. Sens. Actuators B Chem. 2021, 331. [CrossRef]

156. Lee, E.; VahidMohammadi, A.; Yoon, Y.S.; Beidaghi, M.; Kim, D.-J. Two-dimensional vanadium carbide MXene for gas sensors with ultrahigh sensitivity toward nonpolar gases. ACS Sens. 2019, 4, 1603-1611. [CrossRef]

157. Xuan Vuong, L.; Vu Truong, D.; Lan Anh Luu, T.; Van Thang, P.; Huu Lam, N.; Cong Tu, N. Composition of CNT and WO 3 nanoplate: Synthesis and $\mathrm{NH}_{3}$ gas sensing characteristics at low temperature. J. Met. Mater. Miner. 2019, 29, 61-68. [CrossRef]

158. Korent, A.; Zagar Soderznik, K.; Sturm, S.; Zuzek Rozman, K.; Redon, N.; Wojkiewicz, J.-L.; Duc, C. Facile Fabrication of an ammonia-gas sensor using electrochemically synthesised polyaniline on commercial screen-printed three-electrode systems. Sensors 2021, 21, 169. [CrossRef]

159. Lv, D.; Shen, W.; Chen, W.; Tan, R.; Xu, L.; Song, W. PSS-PANI/PVDF composite based flexible $\mathrm{NH}_{3}$ sensors with sub-ppm detection at room temperature. Sens. Actuators B Chem. 2021, 328, 129085. [CrossRef]

160. Kulkarni, S.B.; Navale, Y.H.; Navale, S.T.; Stadler, F.J.; Patil, V.B. Room temperature ammonia gas sensing properties of polyaniline nanofibers. J. Mater. Sci. Mater. Electron. 2019, 30, 8371-8380. [CrossRef]

161. Hu, Q.; Wang, Z.; Chang, J.; Wan, P.; Huang, J.; Feng, L.J.S.; Chemical, A.B. Design and preparation of hollow NiO spherepolyaniline composite for $\mathrm{NH}_{3}$ gas sensing at room temperature. Sens. Actuators B Chem. 2021, 344, 130179. [CrossRef]

162. Hasan, M.I.; Bakr, N.A.; Ibrahim, I.M. Morphological, magnetic, optical, surface potential, and $\mathrm{H}_{2} \mathrm{~S}$ gas sensing behavior of polypyrrole nanofibers. J. Electron. Mater. 2021, 50, 2716-2724. [CrossRef]

163. Zanchin, V.R.; Cavallari, M.R.; Fonseca, F.J. Stability of polythiophene-based transistors upon bending for gas sensing applications. J. Integr. Circuits Syst. 2021, 16, 1-6. [CrossRef]

164. Bulla, S.S.; Bhajantri, R.; Chavan, C.; Sakthipandi, K. Synthesis and characterization of polythiophene/zinc oxide nanocomposites for chemiresistor organic vapor-sensing application. J. Polym. Res. 2021, 28, 1-21. [CrossRef]

165. Liu, A.; Lv, S.; Jiang, L.; Liu, F.; Zhao, L.; Wang, J.; Hu, X.; Yang, Z.; He, J.; Wang, C.; et al. The gas sensor utilizing polyaniline/MoS 2 nanosheets $/ \mathrm{SnO}_{2}$ nanotubes for the room temperature detection of ammonia. Sens. Actuators B Chem. 2021, 332, 129444. [CrossRef]

166. Feng, Q.; Zhang, H.; Shi, Y.; Yu, X.; Lan, G. Preparation and gas sensing properties of PANI/SnO 2 hybrid material. Polymers 2021, 13, 1360. [CrossRef]

167. Choi, H.H.; Lee, J.; Dong, K.-Y.; Ju, B.-K.; Lee, W. Gas Sensing performance of composite materials using conducting polymer/single-walled carbon nanotubes. Macromol. Res. 2012, 20, 143-146. [CrossRef]

168. Lim, J.-H.; Phiboolsirichit, N.; Mubeen, S.; Deshusses, M.A.; Mulchandani, A.; Myung, N.V. Electrical and gas sensing properties of polyaniline functionalized single-walled carbon nanotubes. Nanotechnology 2010, 21, 75502. [CrossRef] [PubMed]

169. Ram, J.; Singh, R.G.; Singh, F.; Kumar, V.; Chauhan, V.; Gupta, R.; Kumar, U.; Yadav, B.C.; Kumar, R. Development of WO 3 -PEDOT: PSS hybrid nanocomposites based devices for liquefied petroleum gas (LPG) sensor. J. Mater. Sci. Mater. Electron. 2019, 30, 13593-13603. [CrossRef]

170. Ram, J.; Singh, R.G.; Singh, F.; Chauhan, V.; Gupta, D.; Kumar, V.; Kumar, U.; Yadav, B.C.; Kumar, R. Ion beam engineering in $\mathrm{WO}_{3}$-PEDOT: PSS hybrid nanocomposite thin films for gas sensing measurement at room temperature. Inorg. Chem. Commun. 2020, 119, 108000. [CrossRef]

171. Lin, C.-Y.; Chen, J.-G.; Hu, C.-W.; Tunney, J.J.; Ho, K.-C. Using a PEDOT:PSS modified electrode for detecting nitric oxide gas. Sens. Actuators B Chem. 2009, 140, 402-406. [CrossRef]

172. Wang, X.; Sun, K.; Li, K.; Li, X.; Gogotsi, Y. Ti ${ }_{3} \mathrm{C}_{2} \mathrm{~T}_{x}$ /PEDOT:PSS hybrid materials for room-temperature methanol sensor. Chin. Chem. Lett. 2020, 31, 1018-1021. [CrossRef]

173. Lee, J.; Jung, Y.; Sung, S.-H.; Lee, G.; Kim, J.; Seong, J.; Shim, Y.-S.; Jun, S.C.; Jeon, S. High-performance gas sensor array for indoor air quality monitoring: The role of Au nanoparticles on $\mathrm{WO}_{3}, \mathrm{SnO}_{2}$, and $\mathrm{NiO}$-based gas sensors. J. Mater. Chem. A 2021, 9 , 1159-1167. [CrossRef]

174. Liu, J.; Zhang, L.; Fan, J.; Zhu, B.; Yu, J. Triethylamine gas sensor based on Pt-functionalized hierarchical ZnO microspheres. Sens. Actuators B Chem. 2021, 331, 129425. [CrossRef]

175. Iordache, S.M.; Ionete, E.I.; Iordache, A.M.; Tanasa, E.; Stamatin, I.; Grigorescu, C.E.A. Pd-decorated CNT as sensitive material for applications in hydrogen isotopes sensing-application as gas sensor. Int. J. Hydrogen Energy 2021, 46, 11015-11024. [CrossRef]

176. Constantinoiu, I.; Viespe, C. Development of $\mathrm{Pd} / \mathrm{TiO}_{2}$ porous layers by pulsed laser deposition for surface acoustic wave $\mathrm{H}_{2}$ gas sensor. Nanomaterials 2020, 10, 760. [CrossRef]

177. Wang, F.; Hu, K.; Liu, H.; Zhao, Q.; Wang, K.; Zhang, Y. Low temperature and fast response hydrogen gas sensor with Pd coated $\mathrm{SnO}_{2}$ nanofiber rods. Int. J. Hydrogen Energy 2020, 45, 7234-7242. [CrossRef]

178. Junkaew, A.; Arroyave, R. Enhancement of the selectivity of MXenes $\left(\mathrm{M}_{2} \mathrm{C}, \mathrm{M}=\mathrm{Ti}, \mathrm{V}, \mathrm{Nb}, \mathrm{Mo}\right)$ via oxygen-functionalization: Promising materials for gas-sensing and -separation. Phys. Chem. Chem. Phys. 2018, 20, 6073-6082. [CrossRef]

179. Kuang, D.; Guo, X.; Zhu, Z.; Ding, Y.; Sun, X.; Wu, Z.; Zhang, L.; Zhou, Y.; He, Y. Enhanced room temperature ammonia response of $2 \mathrm{D}-\mathrm{Ti}_{3} \mathrm{C}_{2} \mathrm{~T}_{x} \mathrm{MXene}$ decorated with $\mathrm{Ni}(\mathrm{OH})_{(2)}$ nanoparticles. Ceram. Int. 2021, 47, 19471-19480. [CrossRef]

180. Choi, J.; Kim, Y.-J.; Cho, S.-Y.; Park, K.; Kang, H.; Kim, S.J.; Jung, H.-T. In situ formation of multiple Schottky Barriers in $\operatorname{~Ti}_{(3)} \mathrm{C}_{(2)} \mathrm{MXene}$ film and its application in highly sensitive gas sensors. Adv. Funct. Mater. 2020, 30, 2003998. [CrossRef] 